\title{
Open Source Course Management System Adoption in Canadian Universities and Colleges
}

\author{
by \\ Mohammed Treif \\ A thesis submitted to the Faculty of Graduate Studies and Research in partial \\ fulfillment of the requirements for the degree of Master of Applied Science in \\ Technology Innovation Management
}

Department of Systems and Computer Engineering

Carleton University

Ottawa, Canada K1S 5B6

September, 2008

(c) Copyright 2008 Mohammed Treif 


$\begin{array}{ll}\begin{array}{l}\text { Library and } \\ \text { Archives Canada }\end{array} & \begin{array}{l}\text { Bibliothèque et } \\ \text { Archives Canada }\end{array} \\ \begin{array}{l}\text { Published Heritage } \\ \text { Branch }\end{array} & \begin{array}{l}\text { Direction du } \\ \text { Patrimoine de l'édition }\end{array} \\ \begin{array}{l}\text { 395 Wellington Street } \\ \text { Ottawa ON K1A 0N4 } \\ \text { Canada }\end{array} & \begin{array}{l}\text { 395, rue Wellington } \\ \text { Ottawa ON K1A 0N4 } \\ \text { Canada }\end{array}\end{array}$

Your file Votre référence ISBN: 978-0-494-44059-9

Our file Notre référence

ISBN: 978-0-494-44059-9

NOTICE:

The author has granted a nonexclusive license allowing Library and Archives Canada to reproduce, publish, archive, preserve, conserve, communicate to the public by telecommunication or on the Internet, loan, distribute and sell theses worldwide, for commercial or noncommercial purposes, in microform, paper, electronic and/or any other formats.

The author retains copyright ownership and moral rights in this thesis. Neither the thesis nor substantial extracts from it may be printed or otherwise reproduced without the author's permission.
AVIS:

L'auteur a accordé une licence non exclusive permettant à la Bibliothèque et Archives Canada de reproduire, publier, archiver, sauvegarder, conserver, transmettre au public par télécommunication ou par l'Internet, prêter, distribuer et vendre des thèses partout dans le monde, à des fins commerciales ou autres, sur support microforme, papier, électronique et/ou autres formats.

L'auteur conserve la propriété du droit d'auteur et des droits moraux qui protège cette thèse. $\mathrm{Ni}$ la thèse ni des extraits substantiels de celle-ci ne doivent être imprimés ou autrement reproduits sans son autorisation.
In compliance with the Canadian Privacy Act some supporting forms may have been removed from this thesis.

While these forms may be included in the document page count, their removal does not represent any loss of content from the thesis.
Conformément à la loi canadienne sur la protection de la vie privée, quelques formulaires secondaires ont été enlevés de cette thèse.

Bien que ces formulaires aient inclus dans la pagination, il n'y aura aucun contenu manquant.

\section{Canada}




\section{Abstract}

This research describes decision makers' perception and attitude towards open source Course Management System (OS CMS) and identifies factors that influence their decisions. A literature review, five case studies, and data from 41 decision makers representing 25 Canadian universities and colleges are used to provide decision making process model, OS CMS evaluation model, and several implications to decision makers. The most important implications that emerged from this research are: first, the decisions to adopt or migrate to OS CMS can be taken at the departmental level, but in fact are considered mostly at the institutional level. Second, decision makers should ensure that other institutions' experiences do not overly influence the decision making process. Third, liberalizing operating costs budgeting rather than onetime funding could yield many benefits in promoting open source products.

Fourth, perceived resource limitations and perceived relative advantage were the most significant factors that influence decision makers' risk perception. 


\section{Acknowledgments}

This study would not have been possible without the advice, assistance, encouragement and support from the following people. I would like to take this opportunity to express my great thanks to,

- Professor John Callahan, my thesis supervisor, for his excellent guidance, support, and encouragement at all stages of this study.

- Professor Tony Bailetti, for his advice and generous guidance, support and persistent encouragement since the first term that I attended this program.

- Professors Douglas King, Michael Weiss, Steven Muegge, Stoyan Tanev, and Thomas Kunz for their generous comments and constructive suggestions at various stages of my work.

- John Tomacic, a friend and a colleague at Nortel, for his continues support.

- My family that supported me throughout the research work and was a source of motivation to me.

- All interviewees and survey respondents who participated in this study. 
Table of Contents

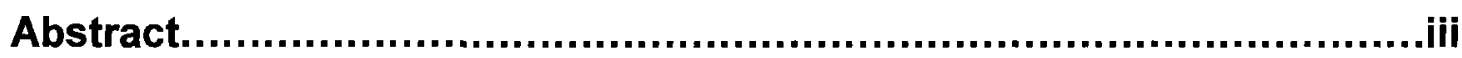

Acknowledgments.....................................................................

Table of Contents......................................................................

List of Tables.........................................................................

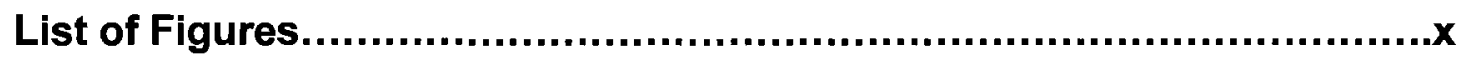

List of Appendices....................................................................

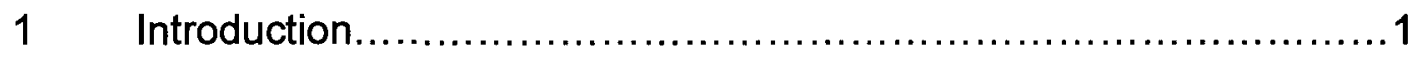

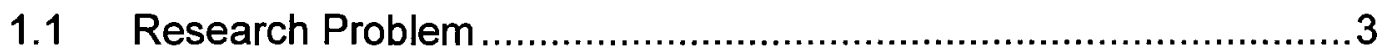

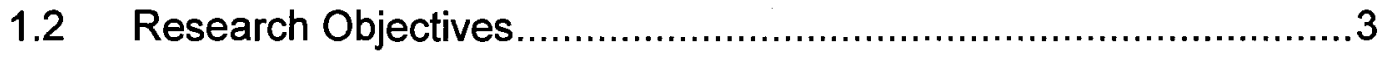

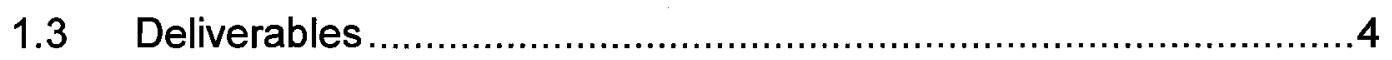

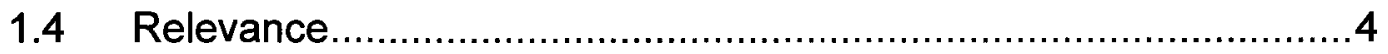

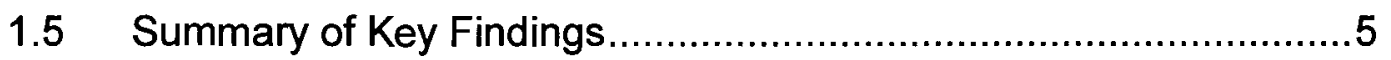

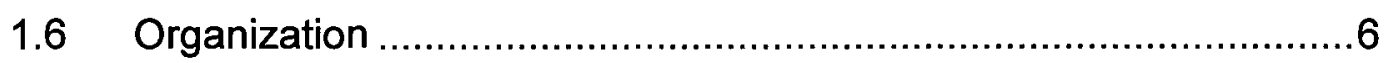

$2 \quad$ Literature Review.....................................................

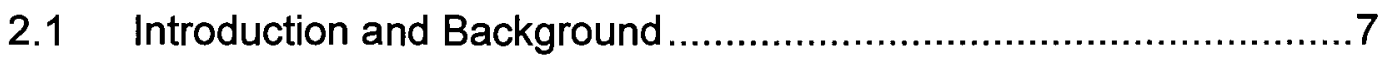

2.1.1 Defining Course Management System ................................

2.1.2 Proprietary Course Management System (CMS) …...............

2.1.3 Open Source Course Management System (OS CMS)...........9

2.2 Universities and Colleges Rationale for OS Adoption...................10

2.3 Slow Adoption of OS CMS in Canadian Academic Institutions ......11

2.4 Innovation, Diffusion, and Adoption ........................................13 
2.5 Organizational Adoption of Innovations 13

2.5.1 Technology Factors ............................................................ 14

2.5.2 Organizational Factors ….............................................. 15

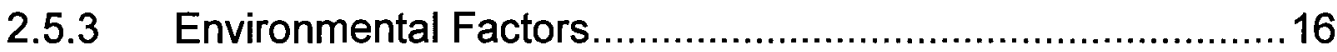

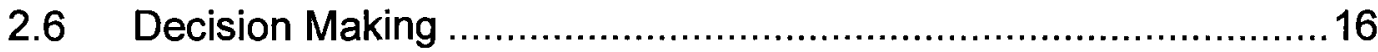

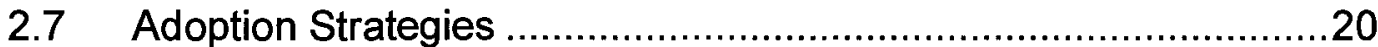

2.8 Lessons Learned from the Literature Review ..............................22

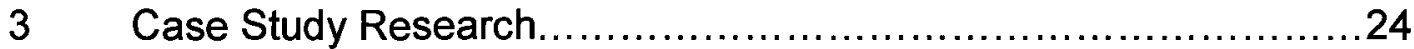

3.1 Case 1: A Comprehensive Canadian University ..........................24

3.2 Cases 2-5: CMS Evaluation Processes .......................................34

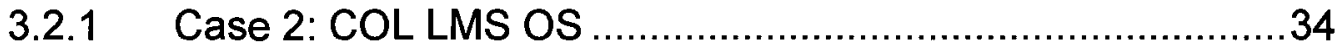

3.2.2 Case 3: University of British Columbia (UBC).......................36

3.2.3 Case 4: University of California ........................................40

3.2.4 Case 5: Alamo Community College District ...........................44

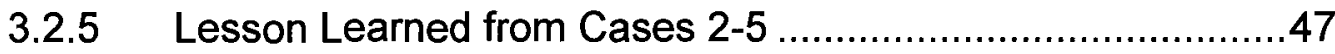

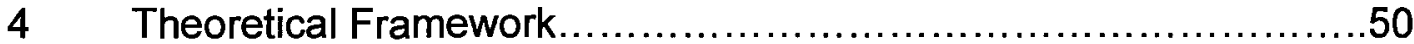

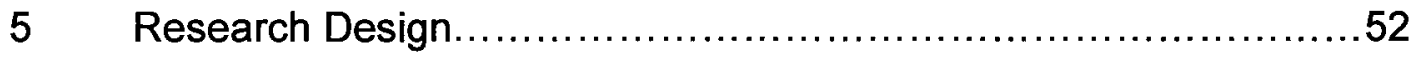

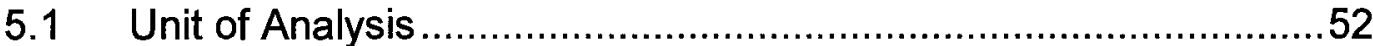

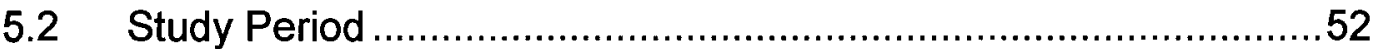

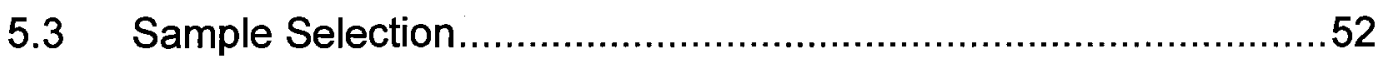

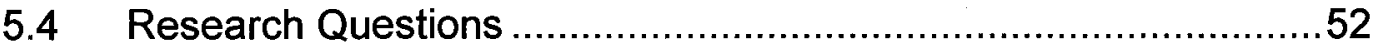

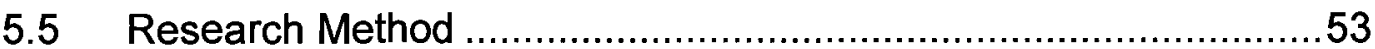

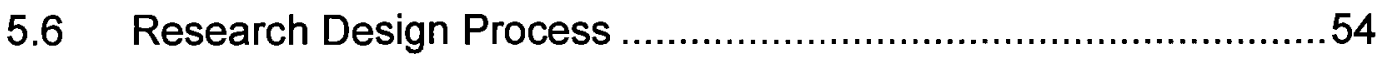




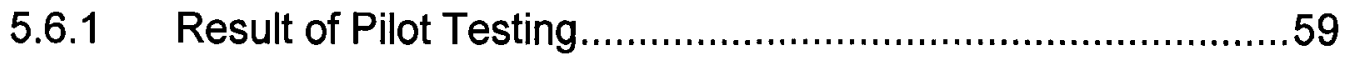

5.6.2 Improving Response Rates of E-mail Surveys .....................60

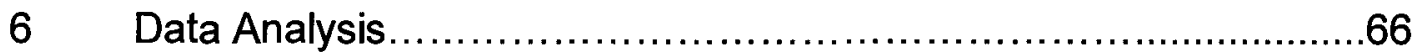

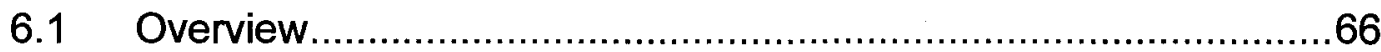

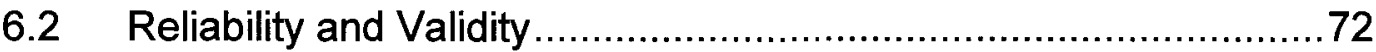

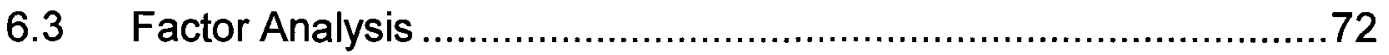

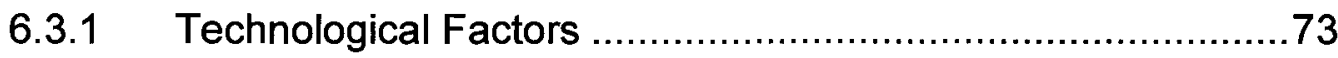

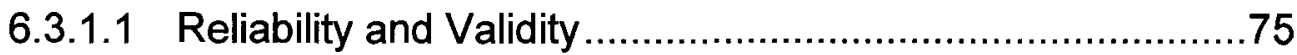

6.3.1.2 Relationship among Technological Variables ...................78

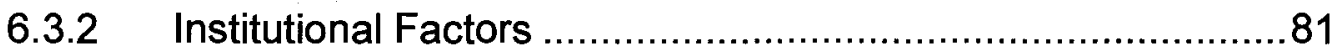

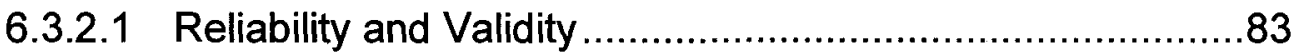

6.3.2.2 Relationship among Institutional Variables .......................86

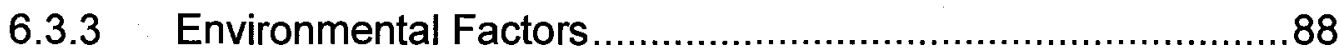

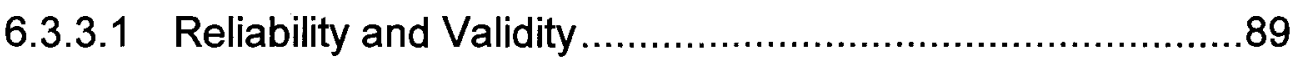

6.3.3.2 Relationship among Environmental Variables ...................89

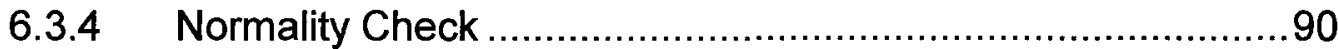

$7 \quad$ Hypothesis Testing ................................................92

8 Conclusion, Implications, Limitation and Future Research...........101

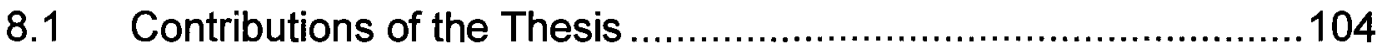

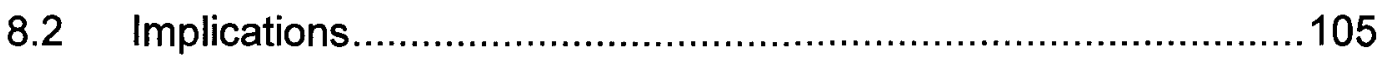

8.3 Limitations and Further Studies …...........................................107

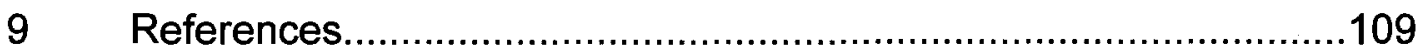

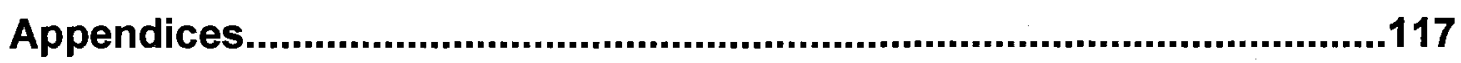




\section{List of Tables}

Table 1: Strategies Used to Increase Questionnaire Response Rate. 65

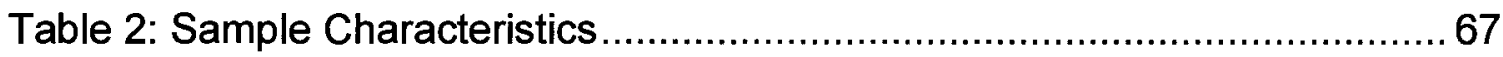

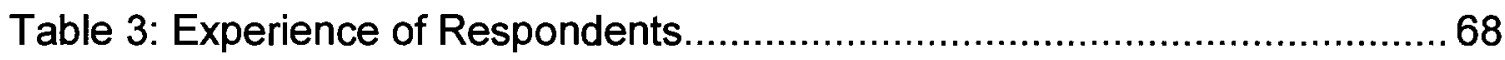

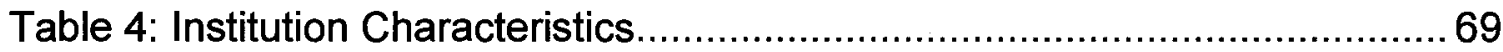

Table 5: Type of Course Management System ..............................................69

Table 6: Current Sources of Information...................................................... 70

Table 7: Evaluation Criteria Methods........................................................... 71

Table 8: Methods to Reach Adoption/Migration Decision ................................. 71

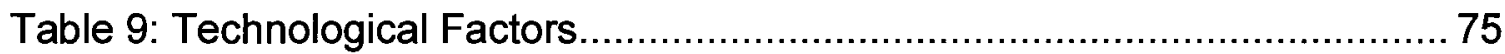

Table 10: Technological Factors - Analysis of Measurement Reliability ............. 76

Table 11: Technology Factors - Principle Component Analysis....................... 77

Table 12: Technological Factors - Varimax Factor Rotation Output ...................78

Table 13: Pearson's Correlation Coefficients for Relative Advantage Items....... 79

Table 14: Pearson's Correlation Coefficients for Complexity Items ................... 79

Table 15: Pearson's Correlation Coefficients for Observability Items ................ 80

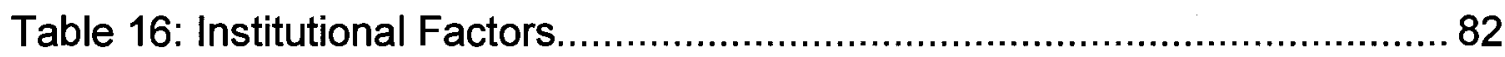

Table 17: Institutional Factors - Analysis of Measurement Reliability ................ 83

Table 18: Institutional Factors - Principle Component Analysis ......................... 84

Table 19: Institutional Factors - Varimax Factor Rotation Output ...................... 85

Table 20: Pearson's Correlation Coefficients for Perceived Resource

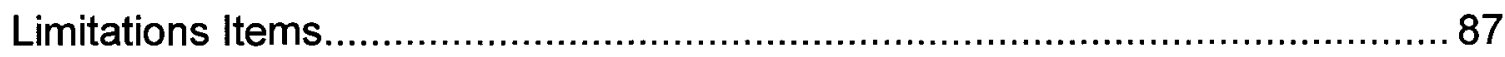


Table 21: Pearson's Correlation Coefficients for Perceived Institutional Benefits Items.

Table 22: Pearson's Correlation Coefficients for Perceived Institutional Image Items. 88

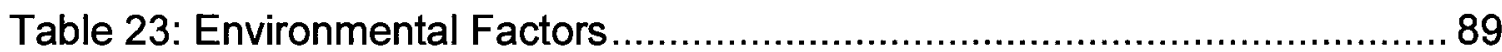

Table 24: Environmental Factors - Pearson Correlation Coefficients .................89

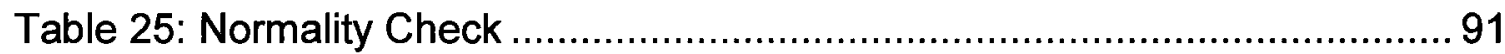

Table 26: Pearson Correlation Coefficients ..................................................92

Table 27: Pearson Correlation Coefficient - Revised Perception Model ............. 94

Table 28: Analysis of Measurement Reliability: Model 2 - Data Reduction........ 95

Table 29: Stepwise Regression Statistics....................................................... 96

Table 30: Stepwise Regression Analysis (ANOVA) _........................................ 96

Table 31: Stepwise Regression Analysis (Coefficients) ..................................97

Table 32: Stepwise Regression Analysis (Excluded Independent Variables) .....97 


\section{List of Figures}

Figure 1: Technology Adoption Model Adopted from Rogers (1995)................. 19

Figure 2: Technology Adoption Life Cycle ..................................................... 20

Figure 3: OS CMS Evaluation Decision Process in the Academic Environment. 49

Figure 4: Conceptual Module for OS CMS Adoption ....................................... 50

Figure 5: Christensen's Theory Building Process ........................................ 54

Figure 6: Technological Factors - Scree Plot................................................ 77

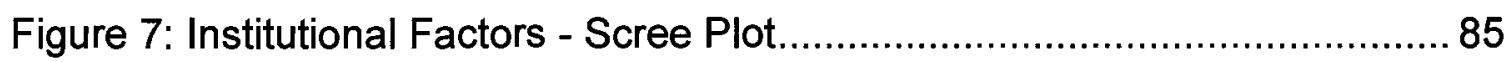

Figure 8: Research Findings with Pearson's Correlation Coefficients ................ 93

Figure 9: Revised Perception Model - Factors Influencing OS CMS Adoption in

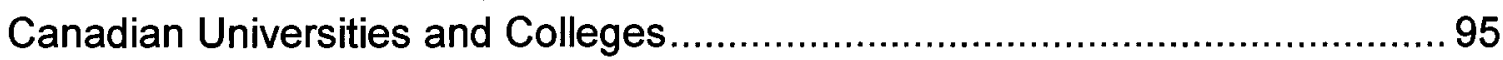




\section{List of Appendices}

Appendix A: Invitation to Participate in a Study about OS CMS

Appendix B: Questionnaire

Appendix C: Relative Advantage Normality Check

Appendix D: Complexity Normality Check

Appendix E: Observability Normality Check

Appendix F: Resource Limitations Normality Check

Appendix G: Perceived Institutional Benefit Normality Check

Appendix H: Perceived Institution Image Normality Check

Appendix I: Internal Pressure Normality Check 


\section{Introduction}

Course Management Systems (CMS) such as Blackboard or WebCT have become more ubiquitous and an increasingly important part in the academic field (Meerts, 2003 \& Morgan, 2003). They have critical implications on all aspect of teaching, learning and student teacher communication and must be accessible all the times (Meerts, 2003). According to a 2004 ECAR study, a survey of thirteen North American higher education institutions indicates that eighty- three percent of the students in the survey had taken a class that used a CMS (Kvavik et al., 2004). Coates (2005) states, "recent estimates suggest that in many countries, about three quarters of institutions have an LMS."

Despite CMS popularity and ubiquity, many educators are not satisfied with current commercial software and have expressed some concerns such as that commercial products are often not well tailored to higher education; commercial vendors have an excessive power to raise prices for the software used in higher education; and commercial software tends to require frequent and costly upgrades (Courant \& Griffiths, 2006).

Open source software is an available alternative to those who are looking to acquire CMS. Open source has gained much popularity in the commercial and education sectors, to the point that the technical debate about it is over and "many of the issues around open support, quality and functionary are pretty much settled." (Patrick, 2007) However, the decision makers at academic institutions 
still consider it as a dilemma when it comes to adoption and appear to be taking the debate all over again (Patrick, 2007). Moreover, open source software in academic institutions has not achieved the expected widespread success achieved in other fields (Courant \& Griffiths, 2006).

Open source Course Management Systems (OS CMS) are an example of open source software that many decision makers at universities and colleges still hesitant to deploy, migrate or adopt. OS CMS provides many advantages such as a lower price. From decision makers' point of view, however, there are still challenges and barriers to a massive adoption in academic institutions. Canadian universities and colleges are among the academic institutions still absent from the OS CMS movement. There is clearly a lack of research and documentation regarding OS CMS adoption in Canadian universities and colleges.

What are the reasons that Canadian universities and colleges do not adopt this technology? Is it decision-makers' lack of sufficient knowledge about OS CMS, or is it their perception and attitude toward open source? What are the factors or obstacles that influence their decisions to adopt open source in their institutions? Are decision makers still in the early adopter segment? If yes, what are the factors that need to be determined in order to cross the chasm and reach the early majority and initiate mass adoption? 


\subsection{Research Problem}

The problem can therefore be formulated as follows:

What are the factors that influence decision makers' decisions to adopt OS CMS in Canadian universities and colleges?

\subsection{Research Objectives}

The objectives of this research are to

- Gain insight into how decisions around the adoption and use of OS CMS are made in Canadian universities and colleges.

- Explore and describe decision makers' perception and attitude towards OS CMS.

- Identify and examine factors or obstacles that influence the decision to adopt OS CMS.

This thesis addresses the following research questions:

- How are decisions made around OS CMS in Canadian universities and colleges' environment?

- What are decision makers' perception and attitude towards OS CMS?

- What are the factors or obstacles that influence decisions makers to adopt OS CMS in their institutions? 
These questions guided the study and were designed to lead to an understanding of the research context.

\subsection{Deliverables}

This research delivers three outcomes:

- One case of a comprehensive Canadian university

- A model of the decision making process

- A model of the most significant factors that influence the evolution of OS CMS in Canadian universities and colleges

\subsection{Relevance}

There are at least three groups who may be interested in the contributions of this research.

First, presidents or leaders of academic institutions who are considering finding another ways of reducing the high cost of the commercial software products and also who are not realizing the importance of OS in boosting the innovation deployed in their institutions.

The second group that may be interested in this research is senior managers of institutions that support innovations and economic development. On one hand, it 
helps them to identify factors that diffuse the OS CMS adoption and on the other hand, it helps them to take leadership position in the academic development and understanding of OS role in academic institutions.

The third group that may be interested in this research is OS community who are interested in boosting OS movement and having the OS crossing the chasm to a massive deployment in the academic filed.

\subsection{Summary of Key Findings}

- Decision makers use several methods to obtain their information regarding OS CMS. However, the main two methods are other institutions' experience and CMS evaluation committee.

- Decision makers' perception and attitudes toward OS CMS are one of the major factors that hinder the adoption. They perceive OS CMS as immature products, with an unclear future and uncertain adoption costs.

- Increasing operating budgets, which can be uncertain during the OS CMS implementation, in place of one-time funding could yield many benefits in promoting OS CMS.

- CMS evaluation committees play an important role in the process of adopting OS CMS. 
- Perceived relative advantage, perceived observability, perceived institutional benefits, perceived institutional image, and perceived internal pressure decrease decision makers' risk perception.

- Perceived complexity and perceived resource limitations increase decision makers' risk perception.

- Perceived resource limitations and perceived relative advantage have the strongest relationship with decision makers' perceived risk of adopting OS CMS.

\subsection{Organization}

This research has been organized into eight chapters. Chapter 1 is the introduction. Chapter 2 provides literature review. Chapter 3 presents five case studies. Chapter 4 describes the theoretical framework used to anchor the research. Chapter 5 describes the research design. Chapter 6 is the data analysis. Chapter 7 is the hypothesis testing. Chapter 8 provides the conclusions and limitations of this research as well as suggestions for future research. 


\section{Literature Review}

The aims of this research are to understand how decisions around the adoption and use of OS CMS are made in Canadian universities and colleges, to explore decision makers' perception and attitude towards OS CMS, and to identify factors or obstacles that influence decision making.

The literature review has been organized into eight sections. Section 2.1 gives an introduction and background about Course Management System (CMS). Section 2.2 reviews the literature on universities and colleges rational for OS adoption. Section 2.3 examines the literature reviews on the slow adoption of OSS in Academia. Section 2.4 defines innovation, diffusion and adoption. Section 2.5 discusses literature reviews on the organizational adoption of innovations. Section 2.6 uses literature reviews to understand decision making definition and process. Section 7 uses literature reviews to discuss adoption strategies. Finally, section 2.8 provides lessons learned from the literature reviews.

\subsection{Introduction and Background}

Since the 1990s, course management systems have been presented to handle all aspects of online training and to focus on organizing and managing course content. Many universalities and colleges have been involved in extensive experimentation either developing their own CMS or work with vendors to 
develop one; they have focused their efforts in tailoring and customizing CMS technologies to higher education. These pose a make or buy decision for each university in selecting appropriate CMS. Universities and colleges have three options available: They can choose to purchase and implement a proprietary or commercial CMS such as Blackboard and WebCT from the market place. Second option is to build their CMS. A third option is to adopt an OS CMS such as Moodle or Sakai (Wheeler, 2002).

\subsubsection{Defining Course Management System}

There are many terms that are used to refer to course management systems. They include: Virtual Learning Environment (VLE), Management Learning Environment (MLE), Learning Management System (LMS), and Learning Support System (LSS) (Van den Berg, 2005). Throughout this study, the term Course Management System (CMS) is used.

A Course Management System (CMS) is a web application that represents a new type of educational technology. It gives educators the tool to interact with their students. On one hand, it enables teachers to handle learning and teaching process. Teachers can post online their lectures, course documents and other materials such as assignments, quizzes and tests to their students. On the other hand, students can view CMS's contents via Internet and download the materials. CMS also allows students to work on group, hold online discussions and take online tests (Van den Berg, 2005). 
Educators who want to use CMS have two available options: proprietary CMS or OS CMS.

\subsubsection{Proprietary Course Management System (CMS)}

In proprietary CMS, the software package is not made fully accessible to anyone. Users are required to pay certain fees for the licenses, and, in most cases, they are prohibited from copying or redistributing the compiled software. The major proprietary CMS vendors are WebCT, Blackboard, LearningSpace, eCollege, and ANGEL. A complete list of vendors can be found at http://www.edutools.info/item_list.jsp?pj=4.

\subsubsection{Open Source Course Management System (OS CMS)}

Open source software is the opposite of proprietary software. It is available under GNU General Public License (GNU GPL), which guarantees the following:

- The program must be freely distributed.

- Anyone must be allowed to modify the program.

- The original or derived works and modification can be distributed without having to pay royalties to previous developers.

OS CMS such as Moodle and Sakai can be downloaded from Internet without any charge. 


\subsection{Universities and Colleges Rationale for OS Adoption}

Recently presidents and leaders of the majority of collages and universities are not satisfied with the current market of software that they use in their institutions. They have expressed the following three concerns:

- Commercial products are often not well tailored to higher education.

- Commercial vendors have an excessive power to raise prices for the software used in higher education.

- Commercial software trends to require frequent and costly upgrades (Courant \& Griffiths, 2006).

Open Source Software (OSS) and development have gained much of its popularity in the education sector and has attracted educators' attention (Couros, 2004). Many reasons for OS adoption were found in the literature. The following are some of the reasons for adopting OS,

- Address longstanding concerns in higher education, economic reasons such as lower total cast of ownership (TCO) in schools, and social democratic ideals of intellectual property (Couros, 2004).

- Functionality, cost, market share, support, maintenance, reliability, performance, scalability, usability, security, flexibility, customizability, interoperability and legal and license issues (Wheeller, 2003).

- 'Relative advantage, compatibility adopters' priorities, beliefs, needs, and previously introduced ideas; ease of understanding and use; ease of 
experimentation; and ease in which positive results are observable" (Bailetti, 2006).

- According to Rahtz (2005), three main reasons that make OS better suited for educational purpose within an academic institution than similar proprietary software:

- The ability to tailor the system completely according to the local needs.

- OS licenses are free so no surprise in increasing licenses fees.

- No incentive for theft; student can download the software free of charge and use it for their own use without the pressure from the vendors.

\subsection{Slow Adoption of OS CMS in Canadian Academic Institutions}

OS has gained much popularity with educators (Couros, 2004) and has attracted many higher education institutions around the world. Some of these institutions have begun to deploy OS CMS products such as Sakai, Moodle, .LRN and ILIAS on a very large scale. For example, in January 2004 , Sakai which is a joint effort of several organizations, including the University of Michigan, Indiana University, MIT, and Stanford was launched with a $\$ 2.4$ million grant from the Andrew Mellon Foundation. The four organizations alone have invested an additional $\$ 4$ million in the development of Sakai. In April 2005, the Open Polytechnic in New Zealand announced a $\$ 1$ million (New Zealand dollars) project to deploy Moodle across 20 higher education institutions and 10 secondary schools. In June 2005, 
the Universidad Nacional de Educación a Distancia in Spain deployed .LRN platform to manage the courseware for their 200,000 globally distributed distance learning students. Moreover, ILIAS has dominated the German university market. (Adkins, 2005)

However, OS products or innovations have not achieved the widespread success to the extent that meets expectations in academic institutions (Merwe, 2000). Some argue that the reasons for slow adoption and diffusion are "inadequate funding" or "entrenched bureaucracies" (Merwe, 2000), others argue that third party support, legal issues and licensing (Rahtz, 2005).

Canadian universities and colleges are among the academic institutions that are still absent from OS CMS movement. An extensive search on the adoption of OS CMS in Canadian universities and colleges revealed only one case study, University of British Columbia case study. There is clearly a lack on researches and documents regarding OS CMS.

This study remedies the lack of information on OS CMS adoption in Canadian universities and colleges and shed the lights on the factors that influence the slow adoption of OS CMS in Canadian universities and colleges. 


\subsection{Innovation, Diffusion, and Adoption}

Some defines innovation as the process of making improvement by introducing something new including development of new technologies or applications for existing technologies, or refinement of existing technologies. Others define it as the process of translating creative ideas into tangible societal impact (Wikipedia, 2007). Rogers (1995) defines an innovation as "an idea, practice, or object that is perceived to be new by an individual or other unit."

Rogers defines diffusion as "the process by which an innovation is communicated through certain channels over period of time among members of a social system." While he defines the adoption process as "the mental process through which and individual passes from hearing about innovation to final adoption."

OS CMS is a process technology that is new to the academic filed and requires the development and modification of the academic system.

\subsection{Organizational Adoption of Innovations}

Tornatzky \& Fleischer (1990) identifies three categories of factors that influence the technology adoption decision: technological, organizational and environmental factors. In order to determine the influencing characteristics of OS 
CMS adoption, each factor was explained by using a specific model. The technological factors were explained by Rogers (1995) five innovation characteristics; organizational factors were explained by Christensen et al. (2004); and the environment factors were explained by Tessmer (1991).

\subsubsection{Technology Factors}

Rogers (1995) identifies five characteristics of innovations as perceived by adopter that diffuse or hinder the innovations. These attributes are relative advantage, compatibility, complexity, trialability, and observability.

1. Relative advantage is the degree to which the innovation is perceived as better than the one that it replaced. The relative advantage of an innovation, as perceived by members of a social system, is positively related to its rate of adoption. Diffusion scholars have found relative advantage to be one of the best predictors of an innovation's rate of adoption. It can be measured by benefits, degree of economic profitability, low initial cost, a decrease in discomfort, social prestige, saving in time and effort, and the immediacy of reward. (Roger, 1995, p. 216)

2. Compatibility is the degree to which the innovation is perceived as compatible with the existing needs, expectations, past experiences, and perceived goals of the potential adopters. The compatibility of an 
innovation, as perceived by members of a social system, is positively related to its rate of adoption. (Rogers, 1995, p234).

3. Complexity is the degree to which the innovation is perceived as difficult to understand and use. The complexity of an innovation, as perceived by members of a social system, is negatively related to its rate of adoption. (Rogers, 1995, p.242)

4. Trialability is the degree at which the innovation is experimented with on a limited basis before adopters make a decision to adopt. The trialability of an innovation, as perceived by members of social system, is positively related to its rate of adoption. (Rogers, 1995, p.243)

5. Observability is the degree to which the results of and innovation are visible to others. It is also defined as the ability to see beneficial results of using an innovation by decision makers. The observability of an innovation, as perceived by members of social system, is positively related to its rate of adoption. (Roger, 1995, p.244)

\subsubsection{Organizational Factors}

Christensen et al., (2004) defines resource, processes, and values as the three capabilities that an organization can use to deal with opportunities. The availability of those capabilities determines the success or failure of the organization. Organizations successfully deal with opportunity when they have abundant and good quality resources; processes that facilitate what need to be done and support investment decisions; and values that allow them to prioritize. 
On other hand, organizations fail when resources, processes, and values do not match the opportunity.

\subsubsection{Environmental Factors}

According to Ahmed (2005), Tessmer (1991) identifies two keys of environmental factors in which they influence the adopter decision to adopt a new technology: instructional environment and support environments. The instructional environment studies the context at which the instructional product will take place. While the support environment analyzes factors that support the employment of the instructional product such as organizational readiness, level of expertise and technological know-how.

\subsection{Decision Making}

The purpose of this research is to identify the factors that motivate or hinder decision makers in adopting OS CMS in Canadian universities and colleges. Harris (1998) defines decision making as the process of identifying and selecting an alternative among several alternatives in a situation of doubt and uncertainty that best fits the values and preferences of the decision makers.

Rogers (1983) proposed one of the best-known models of the innovationadoption process (Lefebvre et al., 1996). According to Rogers, the process can 
be divided into five stages: knowledge, persuasion, decision, implementation, and confirmation. Innovation proceeds from stage to another until it is either adopted or rejected.

1. Knowledge - the potential adopter becomes aware of an innovation and begins learn and know about a new innovation. Rogers claims that the following factors determine whether potential adopter seeks more information about the innovation or not.

- The characteristics of the decision making unit that includes socioeconomic characteristics, personality variables and communication behavior

- The perceived need for the innovation

- The previous practice

- The norms of the social systems After gaining enough information, the potential adopter forms either a positive or negative attitude toward the innovation.

2. Persuasion - the potential adopter ( $s$ ) begins to form a positive or a negative attitude toward the innovation. At this stage, the perceived characteristics of innovation: relative advantage, compatibility, complexity, trialability and observability will determine the potential adopter's attitude towards the innovation.

3. Decision - The potential adopter engages in activities seeking additional information that leads to a choice to adopt or reject the innovation. At this stage, the decision to either adopt or reject the innovation is made based on 
the knowledge gained and the attitude formed about the innovation by potential adopter. This decision can be alerted later. The potential adopter who decides to adopt the innovation can either continuo adopting the innovation and proceed to next stage or reject the innovation. On the other hand, the potential adopter who decides to reject the innovation may stay in his/her position and continuo rejecting the innovation or change his/her mind and decide to adopt it at later stage.

4. Implementation - the potential adopter starts using the new idea or innovation.

5. Confirmation - the potential adopter evaluates the innovation based on the evidence of use, and decides whether to keep or reject the innovation based on the evidence of the evaluation.

In a review article by Dillon \& Morris (1996), a comprehensive examination of many theoretical approaches concluded that all models of adoptions are part of Rogers (1995) diffusion of innovation. Diffusion of innovation theories examine how new innovations are adopted; how adoption decisions process are affected by perceptions of the technology itself, the character of the adopters and their environment; and the innovation decision process that lead to either adoption, a decision to use the technology and reaches the critical mass of adoption, or rejection, a decision not to adopt the innovation (Roger, 1995). 
Most prior adoption innovation literatures have focused mainly on the technology and the adopters' characteristics. It was not known how and why such factors affect decision outcomes. There is a lack of knowledge of critical factors that affect the decision maker's decision to adopt a new technology especially if the technology is an OS technology.

Roger (1995) model was used as a base to understand the actual standard decision and build a rich understanding of the critical factors that effect the decision making in the academic filed.

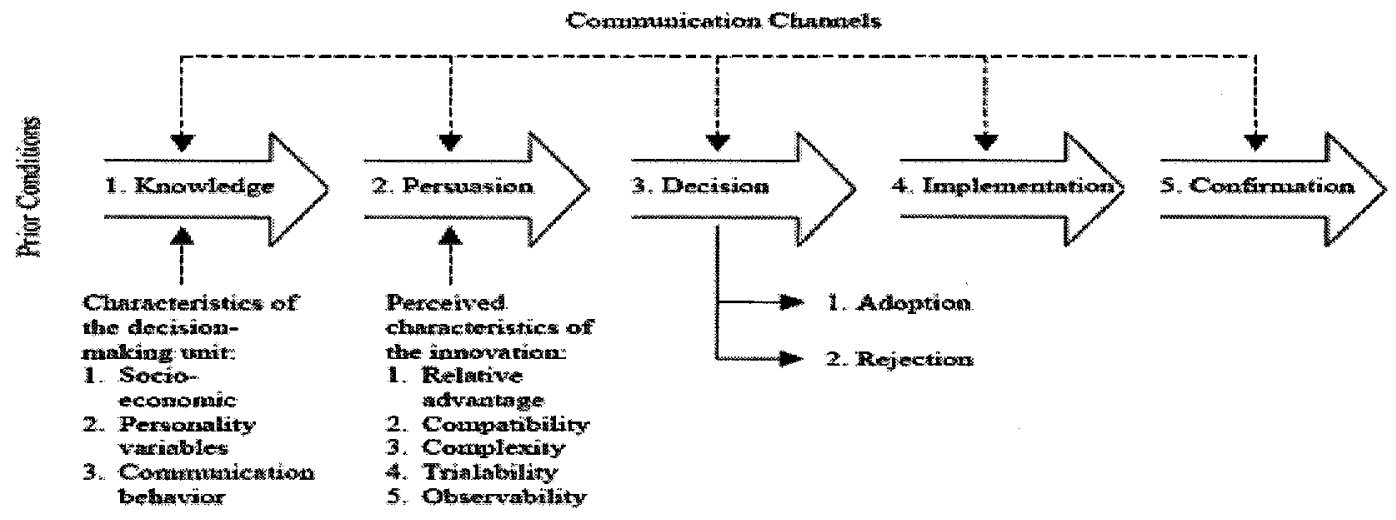

Figure 1: Technology Adoption Model Adopted from Rogers (1995)

In considering the context of the adoption of OS CMS, the pre-implementation stage, the first three stages as shown in Figure 1, was the focus of the study. 


\subsection{Adoption Strategies}

In his book "Crossing the Chasm"(Moore, 1999) and "Inside the Tornado"

(Moore, 1995), Moore speaks about the Technology Adoption Life Cycle (TALC)

model. The model explains the change in attitudes, behaviors, or values of end users who are introduced to new technologies that require them to change dramatically their past behavior or to change or modify the technologies to achieve dramatic new benefits.

The traditional technology adoption life cycle defines five groups of people as illustrated in Figure 2. Each segment of the curve is allocated to a particular group segment.

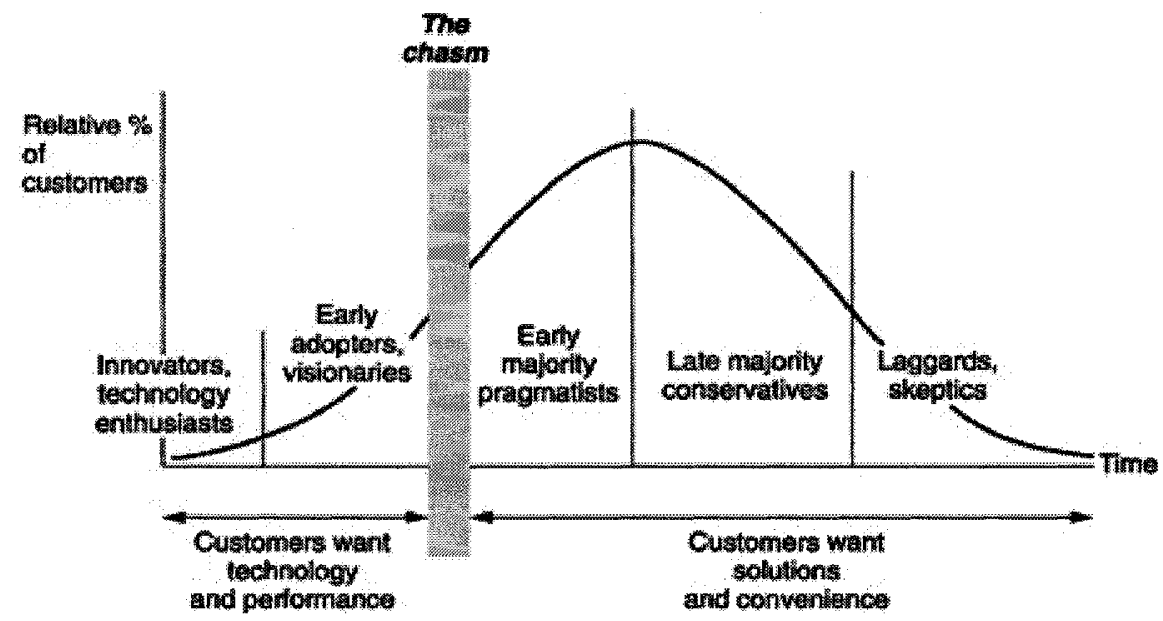

Figure 2: Technology Adoption Life Cycle

The five segments, innovators, early adopters, early majority, late majority and laggards, and their characteristics are defined below: 
- Innovators - Technology enthusiasts

Those pursue new technology with enthusiasm, keen to be first to try it out, and are welling to take the risk.

- Early adopters - Visionaries

This segment represents the true revolutionaries who are not interested in the technology and who look for the application. They are driven by the vision of competitive advantage of the technology. They adopt the new technology, gather all parts to make a revolutionary new solution, and use the technology. They tend to have much more influence in an organization than do innovators.

- Early majority - Pragmatists

This segment represents the people who are looking to solve particular problems. They only adopt the technologies that have been successful for others and have established a proven track record. They take risk when required.

- Late majority - Conservatives

Those are the followers of the pragmatists. They will adopt the technology when it is clearly proven and shown that it is here to stay.

- Laggards - Skeptics

They prefer to avoid new technologies and have no interest in them. They adopt them only if they do not have any other option. They do not take risks. 
Moore claims that the success is achieved when releasing a new product by traveling left to right in the TALC model and that there are small gaps exist between each technology adopter's segment in the TALC. He claims also that the gap between the early adopters and early majority is much larger than the others and refer to it as a chasm.

Moore offers the following steps that end users and their products must follow in order to cross the chasm:

- Target the point of attack - As new market entrant, it is better that you be more effective, focus on a small market, and look at the suitability of the product.

- Assemble the invasion force - Think not just about the product, but about the entire ecosystem: products and services.

- Define the battle - Create your position and show that you are the leader in that segments you are attacking.

- Launch the invasion - Focus on distribution and pricing.

\subsection{Lessons Learned from the Literature Review}

The main lessons learned from the literature reviewed are:

- There is a lack of research and documentation regarding OS CMS adoption in academic institutions. 
- OS projects in the academic institutions have not achieved the widespread success that has occurred in other fields (Courant \& Griffiths, 2006).

- Cost and performance are the main reasons for academic institutions to adopt and support OS projects (Courant \& Griffiths, 2006).

- Migration concerns, third party support, legal issues and licensing are the main concerns of academic institutions' in deploying and developing OS projects (Rahtz, 2005). 


\section{Case Study Research}

In order to increase our understanding of OS CMS slow adoption in an academic environment and to develop more complete picture about the issue, five case studies were carried out. The case studies are presented in this chapter.

\subsection{Case 1: A Comprehensive Canadian University}

Four interviews were conducted with decision makers at a Canadian comprehensive university. The interviewees represented three departments: information technology (IT), instructor support and finance.

The IT department provides computing and communications facilities and infrastructure services to departments and campus wide web based services and infrastructure including a web portal, email services, and content management system (CMS) for courses. It also provides technical support for administrative application systems, databases, and a variety of hardware and software to students, faculty and staff.

Instructor support provides support services to course instructors and teaching assistants including CMS support, design of complex web applications, animations, videos, and building online courses. 
The IT and instructor support departments work together to support decision makers, course instructors and teaching assistants with the selection, implementation, training and deployment of CMS.

The finance department provides academic and administrative departments with the tools, advice and guidance necessary to management of their financial resources and also supports senior management in financial planning.

At the beginning of each interview, the purpose of the study, its anticipated results, and significance were explained for all interviewees. The interview time varied in length from 30 to 45 minutes. The interviews were open discussions regarding the slow adoption of OS products in Canadian universities and colleges. Some pre-developed questions relating to OS CMS adoption in Canadian universities and colleges were also used during the discussion. Questionnaires were sent to each interviewee as a pilot test two weeks after the interview date.

\section{Major Concerns}

Decision makers are not satisfied with current commercial software and have expressed some concerns. A major concern was that commercial vendors have an excessive power to raise prices for the software used in academia. For example, there is a charge of about $25 \%$ for proprietary CMS annual fees. 
Those fees increase by $5 \%$ every year. Another major concern was that commercial software requires frequent and costly upgrade.

Those concerns were increased after Blackboard won a patent dispute against Desire2learn and after its acquisition of Prometheus and WebCT. This gave Blackboard a monopoly of higher education CMS market. It was estimated that Blackboard captures about $70-75 \%$ of the CMS market share.

\section{OS Decision}

OS promises many advantages. The most perceived advantage is the fact that OSS is available at a low cost. A second perceived advantage is that OS reduced dependence on commercial vendors because OS licenses are free so no surprise in increasing licenses fees. Moreover, OS products can be customized to the institution's needs.

Despite its promising advantages, from decision makers' point of view, there are still some challenges and barriers to a massive adoption in the academic field. The decision to adopt or migrate to OS CMS was considered as a risky decision for many reasons. OS CMS products were considered as immature products, its future was unclear, and the total cost of adoption was ambiguous. Moreover, staff and decision makers were satisfied with commercial products functionality and support. 
Neither the IT nor the instructor support departments officially support OS.

Decisions to adopt OS for small projects are mainly a collaborative decision within the departmental level. However, some individual decisions were made by IT and instructor support employees to use OS for their jobs. Employees use a board range of OSS such as GNU software, PHP, Apache, OpenSS, sendmail, and spamassassin.

For big projects such as OS CMS, the decisions to adopt or migrate to OSS CMS can be taken at the departmental level, but in fact it is considered mostly at the institutional level. The decision makers interviewed for this case study classified their institution as conservative in its approach to adopt or migrate to OS CMS. There is always resistance from some decision makers and faculty members to investment in new technologies, especially OS projects. Their philosophy is to keep what is operating without any change. Decision makers were unwilling to risk scarce resources and did not want change. The university is oriented toward proprietary CMS products and recently upgraded its proprietary CMS to a new version of CMS. It has no intention to adopt OS CMS in the near future.

The major reasons why this institution has not yet seriously considered migration to OS CMS are summarized below: 


\section{Limited Budgets}

The main reason for OS CMS slow adoption is limited budgets. Budget funding plays an important role in facilitating university operation, introducing new services, and promoting new technologies. Budget funding is derived from different financial sources such as revenue, government, grants, and private organizations. It comes in form of fees, grants, donations, and gifts.

In this university, operating cost budget and one time capital budget are the main budget categories. This university is not an exception of other Canadian universities that are financially constrained and keep a very tight on operating budget.

In operating budget, the budget may increase or decrease depending on whether more operating expense is required during the project implementation. The operating budget is mainly based on head count which is a very long term commitment in a university. OS run on cheap servers and PCs that require regular maintenance and technical support or head count that is available at all times. A department or university unit needs sufficient head count in order to save money from OS. With operating costs continue to rise faster than revenues; the university does not have the enough funds to spend upfront on projects such as OS CMS even with guaranteed long-term benefits. The university relies more and more on government funding, corporations, and other 
institutions for funding new technologies or projects such as OS CMS as opposed to student fees. On the other hand, in one time capital budget, the budget is one time fixed payment that may spread over a period of time. One time capital budget allocations are easier to obtain for departments. This leads to emphasize equipment purchase - high end computers that naturally run high end proprietary software.

This method of budgeting poses many challenges. The challenges are highlighted below:

Support. The university has various proprietary platforms and products from different vendors such as Cisco, Nortel, Sun, and Alcatel. Those platforms are supported $24 / 7$ by vendors or third party support who can be called upon in an emergency. Not only may OS not have this option, but it may be difficult or impossible to engage specialized support personnel on a particular OS product, on short notice. Supporting a big project such as OS CMS requires enough recourses or some time mobilization of resources across the university, and also technical support that is available at all times. Both IT and instructor support employees are busy on their day-to-day activities, loaded with many tasks, and are paid only for the regular hours of work, 8:00 a.m. to 4:00 p.m., with no one on duty after that time. 
Training. OS projects or products require knowledgeable personnel who are upto-date in the technology, and developers or programmers who can modify and update the technology as required. Employees have little or no direct experience with OS. There was not enough training budget for staff and it was hard if not impossible to send employees to training, OS conferences or OS summits.

Time. Developers and programmers were constrained with what they could do. Decision makers in this university did not want personnel, who had been hired long ago to do programming but had more recently been frustrated by the lack of programming opportunities because they were supporting applications, to get buried into programming OS products. Therefore, they were reluctance to push ideas and did not feel empowered to bring ideas forward.

Resource limitations. There were not enough slack resources for experimenting with OS products. Part of the third budget specified for software licenses, training, support, and infrastructure was spent heavily on buying expensive hardware from top tier vendors.

\section{Satisfaction with Commercial Products}

When comparing proprietary products to OS products, the overall satisfaction with proprietary products was always high especially in functionality and support. Moreover, in case of OS products, tailoring a system to the institution need is a 
difficult task especially with the few slack resources available to complete the job. One of the interviewees summarized with the following, "Organizations are resourced just enough for operating commercial software, may not have the overhead to run OS pilots to prove the software."

\section{Security}

Security was another barrier for OS CMS adoption. Maintaining capabilities and functionality of predecessor software represent a major concern. OS security vulnerabilities may be difficult to deal with because a timely patch may not be available, or the enterprise may not realize there is vulnerability.

\section{OS Collaboration}

OS collaboration among departments in the same institution was really hard. Furthermore, the collaboration and communication between this institution and other universities was really rare.

\section{OS Community}

OS community has played a limited role in promoting OS in academia. Most decision makers do not know what OS Community is and what it is for. 


\section{Other Barriers}

Other barriers included: legal issues; licensing; difficulty of switching to OS; concerns among staff about using OS; more on migration concerns; and incompatible products.

\section{CMS Evaluation Process}

As mentioned previously, this institution has recently upgraded to a new version of proprietary CMS. The evaluation criteria for reaching the decision to upgrade the existing CMS was based on: CMS evaluation committee recommendations, decision makers and faculty members' own direct experience, case studies, product comparisons, discussion in-house, and inputs from both students and faculty members. The final decision was mainly made by the recommendation of CMS evaluation committee.

\section{Case Study 1 Lessons Learned}

- Decision makers' main concerns towards proprietary CMS products: commercial vendors have an excessive power to raise prices for the software; commercial software requires frequent and costly upgrade; and proprietary CMS vendors' monopoly 
- OS CMS products were perceived by decision makers as immature products with unclear future and ambiguous total cost of adoption.

- Decision to migrate or adopt OS CMS in academia is a risky decision.

- CMS evaluation committee plays a critical role in selecting CMS (proprietary or OS).

- The decisions to adopt or migrate to OSS CMS can be taken at the departmental level, but in fact it is considered mostly at the institutional level.

- The main barriers that hinder OS CMS adoption:

- Perception and attitudes toward OS CMS in academia is negative.

- Budget is a critical factor for OS CMS adoption.

- The way how budget was structured, one time capital funding, is resource limited.

- No budget is designated for innovate projects, e.g. OS projects within the department.

- Two-third of the budgets is spent on salaries and the other third on infrastructure and training.

- There are some restrictions on developers and programmers work.

- OS Community has limited role in promoting OS.

- Others barriers such as security, immature OS product and functionality, lack of collaboration within the university's departments and with other universities and colleges, legal issues, staff attitudes toward OS, migration concerns and product incompatibility.

- High satisfaction with commercial products functionality and support 
- Engaging with OS community is important for realizing OS CMS full benefits. Academic institutions need to interact with OS community on OS CMS projects to help them to change the negative attitude about OS CMS and to guide them to find OS CMS the best meet their needs.

\subsection{Cases 2-5: CMS Evaluation Processes}

For universities and colleges, decision makers who are making the transition to select a new CMS or to adopt OS CMS, a set of evaluation process or methodology needs to be applied to smooth the transition. This review covers the typical decision making criteria utilized by some of universities and colleges in selecting an enterprise CMS. Literature reviews and Google search, on universities and colleges that reviewed or evaluated their CMS, showed a lack of information and documents on OS CMS adoption in Canadian universities and colleges. The search revealed only one study for Canadian universities or colleges and many studies for US universities or colleges. The following sections describe four case studies. Commonwealth of Learning, University of British Colombia - Canadian university, University of California - US university, and Alamo Community College - US college.

\subsubsection{Case 2: COL LMS OS}

Commonwealth of Learning (2003) identified and reviewed a list of thirty-five OS 
candidates' products. Only two OS platforms were recommended: ATutor and ILIAS. The methodology used consisted of six evaluation steps.

\section{Evaluation Process}

The following were the processes that were used to select an appropriate CMS:

- Develop evaluation criteria. Two categories were used to develop the evaluation criteria: general criteria and feature- specific criteria. For general criteria, the following criteria were used: features and functionality, cost of ownership; maintainability and ease of maintenance; usability; ease of use and user documentation; current user community; openness; standard compliancy or specification; integration capacity; reliability; scalability; intellectual property; hardware and software considerations; and multilingual support. For feature-specific criteria, the following criteria were used: security; access; course design; development and integration; course monitoring; assessment design; online collaboration and communications; and productivity tools.

- Identify OS candidates. A list of thirty-five OS candidates' products was identified.

- Filter candidates to produce a short list. The candidate list was filtered using the evaluation criteria to create a short list of five Candidates. 
- Systemic evaluation of features. The evaluation criteria were used to rate each feature on a scale of 0 to 5 where $0=$ non existent or poor, $3=$ an average basic standard, and 5 = exceeds standard expectation.

- Systems evaluation of general criteria. Documentation and other online resources were used to assess the other categories. Also products' vendors were contacted to request more information. The outcome of this step was to complete the general rating section of the evaluation spreadsheet.

- Recommendation. ATutor and ILIAS were the top two candidates; ATutor was the winning recommendation and ILIAS was the second choice for recommendation.

\section{Source of Information}

The following sources were used to collect information about OS CMS products, develop criteria and reach a final decision: own direct experience, $\mathrm{COL}$ Knowledge Finder, online resources such as Google to locate case studies, product comparisons, discussion threads, user and instructor documentation, and commentary of the user community.

\subsubsection{Case 3: University of British Columbia (UBC)}

Knorr (2005) conducted a study on CMS evaluation and strategy at UBC. 


\section{CMS Selection Process}

1. Identify issues with current CMS (WebCT CE 4.1)

Knorr (2005) summarized the challenges faced at UBC with respect to WebCT CE 4.1 as follows:

- Usability issues such as slow rating of pages, not very user-friendly, poor file structure, time consuming, not easy to learn and use, lack proper support and discussion forum is unfriendly.

- Technical issues such as

- Performance and scalability issues;

- Support for WebCT CE 4.1 would be discontinued by early 2007;

- WebCT CE 4.1 is not a database-driven package; rather, it is based on flat files. Many corrupted data in it were reported;

- Privacy implications associated with student data, and of course, in keeping assignments, quiz results, and solutions private;

- As a result of adding more campuses to the current UBC system, WebCT CE 4.1 could not cope with the increasing demand;

- Unable to host multiple sections of the same course, sharing some content and keeping other content unique;

- UBC needs to integrate its CMS with other major software applications. For example, the Student Information System and campus-wide Library system. 


\section{- Cost}

The Committee estimated that the cost of other enterprise CMS, such as Blackboard, would be similar to existing WebCT CE 4.1. On the other hand, an OS product like Sakai could save the university over $\$ 500,000$ on perpetual license fees.

- Increasing Student Expectations Few years ago, students were only offered very limited hours of instructor's time, and an hour or two reviews before midterm or final exam. However, now some students expect more from their instructors. They expect $24 / 7$ of online access to course material, regular office hours during school days, review sessions, sample midterms and final exams, and prompt responses on online course discussions.

- Pedagogical Concerns

Due to increase number of online resources such as lecture slides and course notes, there was a decrease in students' attendance in many classes and lectures also a significant decrease in the number of students who were using library and buying the text book.

Because all of these issues mentioned above, the Advisory Committee had to make one of the following decisions:

- Migrating to the enterprise version of WebCT such as WebCT Vista WebCT announced that Vista would no longer be the enterprise product to replace WebCT CE 4.1, but rather a new release of WebCT CE was 
undergoing considerable revisions. The new release, WebCT CE 6.0, would have more robust features, and substantial improvement to its user and instructor interfaces. WebCT CE 6.0 was ultimately selected by UBC.

- Moving to a different enterprise CMS such as Blackboard After Blackboard and WebCT announcement for their merging, this option was disqualified.

- Moving to an OS alternative (e.g., Sakai)

At 2005, Sakai was still in its development process. However, UBC would continue to follow Sakai development, attend and contribute to workshops, and perhaps evaluate Sakai with one or more trials at UBC.

- Letting individual departments or faculties decide on their own preferred method(s) of online course delivery. University of Toronto is an example of the universities that officially supports five CMSs.

- Not pursuing an enterprise CMS solution at all.

This option was disqualified for the following reasons: standardization, increase student expectation about online resources, an existing CMS investment in online course contents, and a general level of satisfaction for models of online content delivery. 
2. Identify motivations and needs

CMS Advisory Committee identified the following needs with respect to any CMS used at UBC: reliability, support for pedagogic innovation, efficient and easy-to-use tools, content sharing, clearly defined user roles with appropriate security and easy-to-use interfaces for each such role, branding (e.g., UBC, Sauder School of Business), multi-institution support, scalability, and integration.

\section{Source of Information}

The following were the main source of information: faculty members who were representing all departments within Science, students, surveys, and external community recommendations.

\subsubsection{Case 4: University of California}

In January 2005, a CMS Strategic Review Committee was formed by University of California to review the existing WebCT Campus Edition (CE) CMS and recommend new enterprise Course Management System (CMS) to carry the university into the future. 


\section{CMS Selection Process}

CMS Strategic Review Committee (2005) used three level of investigation to reach a final decision:

\section{First Level of Investigation}

Initial review was performed on all CMS options under investigation, Blackboard, Desire2Learn, WebCT Campus Edition, and WebCT Vista, and OS options such as Moodle and Sakai. All options were disqualified except Blackboard and WebCT Vista for the following reasons:

Reasons for Disqualifying Commercial CMS (Desire2Learn, and WebCT

\section{Campus Edition)}

- Feature set did not meet current levels of expectations

- Incompatible with campus data center standards

- Limited track record with comparable universities

- Reliability issues

\section{Reasons for Disqualifying OS CMS}

- Incompatible with campus data center standards

- Limited track record with comparable universities

- Need additional staff and support 
- The OS CMS movement is in its infancy

- Supporting the development of enterprise CMS is risky

- Product support options limited and unproven

- Not compliant with accessibility requirements

\section{Second Level of Investigation}

Qualified products, Blackboard and WebCT Vista, advanced to the second level of investigation. In this level, Blackboard and WebCT vendors were invited to the university campus for two days to present and discuss their solutions with members of the campus community. During the vendors' presentations, many questions were asked and comments were collected from participants. After that, migration testing was performed by the university faculty and staff. Moreover, a number of references checked, including a phone meeting with a Gartner Group higher education consultant and surveys of a number of CSU campuses.

The following areas of evaluations were crucial to the committee's final decision making:

- Teaching and learning (Tools and features, ease of use, E-portfolios, and pedagogical flexibility)

- Academic program assessment 
- Support and sustainability (Accessibility, migration of course content, and training and support)

- Enterprise integration (Information security, disaster recovery, and reporting)

- Institutional partnership (Track record)

\section{Final Level of Investigation (Recommendation)}

The committee recommended that the campus proceed with the procurement and deployment of WebCT Vista Enterprise Edition.

\section{Source of Information}

The committee used the following sources to reach to its final decision: Oncampus presentations by CMS vendors, solicitation of comments from the campus community, course migration testing, a survey of past vendor performance at sister CSU campuses, and the committee collaborated in weekly meetings and online.

The committee discussed its findings and formulated its final recommendation which was to proceed with the procurement and deployment of WebCT Vista Enterprise Edition. 


\subsubsection{Case 5: Alamo Community College District}

Alamo Community College District (2006) conducted a review on its current WebCT and other options such WebCT CE 6.0, WebCT Vista, Blackboard, Course Compass, Moodle (OS), and Angel.

\section{CMS Selection Process}

1. Identify reasons for change

The current CMS system, WebCT Campus Edition, was

- An older CMS which did not take advantage of the current technologies such as up to date hardware, database technologies, advanced security options, and enhanced features that support class room connectivity, discussion group assessments, and assignments options;

- Difficult to manage;

- Limited technical options for system integration, enterprise reporting, community branding and third party system integrations; and

- Not robust to meet the current distance education standards. The system was built-in on single point of failures, and was not designed adequately to provide a mission critical service.

2. Decide area of evaluation

A functional and a technical assessment of the following areas: grade book and student record management, online assessment, discussion board, student 
presentation, collaborative tools - calendar, Email, and chat.

3. Develop criteria

The following criteria were developed: transparency, ease of use, student friendly navigation, robust platform, available budget, security, technical support, and file management

4. Identify list of alternative options WebCT CE 6.0, WebCT Vista, Blackboard, Course Compass, Angel and Moodle (OS) were identified for evaluation.

5. Sub task-force groups were created to assess and evaluate the alternative options and also to return their findings for an in-depth product consideration.

6. Disqualified some options

Angel was disqualified because it did not meet the technical network requirements of the institution. Course Compass was disqualified because the materials for it were not available in all academic and applied science areas. The OS option, Moodle, was disqualified for the following reasons:

- Difficult to integrate and interoperate with other applications;

- Limitations in the areas of accessibility;

- Not scalable to meet the demands of the institution;

- Limited vendor support options;

- Strong application development group, additional IT staffing or third party organization support to maintain an enterprise Moodle instance;

- Limited track record with comparable higher education institution; and

- IT security risk. 
7. Qualified products move to the next step of review

Qualified CMS product's vendors were invited to present and discuss their products. Blackboard was invited to present on WebCT versions and Blackboard.

8. Final stage (Recommendation) - WebCT Vista

The Learning Advisory Group made a final decision and selected WebCT

Vista over other Course Management Systems for the following reasons:

- It has more advanced enhancement over the current Campus Edition version;

- Rich content management capabilities;

- It integrates with the university products and systems;

- Easy to use; and

- Better technical infrastructure that supports server clustering, load balancing and system security.

\section{Source of Information}

Regular meeting: advisory group of ACCD Distance Education administrators, Instructional designers, Faculty and IT professionals meet tighter to study the system to date using user statistics, incident database, available network resources and budget options. 


\subsubsection{Lesson Learned from Cases 2-5}

- In all cases, a decision to adopt, migrate or replace existing CMS was made by the recommendation of CMS committee (Commonwealth of Learning, 2003; Knorr, 2005; and LMS Strategic Review Committee, 2005). It was not an individual decision; it was not the director or the president of the institution or other decision maker from the management team. It was a committee that consisted of many experts including faculty members who were representing all departments.

- There are three options available to consider CMS: make at home, buy, or adopt OS.

- The evaluation criteria for selecting CMS system differ from institution to another and are based on the institution needs. The evaluation criteria contain the following important factors; technological, organizational, environmental, and pedagogical factors (Commonwealth of Learning, 2003;Knorr , 2005 ; and LMS Strategic Review Committee, 2005).

- The most important reasons for disqualifying OS CMS were:

- Difficult to integrate and interoperate with other applications (Technology Factor);

- Limitations in the areas of accessibility (Technology Factor);

- Not scalable to meet the demands of the institution (Technology Factor);

- Limited vendor support options (Organizational Factor);

- Need additional staff and support (organizational Factor); 
- Product support options limited and unproven (Technology Factor);

- Limited track record with comparable higher education institution (Environmental Factor);

- IT security risk (Technology Factor);

- Incompatible with campus data center standards (Technology Factor); and

- The OS CMS movement is in its infancy (Technology Factor).

- Each university or college follows its own reviews of CMS. Therefore, the reviews selections criteria were different within the cases reviewed. However, the following criteria were generally considered important: features and functionality, usability, ease of use, user documentation, integration capacity, reliability, scalability, cost, reliability, robust platform, security and technical support.

- A simple compression between the Canadian universities and the public fouryear universities and colleges in the U.S reveals the followings:

- U.S. universities and colleges have significantly more resources to fund research and teaching activities than Canadian universities. In 2006-07, the per-student funding in public four-year U.S. colleges was $\$ 8,000$ higher than universities in Canada. This means greater investment in U.S. than Canadian universities. This also has significant implication on all aspect of teaching and learning. (AUCC, 2008)

- In Canada, unlike U.S., external funding that is specified for some projects usually covers only a portion of those projects' cost. The reminder of the cost, which may include the research time, direct costs and institutional 
costs, is drawn by the university from their other revenues to cover these additional research costs. (AUCC, 2008)

- Based on literature review, case studies and Tornatzky \& Fleischer (1990) frameworks, I proposed the following model, shown in Figure 3, to explain how decisions around OS CMS are made in an academic environment.

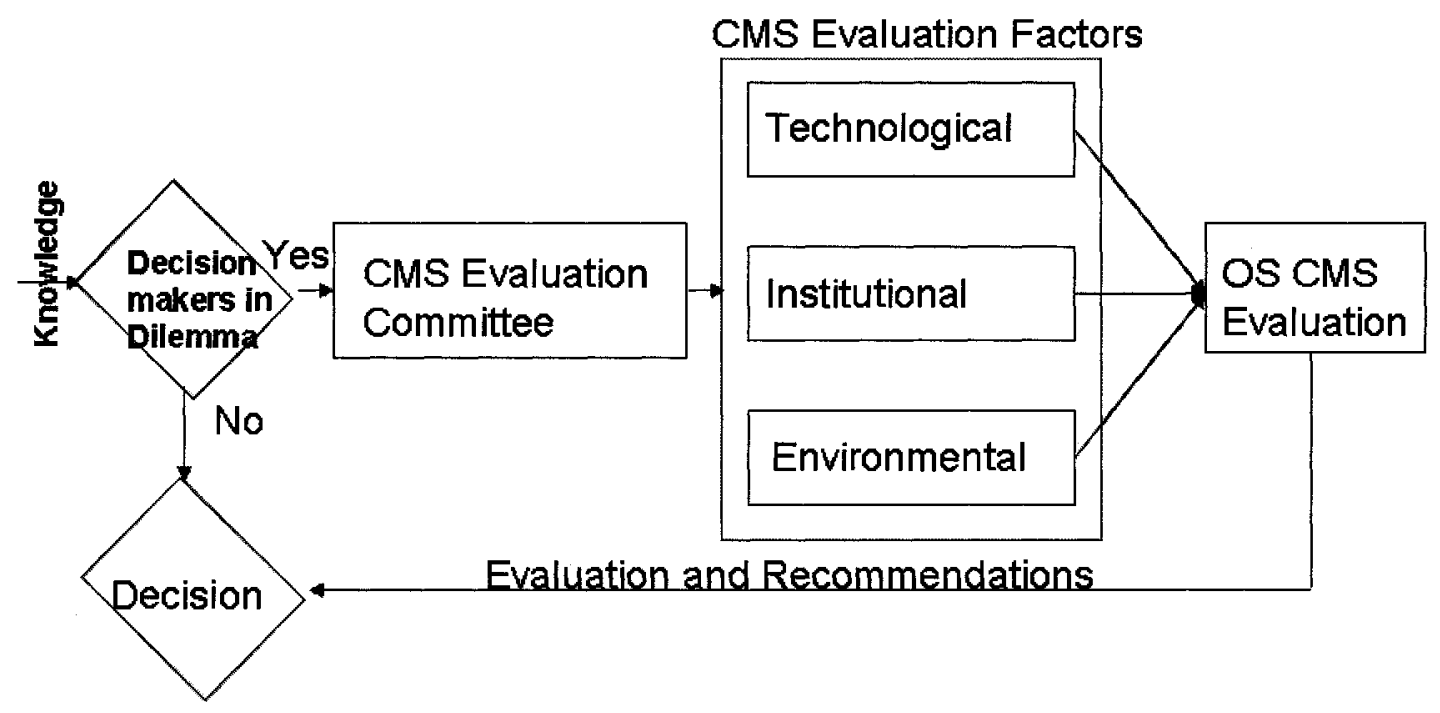

Figure 3: OS CMS Evaluation Decision Process in the Academic Environment 


\section{Theoretical Framework}

Based on the above literature reviews, Tornatzky \& Fleischer (1990) frameworks, Rogers (1995) model, Christensen et al., (2004) and Tessmer (1991), and five case studies, I proposed the following conceptual model for adopting OS CMS in academic field, shown in Figure 4, and also seven hypotheses listed below.

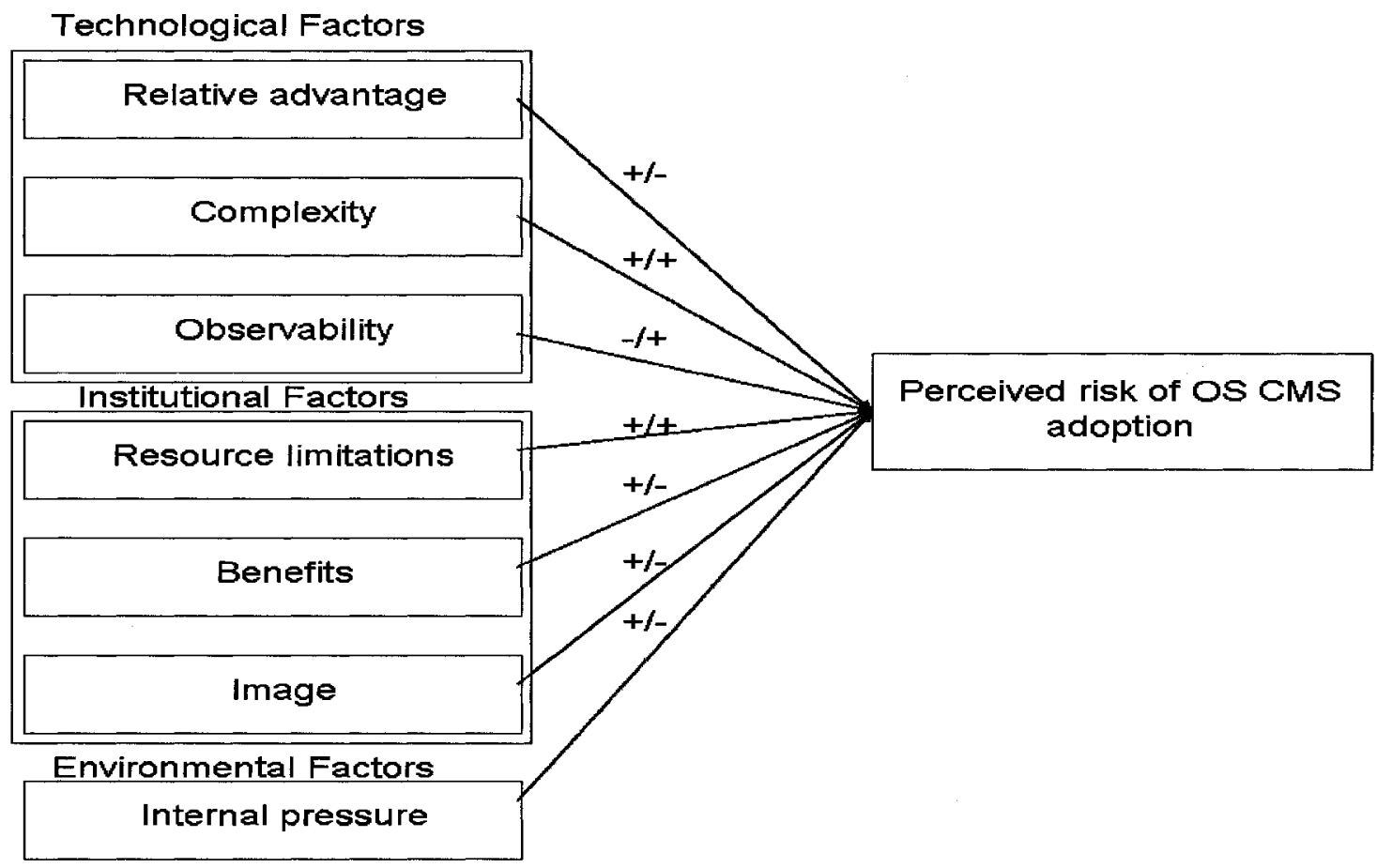

Figure 4: Conceptual Module for OS CMS Adoption

The theoretical frame work of this research consists of seven independent variables - perceived relative advantage, perceived complexity, perceived observability, perceived resource limitations, perceived institutional benefit, perceived institutional image and perceived internal pressure, and one 
dependent variable - perceived risk. The following hypotheses were proposed:

Hypothesis H1: The higher the perceived relative advantage of OS CMS the lower the level of perceived risk to adopt OS CMS

Hypothesis H2: The higher the perceived complexity of OS CMS the higher the level of perceived risk to adopt OS CMS

Hypothesis H3: The lower the perceived observability of OS CMS, the higher the level of perceived risk to adopt OS CMS

Hypothesis H4: The higher the level of perceived resource limitations, the higher the perceived risk to adopt OS CMS

Hypothesis H5: The higher the level of perceived institutional benefits, the lower the perceived risk to adopt OS CMS

Hypothesis H6: The higher the level of perceived institutional image (value), the lower the perceived risk to adopt OS CMS

Hypothesis H7: The higher the level of internal pressure to adopt OS CMS, the lower the perceived risk to adopt OS CMS 


\section{Research Design}

This chapter describes the unit of analysis, study period, and a detail description of research method.

\subsection{Unit of Analysis}

The unit of analysis is a decision maker in Canadian university and/or college.

\subsection{Study Period}

The study period is from January 2007 to 2008 .

\subsection{Sample Selection}

A sample of 111 decision makers representing 25 Canadian universities and colleges was selected. Decision makers such as directors, $\mathrm{ClO}$, managers, and CMS evaluation committee members were targeted.

\subsection{Research Questions}

The study aims to answer the following research questions:

- How are decisions around OS made in Canadian universities and colleges environment? 
- What are decision makers' perception and attitude towards OS?

- What are the factors or obstacles that influence decisions-makers to adopt OS in their institutions?

\subsection{Research Method}

Research, in any area, moves forward through a sequence of inductive and deductive steps as shown in Figure 5 (Christensen et al., 2005).

Inductive research builds theory using three steps: observation, categorization and association. The output is a set of hypothesis, constructs, frameworks or typologies, and models.

Observation $>$ categorization $>$ hypothesis $>$ theory

Deductive research tests theory starting with theoretically based hypotheses; collecting observations to address and test the hypotheses; and accepting or rejection the original theory.

Theory > Test hypothesis > observation $>$ confirmation 


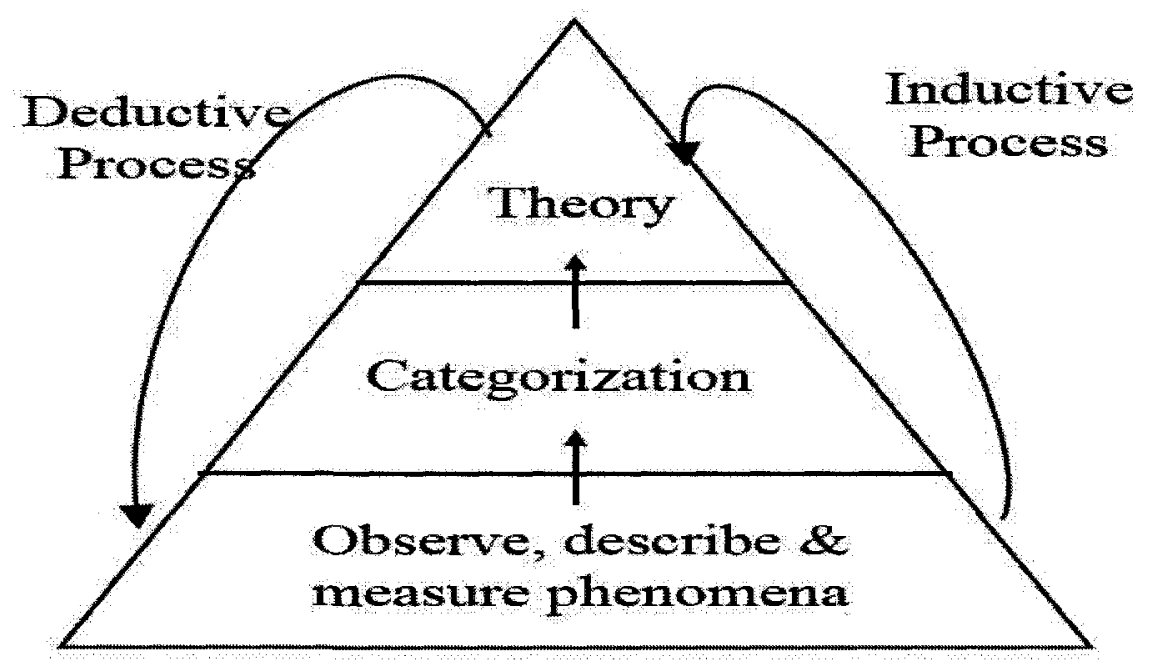

Figure 5: Christensen's Theory Building Process

Since I used previous theories in this research, the research's approach of this study is deductive.

\subsection{Research Design Process}

According to Yin (1994), research design is "the logical sequence that connects the empirical data to a study's initial research questions and, ultimately, to its conclusion." This research commenced by a general literature search that used to develop a quantitative survey instrument based on the research questions to find factors contribute to the adoption of OS CMS and to understand the reasons behind the slow adoption of OS CMS. It also followed by decision maker's interviews to refine and elaborate on the quantitative results. 
A questionnaires and semi-structure interviews were the primary data collection strategies used in the research. Qualitative and quantitative methodologies were used to analyses the data gathered from interviews and survey respectively. The research design consists of six sequential phases:

Phase 1: Literature Review

Phase 2: Initial Questionnaire Design

Phase 3: Interviews

Phase 4: Questionnaire Draft, Testing, and Final Design

Phase 5: Data Collection

Phase 6: Hypotheses Testing, Analysis, and Implication

The six phases are described in detail in the following sections.

\section{Phase 1: Literature Review}

The research aimed to study the adoption of OS CMS in Canadian universities and colleges. It commenced with a general literature search process focused on the following areas: introduction and background about CMS, university and college rationales for OS adoption, slow adoption of OSS in academia, definitions of innovation, diffusion and adoption, the organizational adoption of innovations, decision making definition and processes, adoption strategies, and CMS evaluation processes. 


\section{Phase 2: Initial Questionnaire Design}

Based on the literature review, a list of questions were prepared and the initial design of the questionnaire was developed to complement the TechnologyOrganization-Environment framework, in that we can identify which technological, organizational, environmental, or other factors are most important for each decision maker's adoption decision. The questionnaire was used during the interviews phase and decision makers were asked about their feedback.

\section{Research Ethics Committee Approval}

Before sending the questionnaires to all participants, the questionnaire was sent to Carleton University's Research Ethics Committee to approve it. The approval was granted on April 11, 2008.

\section{Phase 3: Interviews}

Four interviews were conducted with decision makers at one of Canadian comprehensive universities. The interviewees were three managers and one director.

Phase 4: Questionnaire Draft, Testing, and Final Design

A questionnaire draft was completed and sent out to ten decision makers to help 
both the respondents and the researcher in avoiding any problems while dealing with the questionnaire. In one hand, the pilot test will test if the respondents will encounter any problems while filling the questionnaire. On the other hand, it will help the research to test his method of recording and analyzing the data. Researcher will be able to refine the questionnaire accordingly.

The final questionnaires design consisted of three types of questions.

- The first type was a multi-choice answers to which the participants could respond with either choosing one answer or multiple answers.

- The second type was a forty-nine items to which the participants could respond on a Likert five point scales ranging from 'strongly agree' to 'strongly disagree'. Each respondent could choose an answer to each question corresponding to his agreement with a statement.

- The third type was open-ended narrative response items at which the participants were asked to elaborate and give more details on specific question.

The questions were developed based on the potential factors affecting OS CMS adoption as identified in the literature. A list of contact details was created using a Microsoft Excel worksheet in tabular form. Some names on the list were recommended by the managers and decision makers that I interviewed. A search of university and college web sites was also used to get enough samples of decision makers. 


\section{Phase 5: Data Collection}

Questionnaires and invitation letter were sent out by email to all names on the contact list.

The primary sources for collecting the data were semi-structured interviews and questionnaires. Web sites, articles, and literature were used as secondary sources.

- The questionnaires were collected, and database with all responses was built using Microsoft Excel spreadsheet.

- The questionnaires were validated and only one questionnaire was found to be invalid because a participant returned the questionnaire with missing answers.

- The participants' statements were transcribed to the questionnaire.

- Questionnaire coding was used to organize responses to the questionnaire.

- Microsoft Excel spreadsheet was used to provide descriptive statistics for all the variables used in the research.

\section{Phase 6: Hypotheses Testing, Analysis, and Implication}

Based on the results obtained, all the hypotheses were tested, and all the research questions were answered. 


\subsubsection{Result of Pilot Testing}

The response rate was really slow; only one questionnaire was received during the first two weeks. Phones' Follow-ups were made to remind decision makers to send the questionnaires back; the purpose of the research, and the importance for their participation were explained. Also, they were asked about any problem or issues that were preventing them from sending the questionnaire back. The following were some of their feedback:

Two important feedbacks were provided. The first one was a suggestion to use online survey. Some of the decision makers indicated that their time was limited and online survey was easier, safe them a lot of time, and the respond almost instant. For Microsoft document, they indicated that they would send the answers back to me after few weeks. This suggestion was taken into consideration and the online questionnaire was developed and launched.

Other suggestion was to have a five point Likert scales instead of four. A fifth scale," Neither agree nor disagree", was added to the questionnaire.

The study website URL, a user name, and a password were sent to all ten respondents who were chosen for the pilot test. A phone follow up was made on the same time explaining the new changes. 


\subsubsection{Improving Response Rates of E-mail Surveys}

Electronic mail (e-mail) has been used as a method of distributing surveys and collecting data from online users for almost fifteen years (Sheehan, 2001). According to Yun et al. (2001), researches have identified many advantages of email surveys over other types of surveys: email is cost efficient, it reduces complex mail processes, it is faster in transmission, it is less likely to be ignored, it encourages respondents to reply, and it is seen as environmentally friendly.

Some studies have suggested that the response rates to all types of surveys including e-mail surveys have drastically decreased (Sheehan, 2001). The following factors have been found to have a great influence on the response rates.

\section{Survey Length}

Many studies reported in Sheehan (2001) indicated that the length of the survey was seen to have a negative influence on mail survey response rates; shorter surveys yield higher response rates, while longer surveys yield slower response rate.

For the purpose of increasing the response rate in this study, consideration was given to the length of the questionnaire. The length of the questionnaire is only 20 questions. 


\section{Statement of Confidentiality}

In Sheehan \& Hoy (1999), a concern of confidentially was raised because email programs reveal the respondents' names and emails.

In this study, I have assured the respondents' confidentiality by implying the following: first, a unique identifier ID was assigned for each respondent that would separate the respondent's name from the survey as soon the survey received back from respondents. Second, a confidential statement was included in both the invitation letter as well as in the questionnaire that ensure the respondent's confidentiality will be maintained at all times through the course of this research. Finally, I have assured the respondents that the results of the survey will appear in aggregate form.

\section{Salience}

In Sheehan \& Hoy (1999), Martin (1994) defined salience as "the association of importance and/or timeliness with a specific topic. " Many researches have emphasized the importance of salience over other influencing factors such as respondent contact, monetary incentives, and survey length (Sheehan \& Hoy, 1999). Furthermore, it has been found that the salience of an issue has a strong positive correlation with response rate (Peoplepulse, 2008). 
Open source Course Management (OS CMS) is an important topic for decision makers of academic institutions who are considering finding another ways of reducing the high cost of the commercial software products and also who are not realizing the importance of OS in boosting the innovation deployed in their institutions.

Respondents might perceive that replying to a questionnaire would help them to find out the factors that diffuse OS CMS adoption in their institution.

\section{Incentive}

It has been found that offering an incentive to the respondents increases the response rates by $10-15 \%$. Moreover, the response rates increase dramatically when the participants gain values from responding. For business audiences, the most effective form of incentive is the useful, relevant information (Peoplepulse, 2008).

Since our target audiences are decision makers in the academic filed, a copy of the key findings from this study is the most effective incentive to increase response rate.

\section{Personalization}

Personalization of e-mailed survey invites can increase response rates by $7 \%$ or 
more. For example, using 'Dear John' as opposed to 'Dear respondent' increases the response rate by 7.8 percentage points. Moreover, it has been found that respondents that received personalized invites were $2.6 \%$ less likely to drop off before completing all survey questions (Peoplepulse, 2008).

In this study, all the questionnaires were sent to participant using their first and last names, for example, "Dear John Callahan."

\section{Best Time to Send Questionnaires}

It has been found that the best time to send the questionnaire is mid-week and during mid-afternoon. On the first day of the week, most e-mail users will start their day cleansing their mailboxes. The chances of your questionnaire being read are increased by sending out e-mail invitations mid-week, after 12 p.m. (Peoplepuls, 2008).

\section{Pre-notification}

Pre-notification consists of notifying respondents in advance about the questionnaire, the time that they expect to receive the questionnaire in the email, importance of the questionnaire to them and to the researcher. According to Sheehan (2001), some studies have found that "pre-notification for e-mail surveys is imperative, and the practice of sending unsolicited e-mail surveys is unacceptable." 


\section{Follow-up Contacts}

According to Sheehan (2001), it has been found that follow-up contacts have positive effects on response rate and increases the response rate by $25 \%$. Moreover, in Yun et al. (2001), Heberlein \& Baumgartner (1978) indicated that multiple follow-ups yield higher response rate than sending one-time reminders.

Researchers have also been concerned about follow-up timing. In Yun et al. (2001), Dillman's (1978) recommend that the traditional mail follow-up should be sent at one, three, and seven weeks from the first mailing date; however, Anderson and Gansneder (1995) argue that for email survey it should be one week earlier than the time required for traditional mail surveys.

Table 1 shows the strategies that I have used to increase the questionnaire response rate.

\begin{tabular}{|l|l|l|}
\hline Method & Description & Time \\
\hline Pre-notification & $\begin{array}{l}\text { Notify the respondent that I will } \\
\text { be sending a questionnaire in } \\
\text { few days; } \text { Appendix A: Sample } \\
\text { invitation letter }\end{array}$ & $\begin{array}{l}\text { Starting } \\
\text { date: April } \\
23,08 \\
\text { After 12 } \\
\text { p.m. }\end{array}$ \\
\hline First follow up & $\begin{array}{l}\text { A phone call asking for their } \\
\text { permission to send the email; an } \\
\text { offer to fill questionnaire over } \\
\text { phone }\end{array}$ & $\begin{array}{l}\text { Starting } \\
\text { date: April } \\
23,08\end{array}$ \\
\hline $\begin{array}{l}\text { Send the } \\
\text { questionnaire }\end{array}$ & $\begin{array}{l}\text { Email questionnaires to } \\
\text { respondents; Appendix B: The } \\
\text { questionnaire }\end{array}$ & $\begin{array}{l}\text { Three days } \\
\text { later: April } \\
\text { 26, 08 }\end{array}$ \\
\hline Second Follow up & Emphasize the importance of & Two days \\
\hline
\end{tabular}




\begin{tabular}{|l|l|l|}
\hline & $\begin{array}{l}\text { the questionnaire for both } \\
\text { respondents and the } \\
\text { researcher; an offer to fill } \\
\text { questionnaire over phone }\end{array}$ & $\begin{array}{l}\text { later: April } \\
28,08\end{array}$ \\
\hline Third follow up & $\begin{array}{l}\text { Ask if there is any problem on } \\
\text { answering the questionnaire } \\
\text { and offer help to go through it }\end{array}$ & $\begin{array}{l}\text { Two days } \\
\text { later: April } \\
30,08\end{array}$ \\
\hline Fourth follow up & $\begin{array}{l}\text { Ask for help; Pr. John to contact } \\
\text { respondents by phone and } \\
\text { explain the importance of the } \\
\text { study }\end{array}$ & $\begin{array}{l}\text { later: Mays } \\
13,08\end{array}$ \\
\hline
\end{tabular}

Table 1: Strategies Used to Increase Questionnaire Response Rate 


\section{Data Analysis}

\subsection{Overview}

A questionnaire survey was used to collect data from a sample of decision makers representing 25 Canadian universities and colleges. Contact information for the target informants was obtained from interviews, institutions' web sites, referred by peers, and internet search.

A total of 25 names that represented 18 universities and colleges were recommended during the interview phase. An additional 7 Institutions were selected randomly from a list of Canadian universalities and colleges. The list can be found at http://www.uwaterloo.ca/canu/index.php. A Google search was used to compile a contact list that contained detailed information about the recommended names, and also to obtain extra decision makers' names.

Decision makers such as directors, $\mathrm{CIO}$, managers, and $\mathrm{CMS}$ evaluation committee members were targeted. At the end of the search, a total of 100 names representing 25 universities were selected. Some key words were used during the search such as: OS, Course Management System, Learning and Teaching Support, Computing and Communication Services, CMS Evaluation Committee, Educational Technology Services, Information Technology systems, IT departments, Instructional Innovation, Academic Computing, CMS support, and Teaching Services. 
A total of 100 questionnaires were sent out to all target informants. 24 target informants indicated that they were not relevant decision makers; 11 of them offered names of other colleagues who they thought were decision makers. An additional 11 questionnaires were sent out to these additional names. This made the total number of questionnaires sent 111 . Of this number, 41 were returned over an 8-week period. One of these was invalid because a participant returned the questionnaire with missing answers. A total number of 46 surveys were not returned despite many reminders. Table 2 shows the summary of the characteristics of the sample.

\begin{tabular}{|l|l|l|l|l|}
\hline & $\begin{array}{l}\text { Questionnaires } \\
\text { sent }\end{array}$ & $\begin{array}{l}\text { Questionnaires } \\
\text { received }\end{array}$ & $\begin{array}{l}\text { Not } \\
\text { relevant }\end{array}$ & $\begin{array}{l}\text { Non } \\
\text { responses }\end{array}$ \\
\hline Universities & 100 & 38 & 23 & 39 \\
\hline Colleges & 11 & 3 & 1 & 7 \\
\hline Total & 111 & 41 & 24 & 46 \\
\hline $\begin{array}{l}\text { Response } \\
\text { Rate }\end{array}$ & \multicolumn{4}{|l|}{$41 /(111-24)=47 \%$} \\
\hline
\end{tabular}

Table 2: Sample Characteristics

As mentioned in section 2.6, Rogers (1995) proposed one of the best-known models of the innovation-adoption process. The model can be divided into five stages: knowledge, persuasion, decision, implementation and confirmation. For his research purpose, the pre-implementation stages were the focus of the study. 


\section{Knowledge}

Rogers (1995) claims that the characteristics of the decision making unit that includes socioeconomic characteristics, personality variables and communication behavior; the perceived need for the innovation; the previous practice; and the norms of the social systems determine whether potential adopter seeks more information about the innovation or not.

\section{Respondents' Characteristics}

Of the 41 respondents, 8 were directors, 2 were chief information officers, 14 were managers, and 17 were academics (either professors or deans). The data in Table 3 show that the decision makers who participated in the study had significant experience in both education and in IT.

\begin{tabular}{|l|c|c|}
\hline \multirow{2}{*}{} & \multicolumn{2}{|c|}{ Experience } \\
\cline { 2 - 3 } & Education & IT \\
\hline 6-5 years & 8 & 7 \\
\hline 11-20 years & 7 & 13 \\
\hline More than 20 years & 11 & 10 \\
\hline
\end{tabular}

Table 3: Experience of Respondents 


\section{Institutional Characteristic}

$59 \%$ of the respondents described their institutions as conservative in their approach to adopt or migrate to OS while $29 \%$ mentioned that their institutions encourage adoption and migrating to OS CMS. Table 4 shows the results of the question about institutional characteristics.

\begin{tabular}{|l|c|c|}
\hline Institution characteristic & Frequency & Percentage \\
\hline Encourage OS adoption & 12 & $29 \%$ \\
\hline Conservative & 24 & $59 \%$ \\
\hline Against any adoption & 2 & $5 \%$ \\
\hline Don't know & 3 & $7 \%$ \\
\hline
\end{tabular}

Table 4: Institution Characteristics

Table 5 shows the type of Course Management System used in the institutions represented in the 41 questionnaires received.

\begin{tabular}{|l|c|c|}
\hline Type of CMS & Frequency & Percentage \\
\hline Proprietary CMS & 29 & $71 \%$ \\
\hline OS CMS & 8 & $19 \%$ \\
\hline Both & 4 & $10 \%$ \\
\hline
\end{tabular}

Table 5: Type of Course Management System

The majority of Canadian universities and colleges in the sample had not adopted open source Course Management System at the time of the study. The results of the questionnaire and the interviews indicate that discussion makers 
use several methods such as discussion thread, newsgroups, wikis and emaillists to learn and know about OS CMS. A few respondents also mentioned conferences, commercial partners in OS efforts, trade publications and wikis. Table 6 shows the participants' current source of information regarding OS CMS.

\begin{tabular}{|l|c|c|}
\hline Current source of information & Frequency & Percentage \\
\hline Website & 32 & $78 \%$ \\
\hline $\begin{array}{l}\text { Academic community, word of } \\
\text { mouth }\end{array}$ & 30 & $73 \%$ \\
\hline Email-lists & 22 & $54 \%$ \\
\hline Discussion thread & 17 & $42 \%$ \\
\hline CMS evaluation committee & 16 & $39 \%$ \\
\hline Newsgroups & 13 & $32 \%$ \\
\hline
\end{tabular}

Table 6: Current Sources of Information

\section{Evaluating Previous Practice}

Decision makers in the sample used several methods to evaluate their existing

CMS or to compare it to other proprietary or OS CMS available in the market.

Table 7 shows the methods used as indicated by respondents.

\begin{tabular}{|l|c|}
\hline Evaluation method & Frequency \\
\hline CMS evaluation committee & 21 \\
\hline Own direct experience & 14 \\
\hline $\begin{array}{l}\text { Collaboration and communications } \\
\text { methods (online, email, surveys, online } \\
\text { search) }\end{array}$ & 22 \\
\hline $\begin{array}{l}\text { Pilot, Case studies, Product comparisons, } \\
\text { Vendor representations, conferences }\end{array}$ & 32 \\
\hline Inputs from students & 16 \\
\hline
\end{tabular}




\begin{tabular}{|l|c|}
\hline Inputs from faculty members & 18 \\
\hline
\end{tabular}

Table 7: Evaluation Criteria Methods

They also use the following methods or approaches to reach their decision to stay with their existing CMS, replace it with another proprietary CMS, or migrate to an OS CMS. The results in Table 8 indicate that product evaluations, other institutional experience and committee discussion groups were the methods most used by decision makers to reach their decision.

\begin{tabular}{|l|l|}
\hline Evaluation method & Frequency \\
\hline Business cases & 8 \\
\hline Product evaluations & 27 \\
\hline Case studies & 7 \\
\hline Other institutional experience & 22 \\
\hline Committee discussion groups & 21 \\
\hline Software Consultants and representatives & 16 \\
\hline
\end{tabular}

Table 8: Methods to Reach Adoption/Migration Decision

For the second stage of the adoption process and based on Roger's Diffusion of Innovation model, decision makers begin to form a positive or a negative attitude toward the innovation. At this stage, five perceived characteristics of innovation, relative advantage, compatibility, complexity, trialability and observability determine the potential adopter's attitude towards the innovation. The following section discusses only relative advantage, complexity and observability as they concern with the pre-implementation stages. 


\subsection{Reliability and Validity}

Reliability is the degree to which a measure is repeatable and gives the same results over and over again (Trochim, 2006). Reliability does not guarantee validity. Surveys can be reliable without being valid. On the other hand, measurements cannot be valid unless they are reliable (Yu, 2008).

Cronbach alpha is a widely used to assess reliability. The higher alpha is, the more reliable the test (Trochim, 2006). However, there is no agreed threshold for Cronbach alpha. Usually 0.7 is the lowest acceptable value and it may decrease to 0.6 in exploratory research (Robison et al., 1991, p.13).

Validity refers to the degree to which a measure is accurate - whether or not it measures what it is intended to measure. The validity of variables was tested using factor analysis to examine convergent validity and discriminant validity of items. In convergent validity, the degree to which items of a variable converge together on a single construct was examined, while discriminant validity tests whether two constructs differ. Measures of dissimilar construct should not correlate highly with one another (Trochim, 2006).

\subsection{Factor Analysis}

Factor analysis is a data reduction technique used to reduce a large number of 
variables to a smaller number (Charles, 1992). According to Gaur (2006, p. 134) factor analysis can be applied and considered adequate on a sample size of at least 200 and is excellent on a sample size of 500 . Stevens (1996, p. 372), however, indicates that components with four or more loadings above 0.60 in absolute value can be considered reliable regardless of sample size.

The following were used to apply factor analysis on this research. The first step was to use R Software and perform principle components analysis. Principle components analysis was used to test and evaluate convergent validity of items by examining whether items of a variable converged together on a single construct. In addition, Cattell's scree plot was used to determine the number of factors to extract in the final solution. A scree plot is another way of determining the number of factors to extract. It is a plot of the eigenvalues associated with each factors extracted, against each factor. The second step was to determine how many factors to retain. In this study, Kaiser (1960) criterion cited in Steven (1996, p.366) was used: components with eigenvalues greater than one were

retained. A third step is to use factor rotation to clear any ambiguity that may be caused by one or more variables that may load about the same or on more than one factor (Charles, 1992). A Varimax rotation was also conducted.

\subsubsection{Technological Factors}

As discussed in section 2.5.1, Rogers (1995) identifies relative advantage, compatibility, complexity, trialability, and observability as five characteristics of 
innovations as perceived by adopter that diffuse or hinder the innovations. Since the focus of this study is the pre-implementation stages of Roger (1995) model, as discussed in section 2.6 , only relative advantage, complexity, and observability were explored.

Relative advantage. The relative advantage of OS CMS compared to proprietary CMS was perceived by decision makers in terms of cost, reliability, flexibility, and reliability.

Complexity. The complexity of OS CMS compared to proprietary CMS was perceived by decision makers in terms of ease of use, available documentation, security, and technical support.

Observability. The observability of OS CMS was perceived by decision makers in terms of beneficial results expected from using OS CMS.

Table 9 shows a list of all the technological factors derived from the literature.

\begin{tabular}{|c|c|c|c|}
\hline Construct & Code & Items & $\begin{array}{l}\text { Adopted } \\
\text { from }\end{array}$ \\
\hline \multirow{6}{*}{$\begin{array}{l}\text { Relative } \\
\text { advantage } \\
\text { (TRA) }\end{array}$} & TRA_1 & $\begin{array}{l}\text { OS CMS products are more reliable } \\
\text { than proprietary CMS }\end{array}$ & \multirow{6}{*}{$\begin{array}{l}\text { Ahmed } \\
\text { (2005), } \\
\text { Rogers } \\
(1995)\end{array}$} \\
\hline & TRA_2 & $\begin{array}{l}\text { OS CMS products are more efficient } \\
\text { than proprietary CMS }\end{array}$ & \\
\hline & TRA_3 & $\begin{array}{l}\text { OS CMS products are more flexible } \\
\text { than proprietary CMS }\end{array}$ & \\
\hline & TRA_4 & $\begin{array}{l}\text { OS CMS products are easier to use } \\
\text { than proprietary CMS }\end{array}$ & \\
\hline & TRA_5 & $\begin{array}{l}\text { OS CMS products reduce hardware } \\
\text { complexity }\end{array}$ & \\
\hline & TRA_6 & $\begin{array}{l}\text { OS CMS products reduce software } \\
\text { complexity }\end{array}$ & \\
\hline
\end{tabular}




\begin{tabular}{|c|c|c|c|}
\hline \multirow{9}{*}{$\begin{array}{l}\text { Complexity } \\
\text { (TCX) }\end{array}$} & TCX_1 & $\begin{array}{l}\text { Cost of adoption/migration to OS } \\
\text { CMS is not clear. }\end{array}$ & \multirow{9}{*}{$\begin{array}{l}\text { Ahmed } \\
(2005), \\
\text { Rogers } \\
(1995)\end{array}$} \\
\hline & TCX_2 & $\begin{array}{l}\text { Adoption/migration to OS CMS may } \\
\text { involve some legal issues }\end{array}$ & \\
\hline & TCX_3 & $\begin{array}{l}\text { Intellectual property is a concern } \\
\text { when adopting/migrating to OS CMS }\end{array}$ & \\
\hline & TCX_4 & $\begin{array}{l}\text { We have some security concerns } \\
\text { regarding adoption/migration to OS } \\
\text { CMS }\end{array}$ & \\
\hline & TCX_5 & $\begin{array}{l}\text { OS CMS products' documentation } \\
\text { may be poor }\end{array}$ & \\
\hline & TCX_6 & $\begin{array}{l}\text { OS CMS products' documentation } \\
\text { maybe sometime non-existent. }\end{array}$ & \\
\hline & TCX_7 & $\begin{array}{l}\text { OS CMS products require more } \\
\text { maintenance than proprietary CMS. }\end{array}$ & \\
\hline & TCX_8 & $\begin{array}{l}\text { OS CMS products require a high } \\
\text { level of user expertise. }\end{array}$ & \\
\hline & TCX_9 & $\begin{array}{l}\text { OS CMS products require hiring more } \\
\text { staff. }\end{array}$ & \\
\hline \multirow{7}{*}{$\begin{array}{l}\text { Observability } \\
\text { (OBS) }\end{array}$} & OBS_1 & $\begin{array}{l}\text { OS CMS features are not at the level } \\
\text { of proprietary CMS }\end{array}$ & \multirow{7}{*}{$\begin{array}{l}\text { Ahmed } \\
\text { (2005), } \\
\text { Rogers } \\
\text { (1995) }\end{array}$} \\
\hline & $\begin{array}{l}\mathrm{OBS} \\
2\end{array}$ & $\begin{array}{l}\text { Product support options are limited } \\
\text { for OS CMS }\end{array}$ & \\
\hline & $\begin{array}{c}\text { OBS } \\
3\end{array}$ & $\begin{array}{l}\text { Product support options are unproven } \\
\text { for OS CMS }\end{array}$ & \\
\hline & $\begin{array}{c}\bar{O} \text { OBS } \\
4\end{array}$ & $\begin{array}{l}\text { The OS CMS movement is still } \\
\text { immature }\end{array}$ & \\
\hline & $\begin{array}{c}\text { OBS } \\
5\end{array}$ & $\begin{array}{l}\text { The future of OS CMS in higher } \\
\text { education is unclear. }\end{array}$ & \\
\hline & $\begin{array}{l}\text { OBS } \\
6\end{array}$ & $\begin{array}{l}\text { OS CMS product support options are } \\
\text { limited. }\end{array}$ & \\
\hline & $\begin{array}{l}\text { OBS } \\
-7\end{array}$ & $\begin{array}{l}\text { OS CMS products have a limited } \\
\text { track record with comparable } \\
\text { universities/colleges }\end{array}$ & \\
\hline
\end{tabular}

Table 9: Technological Factors

\subsubsection{Reliability and Validity}

After eliminating survey questions (TCX_5 -TCX_9) with low Cronbach alphas, the Cronbach alphas for the composite measures for relative advantage, 
complexity and observability are shown in Table 10. Each is greater than the threshold of 0.70 . Therefore, the factors used in this study provided support for scale's reliability.

\begin{tabular}{|l|c|c|}
\hline Item description & $\begin{array}{c}\text { No. } \\
\text { Items }\end{array}$ & $\begin{array}{c}\text { Cronbach } \\
\text { Alpha }\end{array}$ \\
\hline $\begin{array}{l}\text { Relative advantage } \\
\text { (TRA) }\end{array}$ & 6 & 0.82 \\
\hline $\begin{array}{l}\text { Complexity } \\
\text { (TCX) }\end{array}$ & 4 & 0.75 \\
\hline $\begin{array}{l}\text { Observability } \\
\text { (OBS) }\end{array}$ & 7 & 0.76 \\
\hline
\end{tabular}

Table 10: Technological Factors - Analysis of Measurement Reliability

Table 11 shows the results of Principle Components (PC) analysis used to evaluate the convergent validity of items.

\begin{tabular}{|l|c|c|c|}
\hline \multirow{2}{*}{ Component } & \multicolumn{3}{|c|}{ Initial Eigenvalues } \\
\cline { 2 - 4 } & Total & \% of Variance & Cumulative \% \\
\hline 1 & 4.72 & 27.72 & 27.72 \\
\hline 2 & 3.05 & 17.94 & 45.65 \\
\hline 3 & 1.81 & 10.651 & 56.31 \\
\hline 4 & 1.33 & 7.85 & 64.15 \\
\hline 5 & 1.17 & 6.88 & 71.03 \\
\hline 6 & 0.913 & 5.37 & 76.40 \\
\hline 7 & 0.808 & 4.75 & 81.16 \\
\hline 8 & 0.661 & 3.89 & 85.05 \\
\hline 9 & 0.629 & 3.70 & 88.75 \\
\hline 10 & 0.461 & 2.71 & 91.46 \\
\hline 11 & 0.398 & 2.34 & 93.80 \\
\hline 12 & 0.315 & 1.86 & 95.66 \\
\hline 13 & 0.233 & 1.37 & 97.03 \\
\hline 14 & 0.194 & 1.14 & 98.17 \\
\hline 15 & 0.1481 & 0.871 & 99.04 \\
\hline 16 & 0.116 & 0.681 & 99.72 \\
\hline
\end{tabular}




\begin{tabular}{|l|l|l|l|}
\hline 17 & 0.049 & 0.288 & 100.00 \\
\hline
\end{tabular}

Table 11: Technology Factors - Principle Component Analysis

Factors 1, 2, 3, 4 and 5 have eigenvalues greater than 1.0, and therefore explain more variance than a single variable. The cumulative percentage of variance explained by the first five factors is $71 \%$. The remaining factors 6 through 17 have eigenvalues less than 1.0 and therefore they explain less variance than a single variable. This result suggests that the final solution should not extract more that 5 factors.

The following scree plot, Figure 6 , confirms that the final solution should not extract more than 5 factors.

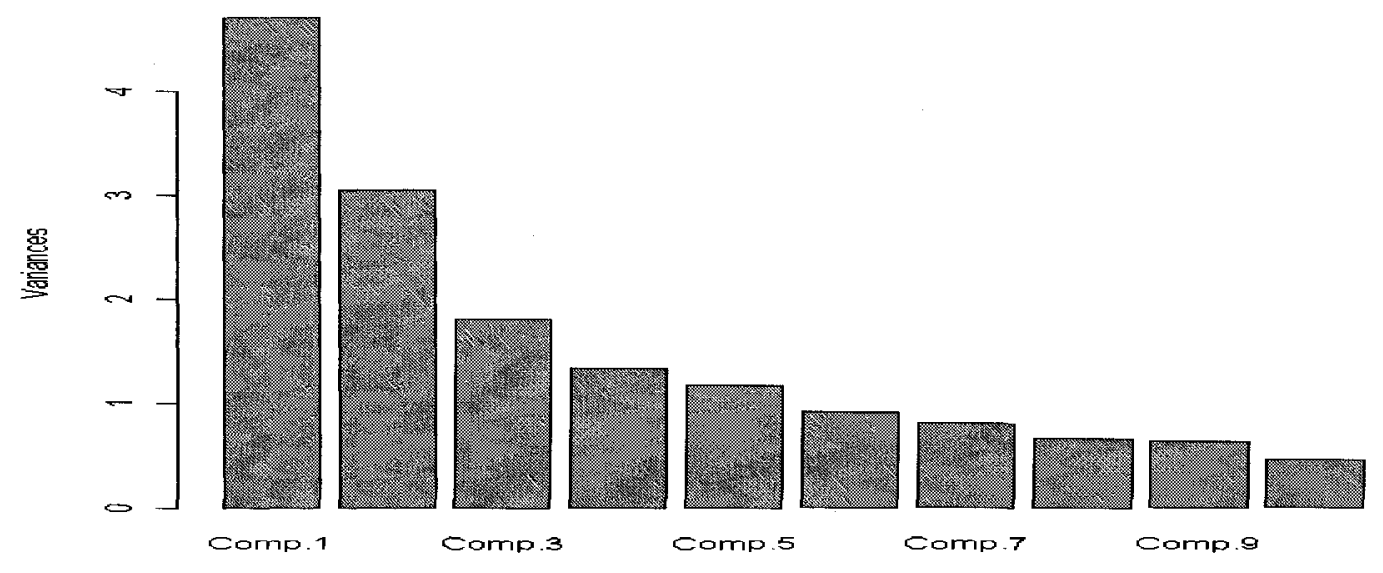

Figure 6: Technological Factors - Scree Plot

A Varimax factor rotation with regression was used to extract the factors. Results are shown in Table 12. 


\begin{tabular}{|l|l|l|l|l|l|}
\hline & Factor 1 & Factor 2 & Factor 3 & Factor 4 & Factor 5 \\
\hline OBS_1 & -0.313 & & 0.179 & $\mathbf{0 . 4 4 5}$ & -0.262 \\
\hline OBS_2 & & 0.131 & $\mathbf{0 . 9 8 6}$ & & \\
\hline OBS_3 & -0.270 & 0.297 & $\mathbf{0 . 7 7 7}$ & 0.264 & -0.167 \\
\hline OBS_4 & -0.272 & 0.260 & & $\mathbf{0 . 6 4 2}$ & 0.154 \\
\hline OBS_5 & & 0.149 & 0.221 & $\mathbf{0 . 4 0 1}$ & -0.245 \\
\hline OBS_6 & & $\mathbf{0 . 5 1 2}$ & 0.308 & & 0.102 \\
\hline OBS_7 & & & & $\mathbf{0 . 8 2 2}$ & -0.189 \\
\hline TCX_1 & & & 0.210 & 0.184 & -0.443 \\
\hline TCX_2 & 0.105 & $\mathbf{0 . 6 4 6}$ & 0.147 & 0.261 & \\
\hline TCX_3 & 0.167 & $\mathbf{0 . 7 2 7}$ & 0.116 & & -0.177 \\
\hline TCX_4 & & $\mathbf{0 . 8 5 5}$ & & & -0.274 \\
\hline TRA_1 & & -0.253 & 0.156 & & $\mathbf{0 . 9 4 9}$ \\
\hline TRA_2 & $\mathbf{0 . 6 0 0}$ & & & -0.128 & 0.456 \\
\hline TRA_3 & $\mathbf{0 . 5 7 5}$ & & & -0.340 & 0.412 \\
\hline TRA_4 & $\mathbf{0 . 7 2 3}$ & 0.154 & & -0.242 & \\
\hline TRA_5 & $\mathbf{0 . 8 0 6}$ & $\mathbf{0 . 1 1 9}$ & & -0.107 & \\
\hline TRA_6 & $\mathbf{0 . 7 6 0}$ & & -0.106 & & \\
\hline
\end{tabular}

${ }^{*}$ Bold designates factor loading with an initial cutoff point of 0.4 or above

Table 12: Technological Factors - Varimax Factor Rotation Output

All the items were loaded (correlated) highest matching the categorization in

Table 9, except items OBS_2 \& OBS_3 were loaded on Factor 3, and item

TRA_1 was loaded on factor 5 .

\subsubsection{Relationship among Technological Variables}

A Pearson's correlation matrix was used to test relationship among variables and to test if there was a need to extract new factors.

\section{Perceived Relative Advantages Variables}

The correlation matrix in Table 13 shows that item TRA_1, "OS CMS products 
are more reliable than proprietary CMS", was not significantly related with any other item.

\begin{tabular}{|l|l|l|l|l|l|l|}
\hline & TRA_1 & TRA_2 & TRA_3 & TRA_4 & TRA_5 & TRA_6 \\
\hline TRA_1 & 1.00 & & & & & \\
\hline TRA_2 & $0.501^{\mathrm{C}}$ & 1.00 & & & & \\
\hline TRA_3 & $0.441^{\mathrm{C}}$ & $0.635^{\mathrm{C}}$ & 1.00 & & & \\
\hline TRA_4 & -0.0122 & $0.506^{\mathrm{C}}$ & $0.525^{\mathrm{C}}$ & 1.00 & & \\
\hline TRA_5 & 0.119 & $0.414^{\mathrm{C}}$ & $0.512^{\mathrm{C}}$ & $0.584^{\mathrm{C}}$ & 1.00 & \\
\hline TRA_6 & 0.0163 & $0.483^{\mathrm{C}}$ & $0.366^{\mathrm{b}}$ & $0.549^{\mathrm{C}}$ & $0.670^{\mathrm{C}}$ & 1.00 \\
\hline
\end{tabular}

Signif. codes: "al" $p<0.1$; 1 ib" $p<0.05$; "cc" $p<0.01$

Table 13: Pearson's Correlation Coefficients for Relative Advantage Items

After deleting this item, the effects on Cronbach alpha and on correlation matrix were not affected significantly. Therefore, I decided to keep all items and used the average score to combine all items on a single construct called relative advantage.

\section{Perceived Complexity Variables}

A correlation matrix in Table 14 shows that item TCX_1, "Cost of adoption/migration to OS CMS is not clear", was not significantly related with the rest of items.

\begin{tabular}{|l|l|l|l|l|}
\hline & TCX_1 & TCX_2 & TCX_3 & TCX_4 \\
\hline TCX_1 & 1.00 & & & \\
\hline TCX_2 & 0.200 & 1.00 & & \\
\hline TCX_3 & 0.208 & $0.595^{C}$ & 1.00 & \\
\hline TCX_4 & 0.192 & $0.572^{C}$ & $0.670^{C}$ & 1.00 \\
\hline
\end{tabular}

Signif. codes: " "a" $p<0.1 ;$ “"b" $p<0.05$; “c” $p<0.01$

Table 14: Pearson's Correlation Coefficients for Complexity Items 
After deleting this item, the effects on Cronbach alpha and on correlation matrix were not affected significantly. Therefore, this item was not considered differently from other items. I decided to keep all items and used the average score to combine all items on a single construct called complexity.

\section{Perceived Observability Variables}

A correlation matrix in Table 15 shows that items OBS_2, "Product support options are limited for OS CMS", and OBS_3, "Product support options are unproven for OS CMS", were strongly correlated with each other, but not with the reset of other items. Deleting both items from the observability category decreases reliability from 0.76 to 0.68 . In other words, it seemed to be that those items increase the reliability scale of this category. Therefore, I decided to keep all items and used the average score to combine all items on a single construct called observability.

\begin{tabular}{|l|l|l|l|l|l|l|l|}
\hline & OBS_1 & OBS_2 & OBS_3 & OBS_4 & OBS_5 & OBS_6 & OBS_7 \\
\hline OBS_1 & 1.00 & & & & & & \\
\hline OBS_2 & 0.182 & 1.00 & & & & & \\
\hline OBS_3 & $0.443^{\mathrm{c}}$ & $0.800^{\mathrm{c}}$ & 1.00 & & & & \\
\hline OBS_4 & $0.300^{\mathrm{a}}$ & 0.125 & $0.331^{\mathrm{b}}$ & 1.00 & & & \\
\hline OBS_5 & $0.331^{\mathrm{b}}$ & 0.248 & $0.348^{\mathrm{b}}$ & $0.448^{\mathrm{c}}$ & 1.00 & & \\
\hline OBS_6 & 0.112 & $0.373^{\mathrm{b}}$ & $0.359^{\mathrm{b}}$ & $0.286^{\mathrm{a}}$ & 0.095 & 1.00 & \\
\hline OBS_7 & $0.450^{\mathrm{c}}$ & 0.044 & $0.281^{\mathrm{a}}$ & $0.515^{\mathrm{c}}$ & $0.408^{\mathrm{c}}$ & 0.035 & 1.00 \\
\hline
\end{tabular}

Signif. codes: " ${ }^{4 a n} p<0.1 ;{ }^{\text {"anp }} p<0.05$; "cc" $p<0.01$

Table 15: Pearson's Correlation Coefficients for Observability Items 
For technological factors, the results of reliability analysis indicated acceptable reliabilities (above $\mathbf{0 . 7 0 )}$ for all items. Moreover, the results of validity analysis indicated significant validity. Therefore, both reliability and validity analyses suggested adequate validity to proceed with the analysis.

\subsubsection{Institutional Factors}

Several institutional factors appear to influence the decision to adopt OS CMS by decision makers. These include perceived resource limitations, perceived institutional benefits, and perceived institutional image.

Perceived resource limitations. Each academic institution has its own budget structure and different ways of revenues. The availability of the funds is an important factor that influence the decision makers' decision to approve or rejects adopting new technologies.

Perceived institutional benefit. Reducing cost, providing better support for faculty, and ending vendor monopoly are some of the benefits that promote OS CMS adoption and influence the decision makers' decision to adopt OS CMS.

Perceived institutional image. An institutional image is directly related to the level of institutional attractiveness, its growth, capabilities and readiness. Table 16 lists all the institutional factors derived from the literature. 


\begin{tabular}{|c|c|c|c|}
\hline Construct & Code & Items & Adopted from \\
\hline \multirow{3}{*}{$\begin{array}{l}\text { Perceived } \\
\text { resource } \\
\text { limitations }\end{array}$} & IR_1 & $\begin{array}{l}\text { Budget is not enough to support } \\
\text { OS CMS adoption/migration. }\end{array}$ & \multirow{3}{*}{$\begin{array}{l}\text { Ahmed (2005), } \\
\text { Christensen et al. } \\
\text { (2004) }\end{array}$} \\
\hline & IR_2 & $\begin{array}{l}\text { Funding is not enough to support } \\
\text { OS CMS adoption/migration }\end{array}$ & \\
\hline & IR_3 & $\begin{array}{l}\text { There are not enough resources } \\
\text { to adopt/migrate to OS CMS. }\end{array}$ & \\
\hline \multirow{6}{*}{$\begin{array}{l}\text { Process ( } \\
\text { perceived } \\
\text { institutional } \\
\text { benefit) }\end{array}$} & IP_1 & $\begin{array}{l}\text { OS CMS products reduce } \\
\text { operational cost }\end{array}$ & \multirow{6}{*}{$\begin{array}{l}\text { Ahmed (2005), } \\
\text { Christensen et al. } \\
\text { (2004) }\end{array}$} \\
\hline & IP_2 & $\begin{array}{l}\text { OS products reduce dependency } \\
\text { on IT staff }\end{array}$ & \\
\hline & IP_3 & $\begin{array}{l}\text { OS CMS products provide better } \\
\text { support for faculty }\end{array}$ & \\
\hline & IP_4 & $\begin{array}{l}\text { OS CMS products reduce } \\
\text { administrative difficulties }\end{array}$ & \\
\hline & IP_5 & $\begin{array}{l}\text { OS CMS products are free so } \\
\text { there can be no surprise } \\
\text { increases in license fees }\end{array}$ & \\
\hline & IP_6 & OS CMS ends vendor monopoly & \\
\hline \multirow{8}{*}{$\begin{array}{l}\text { Values } \\
\text { (Perceived } \\
\text { institution } \\
\text { image) }\end{array}$} & IV_1 & $\begin{array}{l}\text { OS CMS products accelerate } \\
\text { institution growth }\end{array}$ & \multirow{8}{*}{$\begin{array}{l}\text { Ahmed (2005), } \\
\text { Christensen et al. } \\
\text { (2004) }\end{array}$} \\
\hline & IV_2 & $\begin{array}{l}\text { OS CMS products provide better } \\
\text { services to users }\end{array}$ & \\
\hline & IV_3 & $\begin{array}{l}\text { OS CMS products increase } \\
\text { institution capabilities }\end{array}$ & \\
\hline & IV_4 & $\begin{array}{l}\text { OS CMS products increase } \\
\text { community support }\end{array}$ & \\
\hline & IV_5 & $\begin{array}{l}\text { OS CMS products increase } \\
\text { institutional readiness }\end{array}$ & \\
\hline & IV_6 & $\begin{array}{l}\text { OS CMS products support } \\
\text { educational innovation }\end{array}$ & \\
\hline & IV_7 & $\begin{array}{l}\text { OS CMS products help } \\
\text { educators create effective online } \\
\text { learning communities }\end{array}$ & \\
\hline & IV_8 & $\begin{array}{l}\text { OS CMS products decrease } \\
\text { management capacity }\end{array}$ & \\
\hline
\end{tabular}

Table 16: Institutional Factors 


\subsubsection{Reliability and Validity}

After eliminating a survey question (IV_8, "OS CMS products decrease management capacity") with low Cronbach alpha, the Cronbach alphas for the composite measures for perceived resource limitations, perceived institutional benefit, and perceived institution image are shown in Table 17. Each is greater than the threshold of 0.70 . Therefore, the factors used in this study provided support for scale's reliability.

\begin{tabular}{|l|c|c|}
\hline Item description & No. Items & $\begin{array}{c}\text { Cronbach } \\
\text { Alpha }\end{array}$ \\
\hline $\begin{array}{l}\text { Perceived resource } \\
\text { limitations }\end{array}$ & 3 & 0.73 \\
\hline $\begin{array}{l}\text { Perceived institutional } \\
\text { benefit (IP) }\end{array}$ & 6 & 0.74 \\
\hline $\begin{array}{l}\text { Perceived institutional } \\
\text { image (IV) }\end{array}$ & 7 & 0.75 \\
\hline
\end{tabular}

Table 17: Institutional Factors - Analysis of Measurement Reliability

Table 18 shows the results of Principle Components Analysis that was used to evaluate convergent validity of items.

\begin{tabular}{|l|c|c|c|}
\hline \multirow{2}{*}{ Component } & \multicolumn{3}{|c|}{ Initial Eigenvalues } \\
\cline { 2 - 4 } & Total & \% of Variance & Cumulative \% \\
\hline 1 & 5.09 & 31.84 & 31.84 \\
\hline 2 & 1.91 & 11.94 & 43.78 \\
\hline 3 & 1.83 & 11.44 & 55.21 \\
\hline 4 & 1.27 & 7.94 & 63.15 \\
\hline 5 & 1.06 & 6.63 & 69.78 \\
\hline 6 & 0.944 & 5.88 & 75.65 \\
\hline
\end{tabular}




\begin{tabular}{|l|l|l|l|}
\hline 7 & 0.750 & 4.69 & 80.34 \\
\hline 8 & 0.653 & 4.08 & 84.42 \\
\hline 9 & 0.575 & 3.59 & 88.01 \\
\hline 10 & 0.484 & 3.03 & 91.04 \\
\hline 11 & 0.419 & 2.62 & 93.66 \\
\hline 12 & 0.307 & 1.92 & 95.58 \\
\hline 13 & 0.275 & 1.72 & 97.29 \\
\hline 14 & 0.174 & 1.09 & 98.38 \\
\hline 15 & 0.156 & 0.975 & 99.43 \\
\hline 16 & 0.091 & 0.569 & 100.00 \\
\hline
\end{tabular}

Table 18: Institutional Factors - Principle Component Analysis

Factors 1, 2, 3, 4 and 5 have eigenvalues greater than 1.0, and therefore explain more variance than a single variable. The cumulative percentage of variance explained by the first five factors is $69.79 \%$. The remaining factors 6 through 17 have eigenvalues less than 1.0; therefore they explain less variance than a single variable. This result suggests that the final solution should not extract more that 5 factors.

The following scree plot confirms that the final solution should not extract more than 5 factors. 


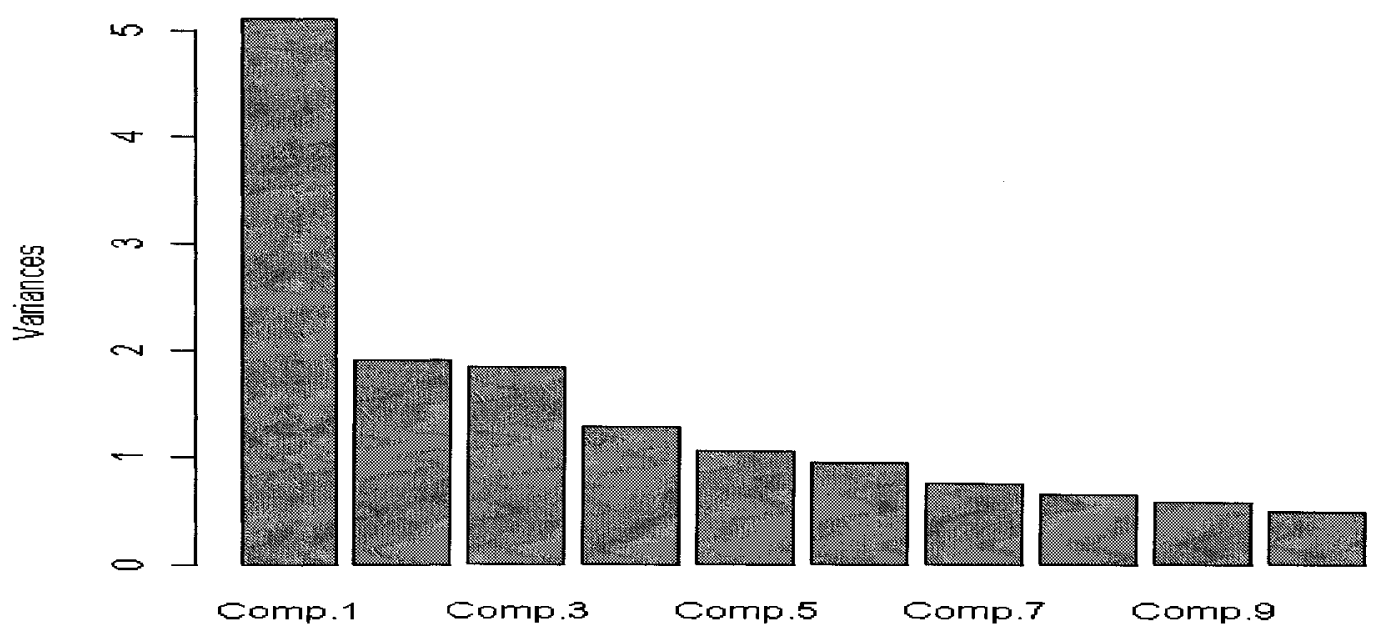

Figure 7: Institutional Factors - Scree Plot

A Varimax factor rotation with regression method was used to extract the factors.

The results are shown in Table 19.

\begin{tabular}{|l|l|l|l|l|l|}
\hline & Factor 1 & Factor 2 & Factor 3 & Factor 4 & Factor 5 \\
\hline IP_1 & 0.179 & -0.123 & -0.118 & $\mathbf{0 . 7 7 4}$ & 0.260 \\
\hline IP_2 & & & 0.117 & 0.405 & 0.235 \\
\hline IP_3 & $\mathbf{0 . 8 6 6}$ & & 0.117 & 0.295 & \\
\hline IP_4 & $\mathbf{0 . 5 3 9}$ & & 0.395 & 0.112 & 0.497 \\
\hline IP_5 & 0.121 & & & 0.333 & $\mathbf{0 . 5 9 9}$ \\
\hline IP_6 & 0.115 & -0.108 & 0.179 & 0.165 & $\mathbf{0 . 6 6 6}$ \\
\hline IR_1 & & $\mathbf{0 . 7 0 6}$ & -0.303 & -0.239 & -0.107 \\
\hline IR_2 & & $\mathbf{0 . 9 8 2}$ & -0.125 & & 0.120 \\
\hline IR_3 & -0.230 & 0.448 & 0.200 & -0.198 & -0.260 \\
\hline IV_1 & $\mathbf{0 . 5 7 7}$ & 0.109 & 0.106 & 0.162 & 0.273 \\
\hline IV_2 & $\mathbf{0 . 6 3 1}$ & & 0.517 & & 0.371 \\
\hline IV_3 & $\mathbf{0 . 4 4 6}$ & & & & \\
\hline IV_4 & $\mathbf{0 . 8 2 9}$ & -0.256 & 0.261 & & \\
\hline IV_5 & $\mathbf{0 . 1 9 0}$ & -0.153 & $\mathbf{0 . 8 9 2}$ & 0.345 & 0.142 \\
\hline IV_6 & 0.331 & -0.131 & $\mathbf{0 . 4 9 6}$ & & \\
\hline IV_7 & $\mathbf{0 . 4 2 1}$ & & & 0.165 & \\
\hline
\end{tabular}

${ }^{*}$ bold designates factor loading with an initial cutoff point of 0.4 or above

Table 19: Institutional Factors - Varimax Factor Rotation Output 
All the items of perceived resource limitations were loaded (correlated) highest on factor 2 matching the categorization in the table 16 (institutional factors).

With regard to perceived institution image, 5 items were loaded on factor 1 , while 2 items (IV_5 \& IV_6) were perceived differently and loaded on factor 3. Deleting items IV_5 \& IV_6 from perceived institutional benefits category would decrease the reliability from 0.75 to 0.63 . In other words, it seemed to be that those items increase the reliability scale of this category. Therefore, I decided to keep all items and used the average score to combine all items on a single construct called observability.

For perceived institutional benefit's items, validity could not be established because the six items were loaded equally on 3 different factors. However, items 3 and 4 were loaded on factor 1 with individual value $>0.54$ suggesting that those items may be perceived by respondents as similar to the items of perceived institutional image.

\subsubsection{Relationship among Institutional Variables}

A Pearson correlation matrix was used to test relationship among institutional variables and to test if there is a need to extract new factors.

\begin{tabular}{|l|l|l|l|}
\hline & IR_1_3 & IR_2_4 & IR_3_7 \\
\hline IR_1_3 & 1.00 & & \\
\hline IR_2_4 & $0.724^{\mathrm{c}}$ & 1.00 & \\
\hline IR_3_7 & $0.335^{\mathrm{b}}$ & $0.392^{\mathrm{b}}$ & 1.00 \\
\hline Signif. codes: " $p<0.1 ;{ }^{\text {"6" }} p<0.05 ;{ }^{\text {"C" }} p<0.01$
\end{tabular}


Table 20: Pearson's Correlation Coefficients for Perceived Resource Limitations Items

The correlation matrix in Table 20 shows that all items were positively correlated and highly significant and also they all load on factor 1 . Therefore, I decided to keep all items and used the average score to combine all items on a single construct called perceived resource limitations.

\begin{tabular}{|c|c|c|c|c|c|c|}
\hline & IP_1_25 & IP_2_28 & IP_3_31 & IP_4_32 & IP 5_33 & IP_6_35 \\
\hline IP_1_25 & 1.00 & & & & & \\
\hline IP_2 28 & $0.352^{b}$ & 1.00 & & & & \\
\hline IP_3_31 & $0.345^{b}$ & 0.175 & 1.00 & & & \\
\hline IP_4_32 & $0.347^{b}$ & $0.280^{\mathrm{a}}$ & $0.504^{\mathrm{C}}$ & 1.00 & & \\
\hline IP_5_33 & $0.398^{b}$ & 0.171 & 0.212 & $0.387^{b}$ & 1.00 & \\
\hline IP_6_35 & $0.309^{\mathrm{a}}$ & 0.244 & 0.233 & $0.351^{b}$ & $0.536^{\mathrm{c}}$ & 1.00 \\
\hline
\end{tabular}

Table 21: Pearson's Correlation Coefficients for Perceived Institutional Benefits Items

A correlation matrix in Table 21 shows that all items were correlated. Deleting any item would decrease the reliability to $<0.70$. In other words, all items were related and were necessary to keep the reliability scale above the threshold. Therefore, I decided to keep all items and used the average score to combine all items on a single construct called perceived institutional benefit.

\begin{tabular}{|l|l|l|l|l|l|l|l|}
\hline & IV_1 & IV_2 & IV_3 & IV_4 & IV_5 & IV_6 & IV_7 \\
\hline IV_1 & 1.00 & & & & & & \\
\hline IV_2 & $0.523^{\mathrm{c}}$ & 1.00 & & & & & \\
\hline IV_3 & 0.031 & $0.290^{\mathrm{a}}$ & 1.00 & & & & \\
\hline IV_4 & 0.250 & $0.351^{\mathrm{b}}$ & 0.106 & 1.00 & & & \\
\hline IV_5 & $0.282^{\mathrm{a}}$ & $0.621^{\mathrm{c}}$ & 0.173 & $0.552^{\mathrm{c}}$ & 1.00 & & \\
\hline IV_6 & 0.192 & $0.532^{\mathrm{c}}$ & $0.340^{\mathrm{b}}$ & 0.261 & $0.504^{\mathrm{c}}$ & 1.00 & \\
\hline IV_7 & 0.123 & $0.290^{\mathrm{a}}$ & 0.208 & $0.3055^{\mathrm{a}}$ & 0.175 & 0.201 & 1.00 \\
\hline
\end{tabular}


Table 22: Pearson's Correlation Coefficients for Perceived Institutional Image Items

A correlation matrix table 22 shows that all items were correlated. Items IV_5 \& IV_6 were positively correlated and significant. Moreover, deleting item IV_5 decreased the reliability to 0.71 while deleting item IV_6 decreased the reliability to 0.687 . Therefore, I decided to keep all items and used the average score to combine all items on a single construct called perceived institution image.

For institutional factors, the results of reliability analysis indicated acceptable reliabilities (above 0.70 ) for all items. Moreover, the results of validity analysis indicated significant validity. Therefore, both reliability and validity analyses suggested adequate validity to proceed with the analysis.

\subsubsection{Environmental Factors}

Several environmental factors that influence the decision to adopt OS CMS by decision makers were discussed in the literature review and the case studies. These factors include products features, availability and customization and also people demand and expectations. For example, commercial products are often not well tailored to higher education, proprietary CMS products have limited features, proprietary products there is more demand from students to adopt/use OS CMS products. Table 23 lists all the environmental factors derived from the literature. 


\begin{tabular}{|l|l|l|l|}
\hline Construct & Code & Items & Adopted from \\
\hline & EE_1 & $\begin{array}{l}\text { Proprietary CMS products have } \\
\text { limited features. }\end{array}$ & \\
\cline { 2 - 3 } & EE_2 & $\begin{array}{l}\text { There is more demand from students } \\
\text { to adopt/use OS CMS products }\end{array}$ & $\begin{array}{l}\text { Ahmed (2005), } \\
\text { Tessmer } \\
\text { (1991), } \\
\text { Courant \& } \\
\text { Griffiths (2006) }\end{array}$ \\
\cline { 2 - 3 } & EE_3 & $\begin{array}{l}\text { Proprietary products are often not } \\
\text { well tailored to higher education. }\end{array}$ &
\end{tabular}

Table 23: Environmental Factors

\subsubsection{Reliability and Validity}

The Cronbach alpha for environmental factors was 0.66 , still acceptable according Robinson et al. (1991, p.13).

\subsubsection{Relationship among Environmental Variables}

The relationships among the environmental variables were investigated using Pearson's correlation coefficient with $95 \%$ confidence using a 2-tailed to test whether the relationship was statistically significant.

\begin{tabular}{|l|l|l|l|}
\hline & EE_1 & EE_2 & EE_3 \\
\hline EE_1 & 1.00 & & \\
\hline EE_2 & $0.338^{b}$ & 1.00 & \\
\hline EE_3 & $0.485^{c}$ & $0.352^{b}$ & 1.00 \\
\hline Signif. codes: " ${ }^{\mathrm{c}} p<0.1 ;{ }^{\text {"bn }} p<0.05 ;{ }^{\text {"cn }} p<0.01$
\end{tabular}

Table 24: Environmental Factors - Pearson Correlation Coefficients

Table 24 shows that all items were significantly positively correlated. Therefore, I decided to keep all items and used the average score to combine all items in a 
single average called perceived internal pressure.

For environmental factors, the results of reliability analysis indicated a moderate and acceptable reliability (between 0.6 and 0.7 ) for all items. Moreover, the results of validity analysis indicated significant validity. Therefore, both reliability and validity analyses suggested adequate validity to proceed with the analysis.

\subsubsection{Normality Check}

Before proceeding to further analysis, the data was checked for normality using

Skewness and kurtosis normality test.

Rule-of-thumb test for normality \#1: Skewness/std error $<=2$

Rule-of-thumb test for normality \#2: Kurtosis/std error $<=2$

Skewness_std $=$ sqrt $(6 / n)$ \& Kurtosis_std $=$ sqrt $(24 / n)$

All the constructs were found to be normal. Table 25 shows the normality results for all the research constructs.

\begin{tabular}{|r|l|l|l|l|l|l|l|l|l|}
\hline & Item1 & Item2 & Item3 & Item4 & Item5 & Item6 & Item7 & Result & App. \\
\hline $\begin{array}{l}\text { Relative } \\
\text { advantage }\end{array}$ & & & & & & & & & \\
\hline Test 1 & -0.25 & -1.36 & -0.08 & -0.27 & -0.15 & -1.11 & & Pass & C \\
\hline Test 2 & 0.15 & 0.30 & -2.21 & 0.04 & -0.08 & 1.55 & & Pass & C \\
\hline Complex. & & & & & & & & & \\
\hline Test 1 & 0.8 & -1.24 & -1.11 & -1.40 & & & & Pass & D \\
\hline Test 2 & -2.90 & 0 & 0.27 & -0.13 & & & & Pass & D \\
\hline Observ. & & & & & & & & & \\
\hline Test 1 & -1.19 & -2.21 & -1.36 & -1.87 & -1.55 & -0.62 & -0.76 & Pass & E \\
\hline Test 2 & -0.10 & -0.94 & -0.21 & 0.27 & 0.27 & -2.52 & -1.31 & Pass & E \\
\hline $\begin{array}{r}\text { Resource } \\
\text { limitations }\end{array}$ & & & & & & & & & \\
\hline
\end{tabular}




\begin{tabular}{|r|l|l|l|l|l|l|l|l|l|}
\hline Test 1 & -1.19 & -1.24 & -1.23 & & & & & Pass & F \\
\hline Test 2 & -0.38 & 1.26 & 0.573 & & & & & Pass & F \\
\hline benefit & & & & & & & & & \\
\hline Test 1 & -1.05 & 0.005 & -1.38 & 1.46 & -0.88 & -0.79 & & Pass & G \\
\hline Test 2 & 0.786 & -0.00 & 0.636 & 1.65 & -1.16 & -0.41 & & Pass & G \\
\hline image & & & & & & & & & \\
\hline Test 1 & -0.64 & -1.50 & -0.84 & -1.36 & 0.355 & -0.20 & 0.437 & Pass & H \\
\hline Test 2 & -0.04 & -1.23 & -1.17 & 0.303 & 1.44 & 0.050 & -1.99 & Pass & H \\
\hline Internal & & & & & & & & & \\
Pressure & & & & & & & & & \\
\hline Test 1 & -1.46 & 0.007 & -0.29 & & & & & Pass & I \\
\hline Test 2 & -0.17 & 1.58 & 1.64 & & & & & Pass & I \\
\hline
\end{tabular}

Table 25: Normality Check 


\section{Hypothesis Testing}

As stated previously, the theoretical frame work of this research consists of seven independent variables - perceived relative advantage, perceived complexity, perceived observability, perceived resource limitations, perceived institutional benefit, perceived institutional image and perceived internal pressure, and one dependent variable - perceived risk.

The relationships among all variables were investigated using Pearson correlation.

\begin{tabular}{|c|c|c|c|c|c|c|c|c|}
\hline & 1 & 2 & 3 & 4 & 5 & 6 & 7 & 8 \\
\hline $\begin{array}{l}\text { 1. Relative } \\
\text { advantage }\end{array}$ & 1.0 & & & & & & & \\
\hline 2.Complexity & $0.118^{\mathrm{a}}$ & 1.0 & & & & & & \\
\hline 3.Observ. & $\overline{0.373^{b}}$ & $0.438^{c}$ & 1.0 & & & & & \\
\hline $\begin{array}{l}\text { 4.Resource } \\
\text { limitations }\end{array}$ & -0.185 & $0.383^{6}$ & 0.249 & 1.0 & & & & \\
\hline 5.Benifits & $0.479^{6}$ & $\overline{0.342^{b}}$ & $\overline{-} .327^{b}$ & $\overline{0.306^{\mathrm{a}}}$ & 1.0 & & & \\
\hline 6.Images & $0.563^{c}$ & $0.364^{b}$ & $0.555^{\mathrm{c}}$ & $0.323^{b}$ & $0.644^{\mathrm{a}}$ & 1.0 & & \\
\hline $\begin{array}{l}\text { 7.Internal } \\
\text { pressure }\end{array}$ & $0.464^{\mathrm{c}}$ & -0.001 & $-\overline{0.359^{b}}$ & -0.024 & 0.241 & $0.476^{c}$ & 1.0 & \\
\hline Risk & $\overline{0} .488^{\mathrm{C}}$ & $0.401^{b}$ & $0.452^{\mathrm{C}}$ & $0.537^{\mathrm{c}}$ & $\overline{0} .265^{\mathrm{b}}$ & $0.470^{c}$ & $\overline{0.27^{\mathrm{a}}}$ & 1.0 \\
\hline
\end{tabular}

Signif. codes: "aa" $p<0.1$; “bl" $p<0.05$; " ${ }^{\text {con }} p<0.01$

Table 26: Pearson Correlation Coefficients

Pearson correlation coefficient analysis was conducted to measure the strength and direction of a linear relationship between the independent and dependent 
variables. All the independent variables were significantly correlated and were in the expected directions.

All the independent variables were correlated with the dependent variable except internal risk which was found just significantly correlated $(p<0.10)$. Figure 8 summarized the results of Pearson correlation coefficient analysis.

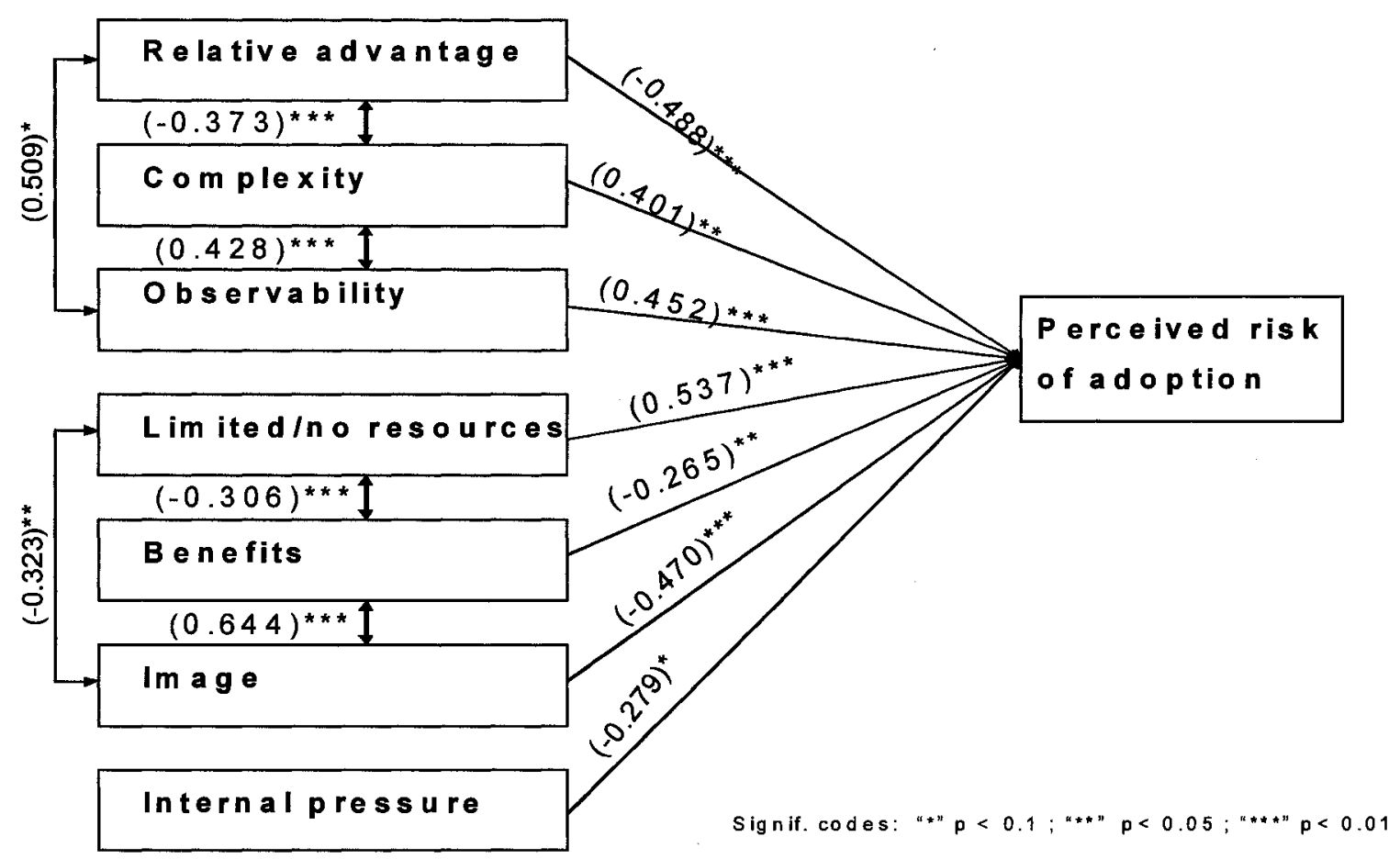

Figure 8: Research Findings with Pearson's Correlation Coefficients

Pearson correlation coefficient analysis revealed the following:

- Perceived observability and complexity were positively correlated and significant; therefore, combining the two factors to extract a new factor is 
possible. Moreover, since each represents technological factors, one could represent the other.

- Perceived institutional benefit and perceived institution image were significantly positively correlated; combining the two factors to extract a new factor is possible. Moreover, since each represents Institutional factors, one could represent the other.

As a result, the factors mentioned above were combined. Pearson correlation coefficient results for all factors are show in Table 27.

\begin{tabular}{|l|l|l|l|l|l|l|}
\hline & 1 & 2 & 3 & 4 & 5 & 6 \\
\hline 1.Relative advantage & 1 & & & & & \\
\hline 2.Complexity \& Observability & $-0.306^{\mathrm{a}}$ & 1 & & & & \\
\hline 3.Limited/no Resources & -0.108 & $0.357^{\mathrm{b}}$ & 1 & & & \\
\hline 4.Benefit \& image & $0.574^{\mathrm{b}}$ & $-0.521^{\mathrm{c}}$ & $-0.347^{\mathrm{b}}$ & 1 & & \\
\hline 5.Internal pressure & $0.464^{\mathrm{b}}$ & -0.239 & -0.024 & $0.393^{\mathrm{b}}$ & 1 & \\
\hline 6.Risk & $-0.488^{\mathrm{c}}$ & $0.506^{\mathrm{c}}$ & $0.537^{\mathrm{c}}$ & $-0.407^{\mathrm{c}}$ & $-0.279^{\mathrm{a}}$ & 1 \\
\hline
\end{tabular}

Signif. codes: "al" $p<0.1$; "bl" $p<0.05 ;$ " $"$ c" $p<0.01$

Table 27: Pearson Correlation Coefficient - Revised Perception Model

The following were observed from Table 27,

- The relationship between the new independent variable (observability \& complexity) and the dependent variable risk was positively correlated and significant.

- The relationship between independent variable (perceived institutional benefit and perceived institution image) and the dependent variable risk was negatively correlated and significant. 
The revised perception model after data reduction is shown in Figure 9. The figure shows that the risk perception of OS CMS adoption in Canadian universities and colleges is influenced by five main factors.

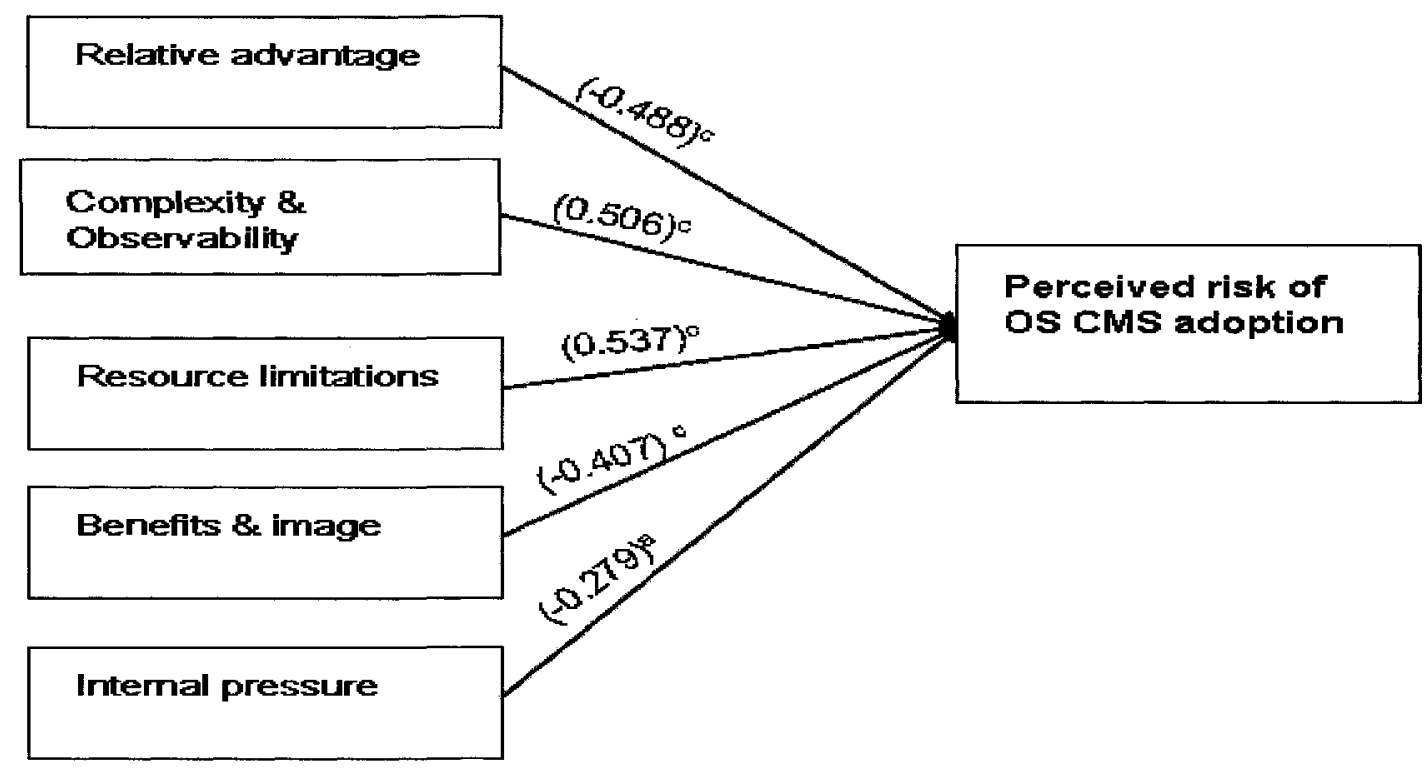

Figure 9: Revised Perception Model - Factors Influencing OS CMS Adoption in Canadian Universities and Colleges

Results of Cronbach alpha for all items on the revised perception model are shown in Table 28.

\begin{tabular}{|l|c|c|}
\hline \multicolumn{1}{|c|}{ Item description } & No. Items & Cronbach's Alpha \\
\hline Relative advantage & 3 & 0.82 \\
\hline Complexity \& Observability & 11 & 0.80 \\
\hline Limited/no resources & 3 & 0.73 \\
\hline Benefits \& image & 13 & 0.84 \\
\hline Internal Pressure & 3 & 0.66 \\
\hline
\end{tabular}

Table 28: Analysis of Measurement Reliability: Model 2 - Data Reduction 
A stepwise regression analysis was used in this research to predict the significant independent variables, or predictor variables, that contribute most to the explanation of the dependent variables. In stepwise method, only the independent variables that contribute significantly to the model are retained, but all other variables in the model that do not contribute significantly to the model are removed (Dillon et al., 1984, pp.239-241). The results of stepwise regression analysis are presented in Tables $29,30,31$ and 32.

\begin{tabular}{|l|l|l|l|l|}
\hline Model & R & R Square & Adjusted R Square & Std. Error \\
\hline 1 & 0.537 & 0.289 & 0.270 & 0.912 \\
\hline 2 & 0.667 & 0.444 & 0.414 & 0.817 \\
\hline
\end{tabular}

Model 1: Independent variable: Resource limitations Dependent variable: Risk Model 2: Independent variable: Resource limitations, Relative advantage.

Dependent variable: Risk

Table 29: Stepwise Regression Statistics

\begin{tabular}{|l|l|l|l|l|l|l|}
\hline Model & & Df & Sum of Squares & Mean Square & F & Sig \\
\hline \multirow{4}{*}{1} & Regression & 1 & 12.82 & 12.82 & 15.43 & 0.000 \\
\cline { 2 - 8 } & Residual & 38 & 31.58 & 0.831 & & \\
\cline { 2 - 8 } & Total & 39 & 44.40 & & & \\
\hline \multirow{2}{*}{2} & Regression & 2 & 19.73 & 9.87 & 14.80 & 0.000 \\
\cline { 2 - 7 } & Residual & 37 & 24.67 & 0.667 & & \\
\cline { 2 - 7 } & Total & 39 & 44.40 & & & \\
\hline
\end{tabular}

Model 1: Independent variable: Resource limitations $\quad$ Dependent variable: Risk Model 2: Independent variable: Resource limitations, Relative advantage.

Dependent variable: Risk

Table 30: Stepwise Regression Analysis (ANOVA)

\begin{tabular}{|l|l|l|l|}
\hline Model & & Standardized coefficients & P-value \\
\hline \multirow{2}{*}{1} & (Constant) & 0.987 & 0.112 \\
\cline { 2 - 4 } & Limited/no resources & 0.775 & 0.000 \\
\hline \multirow{3}{*}{2} & (Constant) & 3.84 & 0.000 \\
\cline { 2 - 4 } & Limited/no resources & 0.668 & 0.000 \\
\cline { 2 - 4 } & Relative advantage & -0.861 & 0.003 \\
\hline
\end{tabular}


Dependent variable: Risk

Table 31: Stepwise Regression Analysis (Coefficients)

\begin{tabular}{|l|l|l|l|l|}
\hline Model & & Beta in & $\mathrm{T}$ & $\mathrm{P}$ \\
\hline \multirow{4}{*}{1} & Relative advantage & -0.827 & -2.21 & 0.034 \\
\cline { 2 - 5 } & Complexity & 0.435 & 1.86 & 0.071 \\
\cline { 2 - 5 } & Observability & 0.242 & 0.747 & 0.046 \\
\cline { 2 - 5 } & Benefits & 0.366 & 0.1 .03 & 0.310 \\
\cline { 2 - 5 } & Images & -0.447 & -0.861 & 0.357 \\
\cline { 2 - 5 } & Internal Pressure & -0.017 & -0.071 & 0.944 \\
\hline 2 & Complexity & 0.366 & 1.50 & 0.144 \\
\hline & Observability & 0.319 & 0.942 & 0.353 \\
\hline & Benefits & 0.177 & 0.487 & 0.630 \\
\hline & Images & -0.682 & -1.30 & 0.201 \\
\hline & Internal Pressure & -0.146 & -0.560 & 0.553 \\
\hline
\end{tabular}

Model 1: Independent variable: resource limitations Dependent variable: Risk Model 2: Independent variable: resource limitations, Relative advantage.

Dependent variable: Risk

Table 32: Stepwise Regression Analysis (Excluded Independent Variables)

Using stepwise regression analysis, about $27 \%$ of the variation in dependent variable risk could be explained by the regression model 1 with one predictor perceived resource limitations. While an additional $14 \%$ of the variance in the dependent variable risk was contributed by perceived relative advantage in model 2. Therefore, a significant model with two predictors, perceived resource limitations and relative advantage, was emerged $(F=14.80, p<0.01)$. Five factors, perceived complexity, perceived observability, perceived institutional benefits, perceived institution image, and perceived internal pressure, were excluded because there were not significant predictors in this model.

Overall, the evidence for the seven hypotheses is as follows:

- Hypothesis $\mathrm{H} 1$, the higher the perceived relative advantage of OS CMS the lower the level of perceived risk of adoption, was supported (corr= - 
$0.488, p<0.01)$. Perceived relative advantage is also a significant variable in the regression analysis model (Table 30). The following comment from one of the participants explained the perceived relative advantage of adopting OS CMS:

"OS can be leaner or faster and more agile in making fixes available and in incorporating new features and technologies."

- Hypothesis H2, the higher the perceived complexity of OS CMS the higher the level of perceived risk of adoption, was supported (corr $=0.401$, $p<0.05)$. The following comment from one of the participants explained the perceived complexity of adopting OS CMS:

"There are legal issues regarding government supply regulations and any form of OSS, as well as security concerns."

- Hypothesis $\mathrm{H3}$, the lower the perceived observability of OS CMS, the higher the level of perceived risk of adoption, was supported (corr $=0.452$, $p<0.01)$. The following comments from some of the participants explained the perceived observability of adopting OS CMS:

"Commercial software has the safety net of professional services, albeit at a steep price, to be called upon in an emergency. Not only OS may not have this option, but it may be difficult or impossible to engage a professional consultant, knowledgeable on a particular OS product, on short notice." 
- Hypothesis H4, the higher the level of perceived resource limitations, the higher the perceived risk to adopt OS CMS, was supported (corr $=0.537, \mathrm{p}$ $<0.01)$. Perceived resource limitations factor is also a significant variable in the regression analysis model (Table 30 ).

- Hypothesis H5, the higher the level of perceived institutional benefits, the lower the perceived risk to adopt OS CMS, was supported (corr=-0.265, $p<0.10)$.

- Hypothesis $\mathrm{H6}$, the higher the level of perceived institutional image (value), the lower the perceived risk to adopt OS CMS, was supported (corr $=-0.470, p<0.01)$.

- Hypothesis $\mathrm{H7}$, the higher the level of internal pressure to adopt OS CMS, the lower the perceived risk of adoption, was supported (corr= -0.279 , $p<0.10)$.

In summary, negative relationships were found between decision maker's risk perceptions, and with five independent variables: perceived relative advantage, perceived observability, perceived image, and perceived internal pressure. Those factors were found to be highly significant in reducing the decision makers' risk perception to adopt OS CMS. On the other hand, positive relationships were 
found with the other two independent variables; perceived complexity and perceived resource limitations. 


\section{Conclusion, Implications, Limitation and Future Research}

This research studied OS CMS adoption decisions using perceived risk. The study applied Tornatzky \& Fleischer (1990) frameworks, Rogers (1995) model, Christensen et al., (2004) and Tessmer (1991), and five case studies, and used several analytical methods to test the hypotheses. The major findings of this research are discussed below by objective.

The first objective of this research was to gain insight into how decisions around the adoption and use of OS CMS were made in Canadian universities and colleges.

The decision processes used for OS CMS adoption are complex and differ from one institution to another. When decision makers consider OS CMS adoption, they face a dilemma between the desirable and undesirable consequences of the OS CMS adoption and therefore they face a risky decision. Decision makers require a lot of information to form their decision. They look for information such as total cost of adoption, features and functionality, usability, ease of use, documentation, integration capacity, reliability, scalability, reliability, robust platform, security, technical support, and many other factors about OS CMS. Rogers best described the information and factors that determine adoption (1995). 
Decision makers use several methods to obtain their information regarding OS

CMS. The following are some of the methods that were used by decision makers to reach a decision,

- A large percentage of decision makers in this study indicated that the experience of other institutions was an important information source used to reach a decision to accept or reject OS CMS adoption.

- A CMS committee is another method that decision makers use often to obtain their information regarding CMS and to reach a decision to adopt or reject OS CMS. Committees play an important role in the decision to adopt, migrate or replace existing CMS.

CMS committee recommendations were the key for selecting CMS in most of the institutions participated in this study. Each institution follows its own reviews of CMS. Therefore, the reviews selections criteria were different from one institution to another, however, the technological, organizational, environmental criteria or factors were mostly used as evaluation criteria in most of the institution participated in this study.

The second objective of this research was to explore and describe decision makers' perception and attitude towards OS CMS. 
OS CMS products were considered as immature products with an unclear future and uncertain cost of adoption. The decision to adopt or migrate to OS CMS, moreover, was described as a risky decision.

This perception toward OS CMS is one of the major reasons for the slow adoption of OS CMS in academia. It also contributes to describing most Canadian institutions as conservative in their attitude toward OS CMS. Canadian Institutions perceived OS CMS as a risk decision.

The third objective was to Identify and examine factors or obstacles that influence the decision to adopt OS CMS. The followings are a summery for the major factors that influence the decision to adopt OS CMS:

- As indicated before, the perception and attitudes toward OS CMS were one of the major factors that hinder the adoption.

- It also found from the interviews, that one-time funding for the whole fiscal year was a resource limit that poses many challenges for OS CMS adoption.

- The results of hypotheses testing indicated that perceived relative advantage, perceived observability, perceived institutional benefits, perceived institutional image, and perceived internal pressure decreased decision makers' risk 
perception. On the other hand, perceived complexity and perceived resource limitations increased decision makers' risk perception.

- Furthermore, this study results suggested that the perceived resource limitations and perceived relative advantage were the most significant factors that influence decision makers' risk perception. Both resource limitations and technological relative advantage are common considerations in new technology adoption.

\subsection{Contributions of the Thesis}

The research makes at least three contributions. First, the comprehensive Canadian university case study provides insights into adopters' attitudes, decisions, and usage of OS CMS and identifies the factors perceived by decision makers that lead to the success of OSS products in universities and colleges. Second, the model of the decision making process was developed rigorously from data on Canadian decision makers. Therefore, the model is valuable and provides insights into how decisions around OS CMS are made in academia. These insights can help decision makers to take leadership position in academic development, and to understand OS role in academic institutions. Third, the model of the most significant factors that influence the evolution of OS CMS in Canadian universities and colleges was developed using Tornatzky \& Fleischer (1990) frameworks, Rogers (1995) model, Christensen et al., (2004) and 
Tessmer (1991). It is valuable and adds significant inputs to the decision makers in universities and colleges that help them to pay a close consideration to the key issues involved in choosing OS CMS and to avoid the typical barriers to successful adoption. Therefore, this model contributes to the innovation adoption literature.

\subsection{Implications}

This study's findings have several implications for decision makers in Canadian universities and colleges and may help them to understand why, despite the OS CMS popularity and ubiquitous, the decision makers at academic institutions still consider OS CMS as a dilemma when it comes to adoption. Based on the findings from this research, the following implications were derived.

- Decision makers use two main methods to help them to make their decision regarding migrating or adopting CMS products (proprietary or OS CMS). The first method was other institutions experience. Since most of the institutions were described as conservative in their approaches to adopt or migrate to OS, this would make the decision in the rejection or wait and see. Decision makers should ensure that other institutions' experiences do not overly influence the decision making process. The second method was CMS evaluation committee. Since the adoption of OS CMS with its promising cost reduction is a critical decision, decision makers should involve students, 
instructors, administrators, members from each department, and technical staff on all decision making process. Also, they need to ensure that the committee members have up to date knowledge about OS products and have adequate expertise to evaluate CMS products. Moreover, they need to ensure that other institutions' experiences do not influence the decision making process, because this may take the decision to a known conclusion wait and see.

- The decisions to adopt or migrate to OSS CMS can be taken at the departmental level, but in fact it is considered mostly at the institutional level.

- This study results suggested that the perceived resource limitations was the most significant factor that influences decision makers' risk perception; not enough budget, funding and resources to adopt or migrate to OS were the main concern for decision makers. The way in which budget structured in academia and unclear cost of OS adoption were mentioned by some decision makers as main barriers for adoption. Liberalizing operating costs budgeting rather than one-time funding could yield many benefits in promoting OS CMS. Decision makers, as key decision makers in their institutions, should provide the infrastructure needed to a successful OS CMS adoption; using OS CMS pilot studies could be useful to evaluate and assess os benefits and also to know the exact resource needed. 
Furthermore, OS supporters have the responsibilities to promote OS CMS cost saving. This was best described by one of the participants, "OS supporters need to be able to make a coherent business case that costs and features will at least be equivalent to proprietary solutions, if not better. And this needs to be backed up with hard numbers drawn from existing largescale deployments, not 'guesstimates'."

- The second most significant factor that influences the decision makers risk perception was the perceived relative advantage. Decision makers perceived huge benefits from adopting OS CMS. They perceived OS products as reliable, efficient and easier to use than proprietary CMS. A gradual implementation of OS CMS project could promote the relative advantage and reduce perceived risk of OS CMS adoption. Decision makers would be advised to fully investigate the advantage of OS CMS and encourage employee, staff and students to use OS CMS. Moreover, collaboration with other Canadian universities and colleges which adopt OS CMS could help decision makers to find out how to overcome the problems that hinder OS CMS adoption.

\subsection{Limitations and Further Studies}

- This research applied only the pre-implementation stages of Rogers (1995) model. Future research is needed to investigate other two stages and 
provides the success stories and lesson learned from universities and colleges who adopted OS CMS.

- Perceived resource limitations and perceived relative advantage were the most significant factors that influence the decision to adopt OS CMS. The sample size may be a factor for not capturing the real effect of other factors on the decisions. Moreover, the small sample size makes it hard to generalize the conclusion. However, future researchers should focus on studying other factors with larger sample of data.

- This study did not investigate the CMS committee roles nor its functions, members or other important components. Future studies can investigate the role of CMS evaluation committee.

- This research was conducted only on Canadian universities and colleges; the results of the research may not be applicable to other countries universities and colleges. 


\section{References}

Adkins, S. B. 2005. Wake-Up Call: Open Source LMS. Learning Circuits, October 2005.

(http://www.learningcircuits.org/2005/oct2005/adkins.htm, last visited Aug 7, 2008).

Ahmed, O. 2005. Migrating from Proprietary to Open Source Learning Content Management Systems. Master Thesis, Department of Systems and Computer Engineering, Carleton University.

Alamo Community College District. 2006. eLearning Advisory Group Task Force Report. Learning Management System Selection Process. September 22, 2006. (http://projects.accd.edu:3455/2/admin/download.html?attachid=131574, last visited July 15,2008$)$.

Bailetti, A.J. 2006. FLOSS in the Public Sector Summit. September 28, 2006. (http://www.governmentciosummit.ca/fileadmin/ciogov/media/docs/cio_gov_2006 _carleton.pdf, last visited August 12, 2008).

Burgelman, R.A. \& Sayles, L.R. 1986. Inside Corporate Innovation. The Free Press, New York, NY. 
Charles, M. 1992. Statistical digests: Notes on Factor Analysis, Sam Houston State University.

(http://www.shsu.edu/ icc_cmf/cj_742/stats9.doc, last visited July 15, 2008).

Christensen, C. M., Antony, S. D., \& Roth, E. A. 2004. Seeing What's Next:

Using the Theories of Innovation to Predict Industry Change. Boston: Harvard Business School Press.

Christensen, C.M. \& Carlile P.R. 2005. The Cycles of Theory-Building in Management Research.

(http://www.innosight.com/documents/Theory\%20Building.pdf, last visited July $23,2008)$.

Coates, H. 2005. Leveraging LMSs to Enhance Campus-Based Student Engagement. EDUCAUSE Quarterly Magazine, Volume 28, Number 1, 2005. (http://connect.educause.edu/Library/EDUCAUSE+Quarterly/LeveragingLMSsto EnhanceCa/39900, last visited July 15, 2008).

Common Wealth of Learning. 2003. COL LMS Open Source. June 25. (http://www.col.org/colweb/webdav/site/myjahiasite/shared/docs/03LMSOpenSou rce.pdf, last visited July 15,2008$)$.

Courant, P. \& Griffiths, R. 2006. Software and Collaboration in Higher Education: A Study of Open Software. (http://www.ithaka.org/strategic-services/oss/OOSS_Report_FINAL.pdf, last visited August 12, 2008). 
Couros, A. 2004. The Open Source Movement: Implication for Education Comprehensive Essays. Spring/Summer .

(http://www.educationaltechnology.ca/couros/publications/unpublishedpapers/Co uros-OpenSource-Comprehensives-June30-04.pdf, last visited June22, 07).

Dillon, A. \& Morris, M. 1996. User Acceptance of New Information Technology: Theories and Models. In M. Williams (ed.) Annual Review of Information Science and Technology, Vol. 31, pp. 3-32. Medford, NJ: Information Today. (http://dlist.sir.arizona.edu/1261/01/AdArist96.pdf, last visited July 15, 2008).

Dillon, W. R., \& Goldstein M. 1984. Multivariate Analysis: Methods and Applications. pp.239-241. John \& Wiley Sons, Inc.

Gaur, A. S. \& Gaur S. S. 2006. Statistical Methods for Practice and Research: A Guide to Data Analysis Using SPSS, Sage Publications: New Delhi.

Harris, R. 1998. Introduction to Decision Making. Version date: July, 2, 1998. (http://www.virtualsalt.com/crebook5.htm, last visited July 17, 2008).

Knorr, E. M. 2005. Course Management System (CMS) Evaluation and Strategy at UBC: A Viewpoint from the Faculty of Science.

(http://www.cs.ubc.ca/ knorr/public/WCCCE_2006_CMS_UBC.pdf, last visited July 15,2008$)$.

Kvavik, R. B., Caruso, J. B., \& Morgan, G. 2004. ECAR Study of Students and Information Technology: Convenience, Connection, and Control. Boulder, 
Colorado: Educause Center for Applied Research (ID: ERS0405). September, 2004.

(http://www.educause.edu/ir/library/pdf/EKF/Ekf0405.pdf, last visited July 15, 2008).

Lefebvre, E. \& Lefebvre, L.1996. Information and Telecommunication Technologies: The Impact of Their Adoption on Small and Medium-sized Enterprises.

(http://www.idrc.ca/es/ev-9303-201-1-DO_TOPIC.html, last visited July 17, 2008).

LMS Strategic Review. 2005. Learning Management System (LMS): Strategic Review, Prepared by the CSU, Chico, LMS Strategic Review Committee, April $28,2005$.

(http://www.csuchico.edu/t|p/LMS2/LMSStrategicReview.pdf, last visited July 15, 2008).

Meerts, J. 2003. Course Management Systems (CMS). EDUCAUSE Evolving Technologies Committee, Wesleyan University.

(http://www.educause.edu/ir/library/pdf/DEC0302.pdf, last visited July 15, 2008).

Morgan, G. 2003. Key Findings: Faculty Use of Course Management Systems. May, 2003.

(http://www.educause.edu/ir/library/pdf/ERS0302/ekf0302.pdf, last visited July $15,2008)$. 
Merwe, A. 2000. Implementing WebCT at Stellenbosch University: The Integrated Approach.

(http://www.webct.com/service/ViewContent?contentID=2386007\&communitylD= 864\&pageName=index.html, last visited July 15, 2008).

Moore, G. A. 1999. Crossing the Chasm: Marketing and Selling High-Tech Products to Mainstream Customers. Revised edition, Harper Business Book.

Moore, G. A. 1995. Inside the Tornado: Marketing Strategies from Silicon Valley's Cutting Edge. Harper Business Book.

Patrick, M. 2007. Barriers to the Adoption of Open Source: Personal and Professional Observations. Terra Incognita. April 17, 2007. (http://blog.worldcampus.psu.edu/index.php/2007/04/17/barriers-to-the-adoptionof-open-source-personal-and-professional-observations, last visited July 15, 2008).

Peoplepulse. 2008. Survey Response Rates: Tips on How to Increase Response Rates.

(http://www.peoplepulse.com.au/Survey-Response-Rates.htm, last visited July $15,2008)$.

Rahtz, S. 2005. Developing an Open Source Policy. OSS Watch, Research Technologies Service, Oxford University Computing Services. 
(http://www.oss-watch.ac.uk/talks/2005-06-23-eunis/rahtz.xml, last visited Feb $22,2007)$.

Robinson, J.P., Shaver P.R., \& Wightman L.S. 1991. Criteria for Scale Selection and Evaluation: Measure of Personality and Social Psychological Attitudes, ch.1, p.13. Academic Press, Inc.

(http://www.runet.edu/ jaspelme/611/Spring-

2007/Robinson_Shaver_and_Wrightsman_1991_Ch1.pdf, last visited June 29, 2008).

Rogers, E. M. 1995. Diffusion of Innovations. $4^{\text {th }}$ Ed., New York: Free Press.

Sheehan, K. 2001. E-mail Survey Response Rates: A Review. Journal of Computer-Mediated Communication, 6 (2), January.

(http://jcmc.indiana.edu/vol6/issue2/sheehan.html, last visited July 30,2008 ).

Sheehan K. B. \& Hoy M. G. 1999. Using E-mail to Survey Internet Users in the United States: Methodology and Assessment. Journal of Computer-Mediated Communication JCMC 4 (3). March.

(http://jcmc.indiana.edu/vol4/issue3/sheehan.html, last visited July 30, 2008)

Stevens, J. 1996. Applied Multivariate Statistics for Social Sciences, $3^{\text {rd }}$ edition. Lawrence Erlbaum Associates. 
Tessmer, M. 1991. Back to the Future: The Environment Analysis Stage of the Front End Analysis. Performance and Instruction, 30(1): 9-12.

Tornatzky, L.G., \& Fleischer, M. 1990. The Process of Technological Innovation. Lexiington, MA: Lexington Books.

The Association of Universities and Colleges of Canada (AUCC). 2008. Trends in Higher Education. Volume 3: Finance.

(http://socrates.aucc.cal_pdf/english/publications/trends_2008_vol3_e.pdf, last visited, August 25, 2008).

Trochim, W.M.K. 2006. Research Methods Knowledge Base: Reliability. (http://www.socialresearchmethods.net/kb/reliable.php, last visited June 29, 2008).

Van den Berg, K. 2005. Finding Open Options: An Open Source Software Evaluation Model with a Case Study on Course Management Systems, Masters Thesis, Tilburg University. August, 2005.

Wheeler, B. C. 2002. A Course Management System Strategy for Indiana University. May 2002.

(http://wheeler.kelley.indiana.edu/pdfs/IU_CMS_Strategy_2002_Public.pdf, last visited June 28,2007$)$. 
Wheeler, D. A. 2003. Why Open Source Software/Free Software (OSS/FS, or FOSS)? Look at the Numbers!

(http://www.dwheeler.com/oss_fs_why.html, last visited June 28, 2007).

Wikipedia. 2007.

(http://en.wikipedia.org/wiki/Innovation, last visited, June 29, 2007).

Yu, C. H. 2008. Reliability and Validity.

(http://www.creative-wisdom.com/teaching/assessment/reliability.html, last visited July 15,2008$)$.

Yun, G. W. \& Trumbo C. W. 2000. Comparative Response to a Survey Executed by Post, E-mail, \& Web Form. Journal of Computer-Mediated Communication, 6 (1), September.

(http://jcmc.indiana.edu/vol6/issue1/yun.html, last visited July 15, 2008). 


\section{Appendices}

Appendix A: Invitation to Participate in a Study about OS CMS

Dear :

I am a Master's student in the Department of Computer and System EngineeringTechnology Innovation Management program at Carleton University (more information at http://www.carleton.ca/tim/sub/details.html). I am conducting a research under the supervision of Professor John Callahan.

I am researching the adoption of open source Course Management System (CMS) in Canadian universities and colleges. The research explores decisionmakers' perception and attitude towards open source CMS, factors or obstacles that influence decision-making, and the solution that decision makers believe would help overcome the obstacles.

The findings of this study will help decision makers to better understand the obstacles that hinder their decisions to adopt or migrate to open source CMS and also will provide recommendations on possible solutions that overcome those obstacles. I will provide each participant with a copy of the key findings from this study.

A questionnaire is an essential part of my Master's thesis research. The questionnaire is intended for decision makers at Canadian universities and colleges. Your institution is one of those selected and I would appreciate your important participation in this research. Completing the questionnaire will take approximately twenty minutes of your time.

Your confidentiality will be maintained at all times through the course of this research. I will not include any information that will make it possible to identify you. You have been assigned a unique identification number (ID), at the top left corner of this letter, which will be used to access the study online survey. At the end of the field period, the identification ID will not be linked to your personal identifying information and your responses. As well, the responses will be separated from any identifying information, including the e-mail addresses of respondents. Moreover, the results of the survey will appear in aggregate form, so again no one will link you to your responses.

Neither your name nor your institution name will appear on the questionnaire, in the thesis, or in any report or publication based on this study. The data collected through this study will be kept in a secure location and will be maintained on a password-protected computer database and will be accessed only by the 
researcher and Professor John Callahan. There are no known or expected risks to participation in this study.

Participation in this research is completely voluntary. You may decline to answer any question that you prefer not to answer or withdraw at any time.

Please note that while you are welcome to contact us via e-mail, Internet transmission is neither private nor secure and there is a chance your answers could be read by a third party.

I would like to assure you that the questionnaire has been reviewed and received ethics clearance by the Carleton University Research Ethics Committee.

If you have any questions or concerns about participation in this research, please contact

\author{
Prof. Antonio Gualtieri, Chair \\ Carleton University Research Ethics Committee \\ Carleton University \\ 1125 Colonel By Drive \\ Ottawa, Ontario K1S 5B6 \\ Tel: 613-520-2517 \\ E-mail: ethics@carleton.ca
}

If you have any question, or would like further information about the study itself, please feel free to email Professor John Callahan at john_callahan@carleton.ca or myself at, mtreif@connect.carleton.ca

Thank you for your time and cooperation.

Sincerely,

Mohammed Treif

Master's Candidate

Technology Innovation Management

mtreif@connect.carleton.ca 
Appendix B: Questionnaire

Thank you for your participation in this survey.

Please complete all $\mathbf{2 0}$ questions in one session. It takes less than $\mathbf{2 0}$ minutes. After some time, your session can expire and your results will be lost. If this happens, they will have to be entered again to complete the survey.

Please note that you will not be able to login again after submitting.

Many thanks again.

Terminology

CMS: Course Management Systems

\section{Section 1: About You and Your Institution}

1. How long have you been working in the education field?
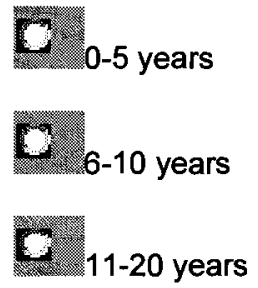

T. more than 20 years

2. How long is your experience in IT sector? 
(1)

$0-5$ years

D. $6-10$ years

Q. 11-20 years

Q more than 20 years

3. What are your current sources of information regarding open source products or projects? Please choose all that apply:

Pis

Website

r Email-lists

re

Newsgroups

rib

Discussion thread

res.

CMS evaluation committee

$\Gamma$

Academic community, word of mouth

Tle

Others, please specify:

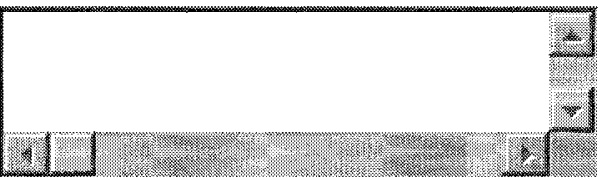

4. What best characterizes your institution/department in terms of adopting/migrating to open source products/projects?

C) Encourage any adoption/migration to open source products/projects

D Conservative in their approach to adopt/migrate to open source products/projects

C Against any adoption or migration to open source products/projects C $x_{\text {Don't know }}$ 
5. What type of Course Management System (CMS) is currently used in your institution/department?

Q

Proprietary Course Management System

C)

Open Source Course Management System

Cis

Both

C

None

\section{Section 2: CMS Selection Factors}

6. Please indicate the extent to which you agree or disagree with the following statements.

\section{Perception and attitude toward open source}

Open source CMS features are not at the level of proprietary CMS.

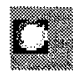

Strongly Agree

(9) Agree

C

Neither agree nor disagree

1. Disagree

Q. Strongly Disagree

Cost of adoption/migration to open source CMS is not clear.

2

Strongly Agree

1 Agree

Q Neither agree nor disagree

C.

Catistrongly Disagree 
Budget is not enough to support open source CMS adoption/migration.

C. strongly Agree

C.

Q

Neither agree nor disagree

1 Disagree

1

Strongly Disagree

Funding is not enough to support open source CMS adoption/migration.

O

Strongly Agree

O.2. Agree

3 Neither agree nor disagree

(2) Disagree

D. Strongly Disagree

Product support options are limited for open source CMS.

Q

Strongly Agree

Q. Agree

B

Neither agree nor disagree

C. Disagree

D. Strongly Disagree

Product support options are unproven for open source CMS.

O. Strongly Agree 
C

Agree

S. Neither agree nor disagree

3. Disagree

U. Strongly Disagree

There are not enough resources to adopt/migrate to open source CMS.

(1)

Strongly Agree

13. Agree

1.

Neither agree nor disagree

1. Disagree

B. Strongly Disagree

Adoption/migration to open source CMS is risky at this time.

Strongly Agree

1. Agree

Finge

Neither agree nor disagree

$\mathrm{C}_{\text {Disagree }}$

3 Strongly Disagree

Adoption/migration to open source CMS may involve some legal issues.

1

Strongly Agree

3. Agree

E Neither agree nor disagree 
2

Disagree

C.

Strongly Disagree

Intellectual property is a concern when adopting/migrating to open source CMS.

D.

Strongly Agree

C

Agree

B

Neither agree nor disagree

O. Disagree

D. Strongly Disagree

We have some security concerns regarding adoption/migration to open source CMS.

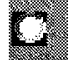

Strongly Agree

O. Agree

13

Neither agree nor disagree

A. Disagree

D. Strongly Disagree

Open source CMS products' documentation may be poor.

ta

Strongly Agree

D.

(3)

Neither agree nor disagree

(1)

Disagree

D Strongly Disagree 
Open source CMS products' documentation maybe sometime non-existent.

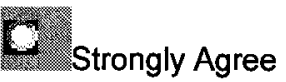

$\mathrm{C}_{\text {Agree }}$

(1)

Neither agree nor disagree

C. Disagree

3

Strongly Disagree

The open source CMS movement is still immature.

3

Strongly Agree

b

Agree

(3)

Neither agree nor disagree

in

Disagree

C. Strongly Disagree

The future of open source CMS in higher education is unclear.

0 Strongly Agree

C. Agree

Deither agree nor disagree

C. Disagree

C Strongly Disagree

Technology Factors 
Open source CMS products are more reliable than proprietary CMS.

Q)

Strongly Agree

C. Agree

D

Neither agree nor disagree

(1)

Disagree

C. Strongly Disagree

Open source CMS products are more efficient than proprietary CMS.

C

Strongly Agree

Q1.

Agree

3

Neither agree nor disagree

Q. Disagree

Q

Strongly Disagree

Open source CMS products are more flexible than proprietary CMS.

Q. Strongly Agree

Q 2 Agree

A. Neither agree nor disagree

B. Disagree

D.

Open source CMS products are easier to use than proprietary CMS.

Li

Strongly Agree 
D Agree

C Neither agree nor disagree

C. Disagree

Q 1 i strongly Disagree

Proprietary CMS products have limited features.

Q Strongly Agree

C

Agree

C. Neither agree nor disagree

U. Disagree

Q. Strongly Disagree

Open source CMS product support options are limited.

C. Strongly Agree

Q.

(3) Neither agree nor disagree

O. Disagree

C

Strongly Disagree

Open source CMS products require more maintenance than proprietary CMS.

(3) Strongly Agree

Q

Agree

C. Neither agree nor disagree 
E.

Disagree

OS

Strongly Disagree

Open source CMS products reduce hardware complexity.

B) Strongly Agree

Bi.

B.

Neither agree nor disagree

C

Disagree

0 Strongly Disagree

Open source CMS products reduce software complexity.

Q

Strongly Agree

B. Agree

(3)

Neither agree nor disagree

E. Disagree

C. Strongly Disagree

Institutional Factors

Open source CMS products reduce operational cost.

a

Strongly Agree

C.

it

Neither agree nor disagree

Q

Disagree

D. Strongly Disagree 
Open source CMS products accelerate institution growth.

6. Strongly Agree

Q

D. Neither agree nor disagree

C)

Disagree

o

Strongly Disagree

Open source CMS products decrease management capacity.

C1: Strongly Agree

Q.

O Neither agree nor disagree

B. Disagree

C.

Open source CMS products reduce dependency on IT staff.

b.

Strongly Agree

G. Agree

C. Neither agree nor disagree

C.

Q Strongly Disagree

Open source CMS products require hiring more staff.

C. Strongly Agree 
G.

Agree

D

Neither agree nor disagree

3 Disagree

D Strongly Disagree

Open source CMS products increase institution capabilities.

O Strongly Agree

Digree

a

Neither agree nor disagree

C. Disagree

C. Strongly Disagree

Open source CMS products provide better support for faculty.

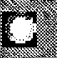

Strongly Agree

1 Agree

C

Neither agree nor disagree

Q Disagree

D) Strongly Disagree

Open source CMS products reduce administrative difficulties.

(2)

Strongly Agree

Q.

2 Neither agree nor disagree 
(1)

Disagree

(1)

Strongly Disagree

Open source CMS products are free so there can be no surprise increases in license fees.

(3)

Strongly Agree

D.

Agree

a

Neither agree nor disagree

Q1. Disagree

C

Strongly Disagree

Open source CMS products have a limited track record with comparable universities/colleges.

a

Strongly Agree

2.

Q. Neither agree nor disagree

I

Disagree

C

Strongly Disagree

Open source CMS ends vendor monopoly.

C. Strongly Agree

CI:

C.

Neither agree nor disagree

0

Disagree

Q 3 Strongly Disagree 


\section{Environment Factors}

Open source CMS products increase community support.

I)

Strongly Agree

1. Agree

a

Neither agree nor disagree

C.

Disagree

o

Strongly Disagree

Open source CMS products require a high level of user expertise.

Q Strongly Agree

2. Agree

(3)

Neither agree nor disagree

C

Disagree

C

Strongly Disagree

Open source CMS products increase institutional readiness.

C

Strongly Agree

B.

Deither agree nor disagree

Q. Disagree

B. Strongly Disagree

Open source CMS products provide better services to users.

Qt.strongly Agree 
C.

Agree

C.

Neither agree nor disagree

C. Disagree

D Strongly Disagree

There is demand from students to adopt open source CMS products.

C.

Strongly Agree

Digree

OU⿻

Neither agree nor disagree

Q

Disagree

C

Strongly Disagree

\section{Pedagogical Factors}

Proprietary products are seldom well tailored to higher education.

1

Strongly Agree

a

Agree

G

Neither agree nor disagree

Q

Disagree

Di... Strongly Disagree

Open source CMS products support educational innovation.

D

Strongly Agree

Pagree

B.

Neither agree nor disagree 
(3)

Disagree

D

Strongly Disagree

Open source CMS products help educators create effective online learning communities.

C Strongly Agree

(2) Agree

C Neither agree nor disagree

Q Disagree

1. Strongly Disagree

7. Please add any additional criteria that you think would be important to your institution/department to consider in adopting open source CMS:

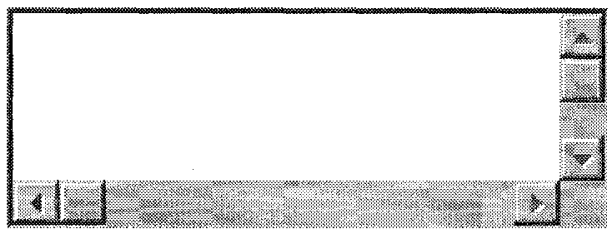

8. How did/will your institution develop evaluation criteria for selecting CMS? Please choose all that apply:<smiles>[AlH2]</smiles>

7. CMS evaluation committee

F. own direct experience

Fe. Online collaboration and communications

$\mathrm{H}$ Case studies

Dis Product comparisons

Fi Discussion threads

TH Inputs from students 
-1.

Inputs from faculty members

1. Search engine such as Google, Yahoo, etc

1. Others, please specify:

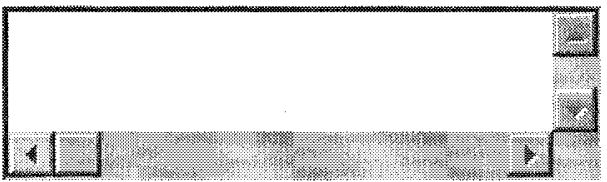

\section{Section 3: CMS Decision}

9. Who participated/will participate in the decision to adopt open source CMS? Please choose all that apply:<smiles>[CH]1[CH]C[CH]1</smiles>

This question does not apply to me/my institution

13

. Chief Information Officer (ClO)

Myself

13 Students

1

2. Faculty members

$\sqrt{3}$

IT management

13:

Administrative management

Academic management

1.

Others, please specify:

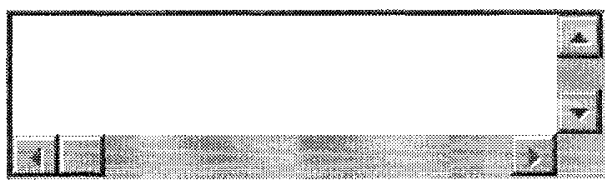

10. What were the methods/approaches used in your institution/department to reach the decision? Please select all that apply:

E 
3

Product evaluations

F

Case Studies

1

Other institutional experience

(1)

Committee discussion groups

H. Software consultants and representatives

$\sqrt{11}$

Other, please specify

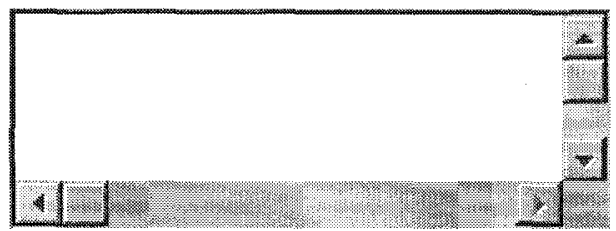

11. Did you collaborate with other institutions/departments that are currently using open source CMS or are considering migrating to open source CMS?

Q.

Yes

18

No

12. If your answer to $\mathrm{Q} 11$ is yes, could you elaborate on how you collaborated with other institutions/departments?

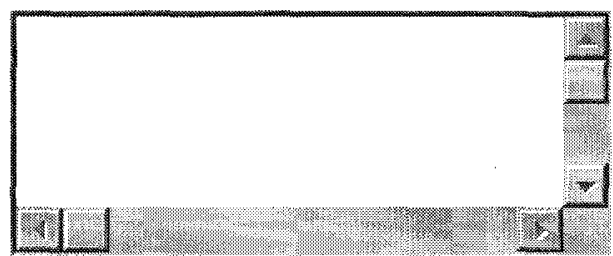

13. What were/are some of the challenges that your institution/department faced or is facing with the selection of open source CMS? 


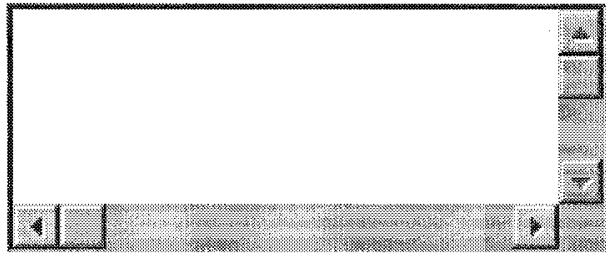

14. How do you think the challenges you described in Q13 can be addressed?

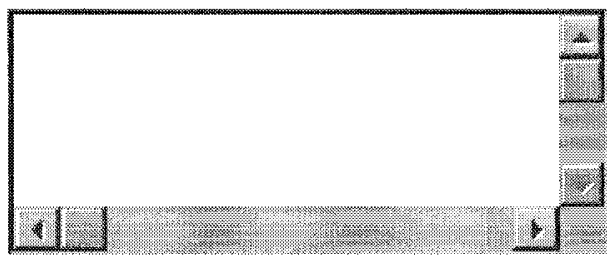

15. Has your institution/department used or is currently using any external services to help with addressing any problems with open source CMS?

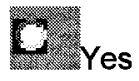

D.

16. Have you or your institution ever gotten any funding or donations during the last five years to support open source software?

C

Yes

(3)

17. What were the big lessons learned during open source CMS usage, adoption or migration process?

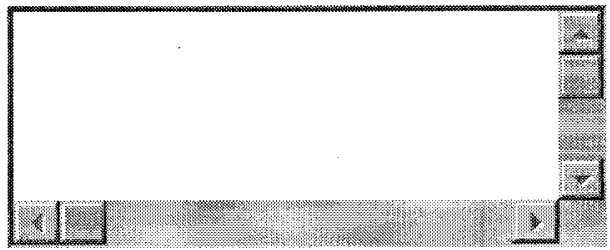

\section{Section 4: Conclusion}


18. May I contact you by phone or e-mail to obtain further insights or clarifications on your responses?

(1) Yes

(3) No

19. Do you wish to receive a copy of the key findings from this study?

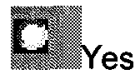

I

20. If you have any other comments or insights about open source CMS, please share them with me:

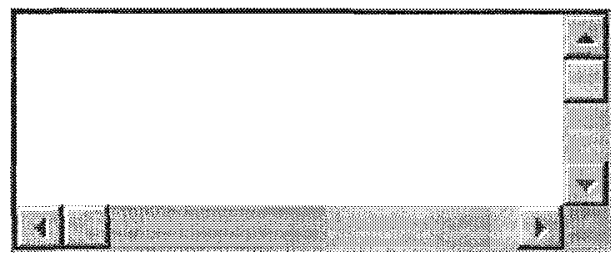

If you have any questions or concerns, please e-mail me at mtreif@connect.carleton.ca

You have reached the end of the questionnaire.

Thank you again for your time and cooperation.

Please click on the "Submit" button to send the survey to Mohammed Treif: 
Appendix C: Relative Advantage Normality Check

\begin{tabular}{|l|l|l|l|l|l|l|}
\hline & TRA_16 & TRA_17 & TRA_18 & TRA_19 & TRA_23 & TRA_24 \\
\hline Mean & 2.83 & 2.93 & 3.52 & 2.98 & 2.7 & 2.68 \\
\hline Standard Error & 0.094 & 0.115 & 0.119 & 0.098 & 0.109 & 0.115 \\
\hline Median & 3 & 3 & 4 & 3 & 3 & 3 \\
\hline Mode & 3 & 3 & 4 & 3 & 3 & 2 \\
\hline Standard & & & & & & \\
Deviation & 0.594 & 0.730 & 0.751 & 0.620 & 0.687 & 0.730 \\
\hline Sample Variance & 0.353 & 0.533 & 0.563 & 0.384 & 0.472 & 0.533 \\
\hline Kurtosis & -0.190 & -1.05 & -0.065 & -0.211 & -0.113 & -0.863 \\
\hline Skewness & 0.057 & 0.117 & -0.855 & 0.014 & -0.030 & 0.599 \\
\hline Range & 2 & 2 & 3 & 2 & 3 & 2 \\
\hline Minimum & 2 & 2 & 2 & 2 & 1 & 2 \\
\hline Maximum & 4 & 4 & 5 & 4 & 4 & 4 \\
\hline Sum & 113 & 117 & 141 & 119 & 108 & 107 \\
\hline Count (n) & 40 & 40 & 40 & 40 & 40 & 40 \\
\hline Kurtosis std & 0.775 & 0.775 & 0.775 & 0.774 & 0.775 & 0.775 \\
\hline Skewness std & 0.387 & 0.387 & 0.387 & 0.387 & 0.387 & 0.387 \\
\hline Kurtosis Test & -0.246 & -1.36 & -0.084 & -0.273 & -0.147 & -1.11 \\
\hline Skewness Test & 0.148 & 0.303 & -2.21 & 0.036 & -0.077 & 1.55 \\
\hline
\end{tabular}


Appendix D: Complexity Normality Check

\begin{tabular}{|l|l|l|l|l|}
\hline & TCX_1_2 & TCX___9 & TCX_3_10 & TCX_4_11 \\
\hline Mean & 3.7 & 3 & 2.95 & 3.1 \\
\hline Standard Error & 0.130 & 0.148 & 0.175 & 0.159 \\
\hline Median & 4 & 3 & 3 & 3 \\
\hline Mode & 4 & 2 & 2 & 4 \\
\hline Standard Deviation & 0.823 & 0.934 & 1.11 & 1.01 \\
\hline Sample Variance & 0.677 & 0.872 & 1.23 & 1.02 \\
\hline Kurtosis & 0.647 & -0.963 & -0.860 & -1.09 \\
\hline Skewness & -1.12 & 0 & 0.103 & -0.051 \\
\hline Range & 3 & 4 & 4 & 4 \\
\hline Minimum & 2 & 1 & 1 & 1 \\
\hline Maximum & 5 & 5 & 5 & 5 \\
\hline Sum & 148 & 120 & 118 & 124 \\
\hline Count (n) & 40 & 40 & 40 & 40 \\
\hline Kurtosis std & 0.775 & 0.775 & 0.775 & 0.775 \\
\hline Skewness std & 0.387 & 0.387 & 0.387 & 0.387 \\
\hline Kurtosis Test & 0.835 & -1.24 & -1.11 & -1.40 \\
\hline Skewness Test & -2.90 & 0 & 0.266 & -0.131 \\
\hline
\end{tabular}


Appendix E: Observability Normality Check

\begin{tabular}{|l|l|l|l|l|l|l|l|}
\hline & OBS & OBS 5 & OBS_6 & OBS_14 & OBS_15 & OBS_21 & OBS_34 \\
\hline Mean & 3.1 & 3.175 & 3.175 & 2.85 & 2.78 & 3.45 & 3.4 \\
\hline Standard Error & 0.155 & 0.143 & 0.133 & 0.146 & 0.174 & 0.118 & 0.123 \\
\hline Median & 3 & 3.5 & 3 & 3 & 2.5 & 4 & 4 \\
\hline Mode & 4 & 4 & 4 & 2 & 2 & 4 & 4 \\
\hline Standard Deviation & 0.982 & 0.903 & 0.844 & 0.922 & 1.097 & 0.749 & 0.778 \\
\hline Sample Variance & 0.964 & 0.815 & 0.712 & 0.849 & 1.20 & 0.562 & 0.605 \\
\hline Kurtosis & -0.92 & -1.71 & -1.06 & -1.45 & -1.20 & -0.482 & -0.589 \\
\hline Skewness & -0.038 & -0.363 & -0.081 & 0.105 & 0.105 & -0.976 & -0.510 \\
\hline Range & 4 & 2 & 3 & 3 & 4 & 2 & 3 \\
\hline Minimum & 1 & 2 & 2 & 1 & 1 & 2 & 2 \\
\hline Maximum & 5 & 4 & 5 & 4 & 5 & 4 & 5 \\
\hline Sum & 124 & 127 & 127 & 114 & 111 & 138 & 136 \\
\hline Count (n) & 40 & 40 & 40 & 40 & 40 & 40 & 40 \\
\hline Kurtosis_std & 0.776 & 0.775 & 0.775 & 0.775 & 0.775 & 0.775 & 0.775 \\
\hline Skewness_std & 0.387 & 0.387 & 0.387 & 0.387 & 0.387 & 0.387 & 0.387 \\
\hline Kurtosis_Test & -1.19 & -2.21 & -1.36 & -1.87 & -1.55 & -0.623 & -0.760 \\
\hline Skewness_Test & -0.097 & -0.938 & -0.208 & 0.270 & 0.272 & -2.519 & -1.31 \\
\hline
\end{tabular}


Appendix F: Resource Limitations Normality Check

\begin{tabular}{|l|l|l|l|}
\hline & $I R \_1 \_3$ & $I R \_2 \_4$ & $I R \_3 \_7$ \\
\hline Mean & 2.85 & 2.88 & 3.24 \\
\hline Standard Error & 0.141 & 0.139 & 0.154 \\
\hline Median & 3 & 3 & 3 \\
\hline Mode & 3 & 2 & 3 \\
\hline Standard Deviation & 0.893 & 0.882 & 0.974 \\
\hline Sample Variance & 0.797 & 0.779 & 0.948 \\
\hline Kurtosis & -0.919 & -0.959 & -0.955 \\
\hline Skewness & -0.147 & 0.490 & 0.222 \\
\hline Range & 3 & 3 & 3 \\
\hline Minimum & 1 & 2 & 2 \\
\hline Maximum & 4 & 5 & 5 \\
\hline Sum & 114 & 115 & 129 \\
\hline Count & 40 & 40 & 40 \\
\hline Kurtosis std & 0.775 & 0.775 & 0.775 \\
\hline Skewness std & 0.387 & 0.387 & 0.387 \\
\hline Kurtosis Test & -1.19 & -1.24 & -1.23 \\
\hline Skewness Test & -0.379 & 1.26 & 0.573 \\
\hline
\end{tabular}


Appendix G: Perceived Institutional Benefit Normality Check

\begin{tabular}{|l|l|l|l|l|l|l|}
\hline & $I P_{-} 25$ & $I P_{-} 28$ & $I P_{-} 31$ & $I P_{-} 32$ & $I P_{-} 33$ & $I P_{-} 35$ \\
\hline Mean & 2.78 & 2 & 2.85 & 2.68 & 3.35 & 3.475 \\
\hline Standard Error & 0.154 & 0.095 & 0.116 & 0.121 & 0.158 & 0.140 \\
\hline Median & 3 & 2 & 3 & 3 & 4 & 4 \\
\hline Mode & 2 & 2 & 3 & 3 & 4 & 4 \\
\hline Standard Deviation & 0.974 & 0.599 & 0.736 & 0.764 & 1.00 & 0.878 \\
\hline Sample Variance & 0.948 & 0.359 & 0.541 & 0.584 & 1.00 & 0.769 \\
\hline Kurtosis & -0.815 & 0.004 & -1.07 & 1.13 & -0.682 & -0.613 \\
\hline Skewness & 0.304 & $-4.79 \mathrm{E}-17$ & 0.246 & 0.640 & -0.451 & -0.160 \\
\hline Range & 4 & 2 & 2 & 4 & 4 & 3 \\
\hline Minimum & 1 & 1 & 2 & 1 & 1 & 2 \\
\hline Maximum & 5 & 3 & 4 & 5 & 5 & 5 \\
\hline Sum & 111 & 80 & 114 & 107 & 134 & 139 \\
\hline Count & 40 & 40 & 40 & 40 & 40 & 40 \\
\hline Kurtosis std & 0.775 & 0.775 & 0.775 & 0.775 & 0.775 & 0.775 \\
\hline Skewness std & 0.387 & 0.387 & 0.387 & 0.387 & 0.387 & 0.387 \\
\hline Kurtosis Test & -1.052 & 0.005 & -1.38 & 1.46 & -0.881 & -0.792 \\
\hline Skewness Test & 0.786 & $-1.24 \mathrm{E}-16$ & 0.636 & 1.65 & -1.16 & -0.41 \\
\hline
\end{tabular}


Appendix H: Perceived Institution Image Normality Check

\begin{tabular}{|c|c|c|c|c|c|c|c|}
\hline & $I V \_26$ & IN_30 & & & $y=0$ & $y / y_{-42}$ & \\
\hline Mean & 2.80 & 3.25 & 3.33 & 2.93 & 2.90 & 3.58 & 3.225 \\
\hline tandard Error & 0.120 & 0.123 & 0.104 & 0.115 & 0.118 & 0.101 & 0.121 \\
\hline Median & 3 & 3 & 3 & 3 & 3 & 4 & 3 \\
\hline lode & 3 & 4 & 3 & 3 & 3 & 4 & 3 \\
\hline tandard Deviatior & 0.758 & 0.776 & 0.656 & 0.730 & 0.744 & 0.636 & 0.767 \\
\hline amp & 0.574 & 0.603 & 0.430 & 0.533 & 0.554 & \begin{tabular}{l|l}
40.404 \\
4
\end{tabular} & 0.589 \\
\hline Curto & -0.492 & -1.16 & -0.648 & -1.05 & 0.275 & $5-0.154$ & 0.338 \\
\hline en & -0.0149 & $9-0.47 t$ & -0.452 & 0.117 & 0.558 & 0.019 & -0.77 \\
\hline Tang & 3 & 2 & 2 & 2 & 3 & 3 & 3 \\
\hline nin & 1 & 2 & 2 & 2 & 2 & 2 & 1 \\
\hline Maxin & 4 & 4 & 4 & 4 & 5 & 5 & 4 \\
\hline um & 112 & 130 & 133 & 117 & 116 & 143 & 129 \\
\hline Soun & 40 & 40 & 40 & 40 & 40 & 40 & 40 \\
\hline rtos & 0.775 & 0.775 & 0.775 & 0.775 & 0.775 & 0.775 & 0.775 \\
\hline kew & 0.387 & 0.387 & 0.387 & 0.387 & 0.387 & 0.387 & 0.387 \\
\hline urtos & -0.635 & -1.50 & -0.836 & -1.36 & 0.355 & 5 & 0.437 \\
\hline kewness_Te & -0.038 & -1.23 & -1.17 & 0.30 & 1.44 & 0.050 & -1.99 \\
\hline
\end{tabular}


Appendix I: Internal Pressure Normality Check

\begin{tabular}{|l|l|l|l|}
\hline & EE_1_20 & EE____40 & EE_3_41 \\
\hline Mean & 2.9 & 2.625 & 2.63 \\
\hline Standard Error & 0.167 & 0.142 & 0.146 \\
\hline Median & 3 & 2 & 2 \\
\hline Mode & 2 & 2 & 2 \\
\hline Standard Deviation & 1.06 & 0.897 & 0.925 \\
\hline Sample Variance & 1.12 & 0.804 & 0.856 \\
\hline Kurtosis & -1.13 & 0.005 & -0.222 \\
\hline Skewness & -0.066 & 0.614 & 0.636 \\
\hline Range & 4 & 4 & 4 \\
\hline Minimum & 1 & 1 & 1 \\
\hline Maximum & 5 & 5 & 5 \\
\hline Sum & 116 & 105 & 105 \\
\hline Count (n) & 40 & 40 & 40 \\
\hline Kurtosis_std & 0.775 & 0.775 & 0.775 \\
\hline Skewness_std & 0.387 & 0.387 & 0.387 \\
\hline Kurtosis Test & -1.46 & 0.007 & -0.286 \\
\hline Skewness_Test & -0.170 & 1.58 & 1.64 \\
\hline
\end{tabular}

